Denis Borg

Implementação de uma rede neural em ambiente foundation fieldbus para computação de vazão simulando um instrumento multivariável.

Orientador: Prof. Dr. Dennis Brandão 

Denis Borg

\title{
Implementação de uma rede neural em ambiente foundation fieldbus para computação de vazão simulando um instrumento multivariável.
}

\author{
Dissertação apresentada à Escola de \\ Engenharia de São Carlos da Uni- \\ versidade de São Paulo, como parte \\ dos requisitos para obtenção do título \\ de Mestre em Ciências, Programa de \\ Engenharia Elétrica.
}

Área de concentração de Sistemas Dinâmicos

Orientador: Prof. Dr. Dennis Brandão 
AUTORIZO A REPRODUÇÃO E DIVULGAÇÃO TOTAL OU PARCIAL DESTE TRABALHO, POR QUALQUER MEIO CONVENCIONAL OU ELETRÔNICO, PARA FINS DE ESTUDO E PESQUISA, DESDE QUE CITADA A FONTE.

Ficha catalográfica preparada pela Seção de Tratamento da Informação do Serviço de Biblioteca - EESC/USP

B732i Dorg, Denis.
Implementação de uma rede neural em ambiente
foundation fielbus para computação de vazão simulando um
instrumento multivariável / Denis Borg; orientador Dennis
Brandão. São Carlos, 2011.
Dissertação (Mestrado - Programa de Pós-Graduação em
Engenharia Elétrica e Área de Concentração em Sistemas
Dinâmicos) -- Escola de Engenharia de São Carlos da
Universidade de São Paulo, 2011.
1. Computador de vazão. 2. Foundation fielbus. 3.
Medidor de vazão. 4. Instrumento multivariável. 5. Delta
V. 6. Software sensor. 7. Rede neural artificial. 8.
Hart. 9. Placa de orifício. I. Título.




\section{FOLHA DE JULGAMENTO}

Candidato(a): Engenheiro DENIS BORG.

Dissertação defendida e julgada em 20/06/2011 perante a Comissão Julgadora:

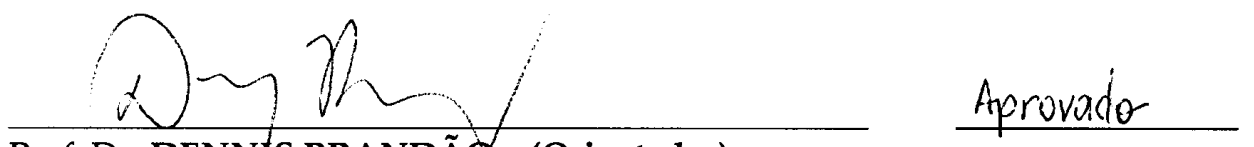

Prof. Dr. DENNIS BRANDÃ - (Orientador)

(Escola de Engenharia de São Carlos/USP)
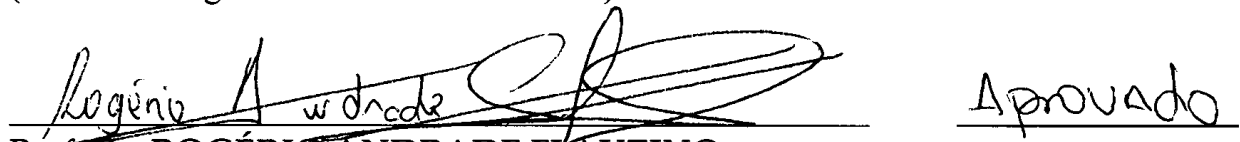

Prof. Dr. ROGÉRIO ANDRADE FLAUZINO

(Escola de Engenharia de São Carlos/USP)

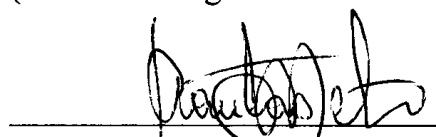

Prof. Dr. JORGEDANTAS DE MELO

APROUADO

(Universidade Federal do Rio Grande do Norte/UFRN).
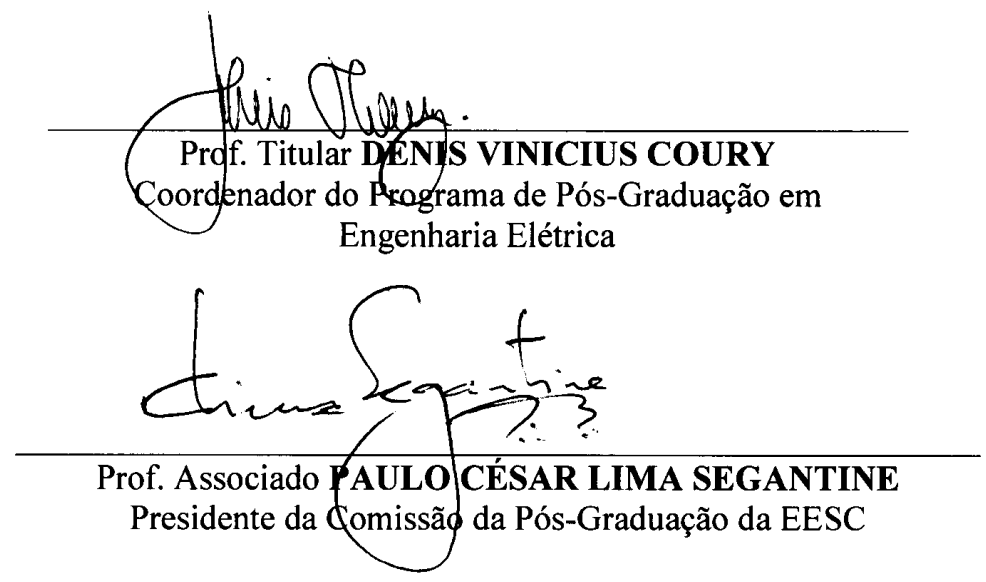



\section{Agradecimentos}

Agradeço a Deus, a Jesus e a meus pais pela oportunidade da vida. A meu orientador, Dennis Brandão, por todo aconselhamento, confiança e amizade. Muito obrigado à empresa Emerson Process Management e em especial aos gerentes Leonel Bertuso, Fabiano Pitzer e Elkin Suarez pela compreensão e pelo empréstimo de transmissores e softwares que possibilitaram a aquisição de dados e testes, além da liberação de um dia na semana para que eu me empenhasse no meu projeto de Mestrado. Sou grato também ao Flávio Barbosa por todo o incentivo no início do meu regresso à universidade, depois de estar fora da vida acadêmica por quase dez anos. Aos amigos do laboratório da USP em especial ao Marcelo Suetake pela cooperação nos artigos do CBA e do Induscon. Estendo meus agradecimentos também aos doutores presentes na banca examinadora Rogério Andrade Flauzino, Marcelo Selli e Jorge Dantas de Melo pela apreciação do trabalho e pelas contribuições para melhoria do mesmo. 



\section{Resumo}

Esta dissertação propõe o desenvolvimento de uma rede neural artificial (RNA) direcionada a ambientes foundation fieldbus para realização do cálculo de vazão em dutos fechados. Para tanto, a metodologia proposta utiliza-se de medidas de pressão, temperatura e pressão diferencial, as quais normalmente estão disponíveis em plantas industriais. A principal motivação do emprego das redes neurais reside no seu baixo custo e simplicidade de implementação, o que possibilita o emprego de apenas blocos fieldbus padrões tornando a metodologia independente do fabricante. Foi utilizada uma rede perceptron multicamadas com algoritmo de treinamento backpropagation de Levenberg-Marquardt. O treinamento foi realizado numa programação elaborada para o software Matlab ${ }^{T M}$. A arquitetura da rede neural foi determinada por métodos empíricos variando-se o número de neurônios e de camadas neurais até se atingir um erro aceitável na prática. Após esses treinamentos foi desenvolvida uma programação para realizar os cálculos de vazão em um ambiente foundation fieldbus utilizando-se para tanto o software DeltaV ${ }^{T M}$ do fabricante Emerson Process Management. Foram obtidos resultados com erro relativo médio de valor de vazão em torno de $1.43 \%$ para um primeiro cenário utilizando uma placa de orifício e ar como fluido, e de 0,073 \% para um segundo cenário utilizando uma placa de orifício e gás natural como fluido, com relação aos valores obtidos através do instrumento multivariável $3095 \mathrm{MV}^{T M}$ do fabricante Rosemount. Os valores de erro encontrados validam o método desenvolvido nessa dissertação.

Palavras chave: Computador de vazão, foundation fieldbus, medidor de vazão, instrumento multivariável, Delta $\mathrm{V}^{T M}$, software sensor, rede neural artificial, HART, placa de orifício. 



\section{Abstract}

This dissertation proposes the development of an artificial neural network (ANN) directed to foundation fieldbus environment for calculation of flow in closed ducts. The proposed methodology uses measurements of pressure, temperature and differential pressure, which are usually available in industrial plants.

The main motivation of the use of neural networks lies in their low cost and simplicity of implementation, which allows the use of standard fieldbus blocks by just making the method independent of the manufacturer.

It was used a multilayer perceptron network with backpropagation training and algorithm from Levenberg-Marquardt. The training was programmed in the software Matlab ${ }^{T M}$. The architecture of the ANN was determined by empirical methods by varying the number of neurons and neural layers until it reaches an acceptable error. After such trainings, it was developed a program to perform the flow calculations in an foundation fieldbus environment using Emerson Process Management's Delta $V^{T M}$ software. The results were obtained with an average relative error of flow rate of $1.43 \%$ for the first scenario using an orifice plate and air as a process fluid, and $0.073 \%$ for a second scenario using an orifice plate and natural gas as the fluid related to the values obtained from Rosemount $3095 M V^{T M}$ multivariable instrument. The values of error found validate the method developed in this dissertation.

Keywords: Flow computer, foundation fieldbus, flow measurement, multivariable instrument, Delta $V^{T M}$, software sensor, artificial neural network, HART, orifice plate. 



\section{Lista de Figuras}

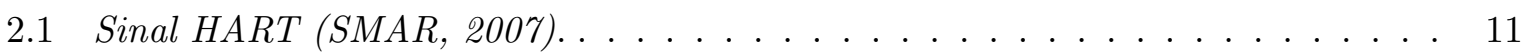

2.2 Transmissor multivariável acoplado a um elemento deprimogênio (annubar). . . . 12

$2.3 \quad$ Célula capacitiva . . . . . . . . . . . . . . . . . . . . . . . . . . . 13

$2.4 \quad$ Sensor piezorresistivo $\ldots \ldots \ldots \ldots \ldots$. . . . . . . . . . . . . . . . . . 14

2.5 Detalhe da medição de um processo indicando a medição de vazão. . . . . . . . . . 15

2.6 Módulo sensor do trasmissor multivariável. $\ldots \ldots \ldots \ldots \ldots$

$2.7 \quad$ Diagrama de funções do transmissor multivariável. $\ldots \ldots \ldots$. . . . . . . . . . . . 16

2.8 Limites de alimentação e reta de carga do transmissor multivariável. $\ldots$. . . . . . 17

2.9 Medidor volumétrico de vazão tipo turbina (MELO $[2007)$. . . . . . . . . . . . . 19

2.10 Principais componentes do medidor vortex. . . . . . . . . . . . . . . . . 20

2.11 Princípio de funcionamento do medidor vortex $\ldots \ldots \ldots \ldots \ldots$

2.12 Medidores tipo ultra-sônicos $(\mathrm{MELO}, 2007) . \ldots \ldots \ldots$. . . . . . . . . 21

2.13 Medidores tipo eletromagnético. . . . . . . . . . . . . . . . . . . 22

2.14 Aspecto físico dos medidores eletromagnéticos. . . . . . . . . . . . . . . . 23

2.15 Elementos do medidor tipo coriolis. . . . . . . . . . . . . . . . . . 24

2.16 Funcionamento do medidor tipo coriolis. . . . . . . . . . . . . . . . . . . 24

2.17 Placa de orifício em perfil (ISO5167-2, 2003). . . . . . . . . . . . . 25

2.18 Montagem da placa de orifício (GUIDE $[2007) . \ldots \ldots \ldots \ldots$

2.19 Perfil do fluxo na placa de orifício (ISO5167-2 [2003). . . . . . . . . . . . . 26

3.1 Representação de uma restrição na tubulação. . . . . . . . . . . . . . . . . . . . . 29 
3.2 Variação do coeficiente de descarga com relação ao número de Reynolds. . . . . . . 33

3.3 Variação empírica do coeficiente de descarga com relação ao número de Reynolds. 34

3.4 Incerteza do coeficiente de descarga com relação ao número de Reynolds. ... 35

$3.5 \quad$ Variação empírica do fator de expansão dos gases com relação a $\frac{\Delta P}{P_{a b s}}$. . . . . . . . 36

3.6 Incerteza do fator de expansão dos gases. $\ldots \ldots \ldots \ldots \ldots$

4.1 Placas condicionadoras (ZANKER e GROUP $[2005)$. . . . . . . . . . . . . . 40

4.2 Complexidade do cálculo de vazão . . . . . . . . . . . . . . . . . . . . 44

4.3 Algoritmo simplificado $\ldots \ldots \ldots \ldots \ldots \ldots$

4.4 Esquema interno do bloco aritmético $\ldots \ldots \ldots \ldots \ldots$

4.5 Esquema interno do bloco caracterizador. $\ldots \ldots \ldots \ldots$

$4.6 \quad$ Esquema de um neurônio tipo perceptron . . . . . . . . . . . . . . . . . 50

$5.1 \quad$ Bancada com os elementos para a aquisição dos dados. . . . . . . . . . . . . 54

5.2 Sequência de telas principais na configuração do transmissor multivariável. . . . . 56

5.3 Tela de escolha do fluido do processo $\ldots \ldots \ldots \ldots \ldots \ldots$

5.4 Tela de entrada da composição do gás natural. $\ldots \ldots \ldots \ldots$. . . . . . . . . 57

5.5 Tela de escolha do elemento deprimogênio e sua configuração. . . . . . . . . . . 58

$5.6 \quad$ Tela de limites de pressão, temperatura e unidades de medidas. . . . . . . . . . . 59

5.7 Tela dos valores calculados de densidade e viscosidade do fluido. . . . . . . . . . 59

5.8 Tela de simulação: Test calculation $\ldots \ldots \ldots \ldots$. . . . . . . . 60

5.9 Aquisição de dados. . . . . . . . . . . . . . . . . . 61

5.10 Estrutura do estimador neural de vazão. . . . . . . . . . . . . . . . . . . . . . 62

5.11 Tela com valores dos pesos configurados no bloco aritmético. . . . . . . . . . . 63

5.12 Tangente hiperbólica configurada via tabela de 21 pontos no bloco caracterizador. 63

5.13 Visão geral do control studio (Delta $V^{T M}$ ) mostrando a tela dos blocos interligados. 65

5.14 Rede neural no ambiente foundation fieldbus. . . . . . . . . . . . . . . 65

5.15 Normalização.$\ldots \ldots \ldots \ldots$. . . . . . . . . . . . . . . . 66

5.16 Desnormalização. . . . . . . . . . . . . . . . . . . . . 66 
5.17 Gráfico comparativo - rede de 5 neurônios. . . . . . . . . . . . . . . . . 68

5.18 Gráfico comparativo - uma das redes treinadas com 8 neurônios. . . . . . . . . . 69

5.19 Gráfico comparativo - rede de 10 neurônios. . . . . . . . . . . . . . . . . . . . 69

5.20 Gráfico comparativo - rede de 15 neurônios. . . . . . . . . . . . . . . . . 69

5.21 Gráfico comparativo - rede de 20 neurônios. ～. . . . . . . . . . . . . . . . 70

5.22 Gráfico comparativo - rede escolhida de 8 neurônios. . . . . . . . . . . . . . . 70

5.23 Desempenho do treinamento da rede neural $\ldots \ldots \ldots \ldots$. . . . . . . 71

5.24 Tangente tabulada com 21 e 39 pontos $\ldots \ldots \ldots \ldots$. . . . . . . . 74

5.25 Erro comparativo das curvas tabeladas com 21 e 39 pontos. . . . . . . . . . 75

5.26 Estratégia montada para comparação entre as tangentes elaboradas com 21 e 39 pontos. . . . . . . . . . . . . . . . . . . . 75

5.27 Histograma do erro agrupando-se os padrões em 25 divisões $\ldots . \ldots . .77$

5.28 Histograma do erro agrupando-se os padrões em 100 divisões $\quad \ldots \ldots$. . . . . 77

5.29 Gráfico comparativo - rede de 5 neurônios. . . . . . . . . . . . . . . . 78

5.30 Gráfico comparativo - rede de 8 neurônios. . . . . . . . . . . . . . . 78

5.31 Gráfico comparativo - rede de 10 neurônios. . . . . . . . . . . . . . . . . 79

5.32 Gráfico comparativo - rede de 15 neurônios . . . . . . . . . . . . . . . 79

5.33 Gráfico comparativo - rede de 20 neurônios. . . . . . . . . . . . . . . . . . . . . 79

5.34 Gráfico comparativo - rede de 12 neurônios - treinamento $1 . \ldots$. . . . . . 80

5.35 Gráfico comparativo - rede de 12 neurônios - treinamento $2 . \ldots . . .81$

5.36 Gráfico comparativo - rede de 12 neurônios - treinamento $3 . \ldots . . .81$

5.37 Gráfico comparativo - rede de 12 neurônios - treinamento $4 . \ldots$. . . . . . 81

5.38 Gráfico comparativo - rede de 12 neurônios - treinamento $5 . \ldots \ldots$. . . . . 82

5.39 Gráfico comparativo - rede escolhida de 12 neurônios. . . . . . . . . . . . . . . . 82

5.40 Desempenho do treinamento da rede neural . . . . . . . . . . . . . . . 83

A.1 Primeiro cenário implementado em ambiente foundation fieldbus. . . . . . . . . . 105

A.2 Segundo cenário implementado em ambiente foundation fieldbus. . . . . . . . . 106 



\section{Lista de Tabelas}

$2.1 \quad$ Medidores de vazão $\ldots \ldots \ldots \ldots \ldots \ldots$

A.1 Dados de treinamento para a rede neural. . . . . . . . . . . . . . . . . . . . 91

A.2 Dados de validação da rede neural com 8 neurônios e os erros associados a cada

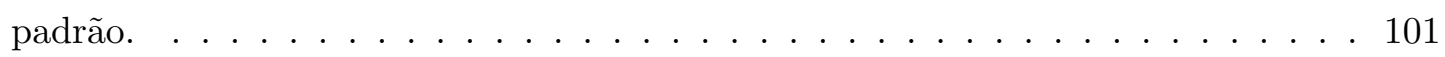

A.3 Pesos 1-Primeiro cenário. . . . . . . . . . . . . . . . . . . . . . . . . 107

A.4 Pesos 2 - Primeiro cenário. . . . . . . . . . . . . . . . . . . . . . . . . . 107

A.5 Pesos 3-Primeiro cenário. . . . . . . . . . . . . . . . . . . . 107

A.6 Peso 4 - Primeiro cenário . . . . . . . . . . . . . . . . . . . . . . . . . 107

A.7 Valores configurados dos principais parâmetros dos blocos em foundation fieldbus configurados no ambiente Delta $V^{T M}$ para o primeiro cenário. . . . . . . . . . . . 108

A.8 Comparação da tangente hiperbólica tabulada com 21 e 39 pontos em ambiente foundation fieldbus. . . . . . . . . . . . . . . . . . . . . . . . . . . 112

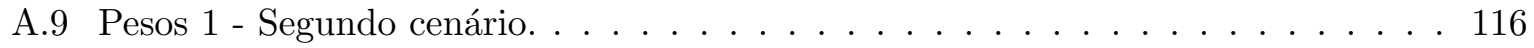

A.10 Pesos 2-Segundo cenário. . . . . . . . . . . . . . . . . . 117

A.11 Pesos 3 - Segundo cenário. . . . . . . . . . . . . . . . . . . . . 117

A.12 Peso 4 - Segundo cenário . . . . . . . . . . . . . . . . . . . . . . 117

A.13 Valores configurados dos principais parâmetros dos blocos em Foundation Fieldbus configurados no ambiente Delta $\mathrm{V}^{T M}$ para o segundo cenário. . . . . . . . . . . . 118 



\section{Sumário}

Resumo v v

Abstract vii

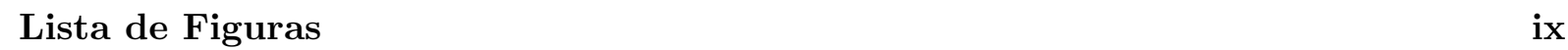

Lista de Tabelas $\quad$ xiii

$\begin{array}{lll}1 & \text { Introdução } & 1\end{array}$

1.1 Histórico . . . . . . . . . . . . . . . . . . . . . . . . . . 1

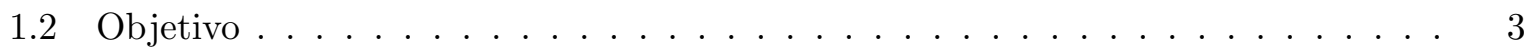

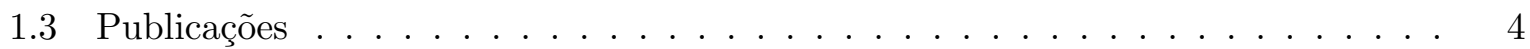

1.4 Organização do trabalho $\ldots \ldots \ldots \ldots \ldots \ldots \ldots$. . . . . . . . . . . . . 4

\begin{tabular}{lll}
\hline 2 & Conceitos de vazão e medidores & $\mathbf{7}$
\end{tabular}

2.1 Unidades de vazão $\ldots \ldots \ldots \ldots \ldots \ldots \ldots$

$2.1 .1 \quad$ Unidade normal e unidade padrão $\ldots \ldots \ldots$. . . . . . . . . . . 9

2.2 Transmissores inteligentes $\ldots \ldots \ldots \ldots \ldots \ldots \ldots$

2.3 Transmissores multivariáveis . . . . . . . . . . . . . . . . . . . . . . . . . . . 12

$2.3 .1 \quad$ Medidores por pressão diferencial . . . . . . . . . . . . . . . . . 25

3 A teoria de medição de vazão a partir da pressão diferencial 29

3.1 Equação de Bernoulli e a equação da continuidade . . . . . . . . . . . . . . . . 30

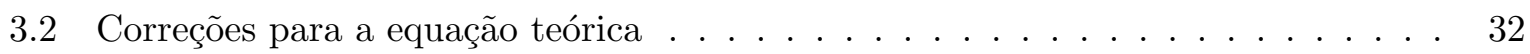

$3.3 \quad$ A equação completa para $D P F L O W \ldots \ldots \ldots$. . . . . . . . . . . . 37

4 Utilização de técnicas de inteligência artificial para medição de vazão em $\begin{array}{ll}\text { sistemas de automação } & 39\end{array}$

4.1 Redes neurais artificiais $\ldots \ldots \ldots \ldots$

\begin{tabular}{|lll}
5 & Experimentos, desafios e resultados & 53
\end{tabular} 


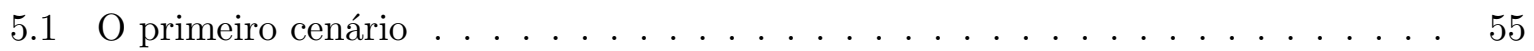

$5.2 \quad$ Utilizando os dados adquiridos para o treinamento da rede neural . . . . . . . . . 61

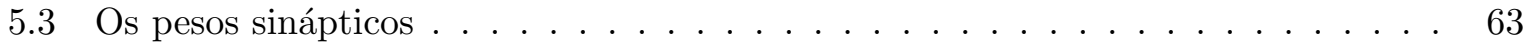

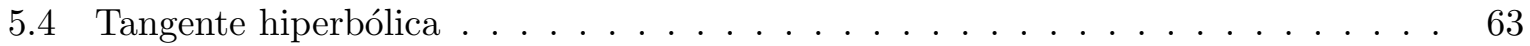

5.5 Normalização e desnormalização $\ldots \ldots \ldots \ldots$. . . . . . . . . . 65

5.6 Desafios na implementação da rede neural no ambiente foundation fieldbus. . . . 67

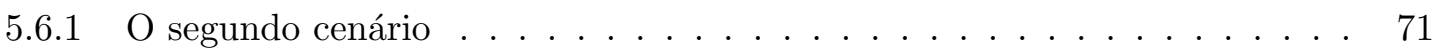

5.6.2 Número de blocos e melhoria da precisão da tangente tabulada . . . . . . 72

$\begin{array}{llr}6 & \text { Conclusão } & 85\end{array}$

\begin{tabular}{ll}
\hline Referências Bibliográficas & 87
\end{tabular}

\begin{tabular}{|l|l|l|}
\hline A Dados para treinamento da rede, dados de validação e resultado dos testes. & 91
\end{tabular} 


\section{Capítulo 1}

\section{Introdução}

\subsection{Histórico}

A necessidade de se medir vazão surgiu quando, depois de canalizar a água para o consumo doméstico, a administração pública sentiu a necessidade de arrecadação por esse serviço, e estabeleceu taxas para o seu consumo. Isso ocorreu já há muitos séculos. As primeiras medições de água teriam sido executadas por egípcios e romanos, cujas obras de adução de água fazem parte, hoje, das ruínas turísticas de vários países da Europa e do norte da África. Existe um texto do governador e engenheiro romano Julius Frontinus (30-103 d.C.) que traz referências precisas a esse respeito. Foi com Leonardo da Vinci (1452-1519) no século XV que o assunto voltou a ser estudado no trabalho intitulado "Sobre o movimento da água e das águas pluviais".

Galileu Galilei (1564-1642), no início do século XVII, trouxe sua participação aos fundamentos da medição de vazão, e seu discípulo Evangelista Torricelli (1608-1647) estabeleceu a equação sobre o escoamento livre da água através de orifícios.

As bases da mecânica dos fluidos foram estabelecidas de forma definitiva por dois físicos do século XVIII: Daniel Bernoulli (1700-1782) e Leonardo Euler (1707-1783). Bernoulli formulou, em seu tratado de hidrodinâmica, publicado em 1738, a principal lei sobre o movimento dos líquidos, comumente chamada de "equação de Bernoulli"; e Euler estabeleceu as equações diferenciais gerais relativas ao movimento dos líquidos perfeitos. Ainda no século XVIII, Henri Pitot (1695 -1771) apresentou um trabalho descrevendo o instrumento que ficou conhecido como "tubo de Pitot", ou apenas "Pitot", capaz de medir a velocidade da água. Em 1797, Giovanni Venturi (1746-1822) publicou o resultado dos seus estudos sobre o que ficou conhecido como "tubo de 
Venturi".

No século XIX, os trabalhos dos físicos Jean Poiseuille (1799-1869) (escoamento em tubos capilares e viscosidade dos fluidos), sir George Stokes (1819-1903) (trabalhos sobre a hidrodinâmica) e Osborne Reynolds (1842-1912) contribuíram significativamente para a evolução da tecnologia da medição de vazão.

No século XX, a necessidade de se medir a vazão de fluidos em geral tornou-se premente, em decorrência do crescimento da aplicação dos processos contínuos na indústria, em substituição aos processos em batelada. Princípios já conhecidos foram aplicados em conjunto com novas tecnologias, resultando em instrumentos modernos e confiáveis. Foram desenvolvidos novos medidores, baseados em princípios e resultados de estudos de físicos que haviam pesquisado outros fenômenos. Os estudos de Theodor von Karman (1881-1963) deram origem aos medidores "vortex"; os de Michael Faraday (1791-1867), ao medidor eletromagnético; e os de Gaspard Coriolis (1792-1843), ao medidor que aproveita os efeitos da aceleração complementar devido à "força de Coriolis". Foi o século dos congressos, das normas e da cooperação significativa das universidades e dos institutos de pesquisas com a iniciativa privada, para o desenvolvimento dos instrumentos e das normas.

Os congressos de importância histórica sobre o assunto, na primeira metade do século XX, foram os seguintes:

- 1932, Congresso de Milão - estabeleceram-se os dados básicos sobre placas de orifício e bocais de vazão;

- 1934, Congresso de Estocolmo - consolidaram-se os dados existentes para as placas de orifício;

- 1939, Congresso de Helsinque - normalizaram-se os bocais-Venturi;

- 1948, Congresso de Paris - mudaram-se determinados coeficientes existentes e normalizaram os coeficientes correspondentes as tomadas a $\mathrm{D}$ e $\mathrm{D} / 2$, sendo $\mathrm{D}$ o valor do diâmetro da tubulação. As distâncias com valores de D e D/2 são tomadas a partir da placa de orifício onde as tomadas de pressão a montante e a jusante respectivamente estão localizadas.

Publicadas nos anos 60, as normas internacionais ISO-R541, "Medição de vazão por placas de orifício", e ISO-R781, "Medição de vazão por tubo de Venturi”, foram atualizadas pela ISO-5167, "Measurement of fluid flow by means of pressure differential devices inserted in circular cross- 
section conduits running full" e suas partes ISO 5167-1 "General principles and requirements", ISO 5167-2 "Orifice plates", ISO 5167-3 "Nozzles and Venturi nozzles", ISO 5167-4 "Venturi tubes", publicadas inicialmente em 1981 e subscrita por todos os países-membros 10 anos depois. Devido a importância dos resultados da medição de vazão para a realização de operações comerciais - desde a compra de gasolina no posto de abastecimento até o uso de gasodutos e oleodutos internacionais, as normas nacionais e internacionais, bem como as portarias e outros dispositivos legais, passaram a ser fundamentais. As normas sobre medição de vazão são fontes de informação extremamente importantes. No caso particular dos medidores baseados em placas de orifício, as normas utilizadas no Brasil são a IS0-5167 e a AGA 3. Desde os anos 80, as sucessivas revisões dessas normas vem reduzindo suas pequenas diferenças e unificando os critérios que fundamentam os pontos principais: equação básica, tolerâncias de fabricação, limites de aplicação e trechos retos necessários. As normas sobre o assunto costumam ser o resultado dos estudos dos comitês de trabalho, que, por sua vez, depuram e consolidam os resultados de ensaios realizados em centros de desenvolvimento e de trabalhos desenvolvidos por pesquisadores.

Entre os congressos que contribuem para o desenvolvimento das técnicas de medição de vazão, o Flomeko é o mais importante. Em sua décima quinta conferência Internacional, no ano 2010, em Taipei - Taiwan, foram apresentadas algumas palestras relativas ao medidor tipo vortex, placas de orifício, venturis e bocais. Contudo, o maior número de palestras se referiam ao medidor ultrassônico (DELMÉE, 2003) e (FLOMEKO, 2010).

\subsection{Objetivo}

Esse trabalho tem por objetivo apresentar uma metodologia para o cálculo de vazão de fluidos compressíveis em dutos fechados a partir de valores medidos de pressão diferencial, pressão estática e temperatura utilizando-se de técnicas de redes neurais cujos parâmetros de treinamento e a topologia da rede são transportados para blocos funcionais em um ambiente foundation fieldbus.

Espera-se que a implementação desse software sensor possa ser realizada a um menor custo quando comparado à técnica atual baseada no emprego de um transmissor multivariável para esta finalidade. O objetivo proposto será comprovado em uma abordagem industrial que será explicada em detalhes mais adiante. 


\subsection{Publicações}

O presente trabalho resultou em alguns artigos publicados entre 2009 e 2010 , identificados a seguir:

1. Aplicação de redes neurais para detecção de linhas de impulso entupidas em medições de vazão ISA 2009 - 13o. Congresso Internacional e exposição de automação, sistemas e instrumentação - cidade de São Paulo - SP Autores: Denis Borg, Rodrigo Palucci Pantoni, Eduardo André Mossin e Dennis Brandão;

2. Implementação de uma rede neural em ambiente Foundation Fieldbus para simulação de computação de vazão simulando um instrumento multivariável XVIII Congresso Brasileiro de Automática - CBA 2010 em 16 de Setembro de 2010. Autores: Denis Borg, Marcelo Suetake e Dennis Brandão;

3. Simulação de Cálculos de Vazão de Fluidos Compressíveis Através de uma Rede Neural em Ambiente Foundation Fieldbus INDUSCON 2010 - IX Induscon 9a. IEEE/IAS International Conference on Industry Applications - 8 a 10 de Novembro de 2010 Autores: Denis Borg, Marcelo Suetake e Dennis Brandão.

\subsection{Organização do trabalho}

O presente Capítulo trata do histórico da medição de vazão e do objetivo do trabalho.

O Capítulo 2 traz informações sobre as unidades de vazão, a utilização de transmissores inteligentes e multivariáveis nos processos de medição de vazão e relata algumas diferenças entre os principais medidores de vazão utilizados em processos industriais.

No Capítulo 3 é demonstrado o embasamento teórico de como é realizada a medição de vazão à partir da leitura da pressão diferencial conhecida como DPFLOW. Partindo-se da Equação de Bernoulli e da Equação da Continuidade e considerando-se as correções para a equação teórica, é demonstrado nesse capítulo como se chega à equação completa para o cálculo de vazão a partir das variáveis de pressão diferencial, pressão estática e da temperatura.

No Capítulo 4 é desenvolvida uma revisão bibliográfica e também apresenta a aplicação da técnica da rede neural implementada em blocos de função foundation fieldbus com o objetivo de se calcular a vazão. 
O Capítulo 5 descreve como foi montado o kit para aquisição dos dados e como esses foram aplicados na rede neural implementada em blocos como referenciado no capítulo 4 . Ainda no capítulo 5 são discutidas algumas dificuldades encontradas na implementação da rede neural em blocos padrão foundation fieldbus e os resultados obtidos.

No Capítulo 6 está a conclusão do trabalho, e, depois desse, se econtram as Referências bibliográficas que serviram de base para o trabalho.

No Apêndice são ilustrados os principais dados configurados nos blocos foundation fieldbus, a estratégia de controle (distribuição dos blocos e os links que mostram o fluxo das informações) e as tabelas dos dados de treinamento e dos testes utilizados. 


\section{Capítulo 2}

\section{Conceitos de vazão e medidores}

Entre as variáveis mais frequentemente medidas, a vazão é a que requer os recursos tecnológicos mais diversos para o desenvolvimento de medidores e transmissores. A medição de vazão encontra importantes aplicações no transporte de fluidos (oleodutos, gasodutos), nos serviços públicos (abastecimento, saneamento) e na indústria em geral, para controle de relação, bateladas, balanços de massas, contribuindo para a qualidade e otimização de controles de processos. Em outra faixa de aplicações, os medidores domésticos (hidrômetro, medidor de gás) e os medidores de combustíveis (bombas de postos de abastecimento) fazem parte do cotidiano do consumidor. A vazão é definida como a quantidade de fluido que passa pela seção reta de um duto, por unidade de tempo. O fluido pode ser um líquido, gás ou vapor. A maioria dos instrumentos de vazão é projetada para se medir fluidos homogêneos, numa única fase; porém existem instrumentos para medir vazão de fluidos em fases múltiplas, sob a forma de suspensões coloidais de pastas ou de geléias. Geralmente, a medição é feita aproveitando-se o efeito de uma interação entre o fluido e o medidor (DELMÉE, 2003).

Os únicos padrões de definição disponíveis são dados em ASME-IM(1991) e ISO 4006 (1991). Nesses documentos as seguintes definições são dadas:

- Medidor de vazão: Instrumento que mede a vazão ou a quantidade de um fluido em movimento em um canal fechado ou aberto. Usualmente consiste de um instrumento primário e um secundário. É aceitável na prática identificar um medidor pela teoria de seu princípio de funcionamento como pressão diferencial, velocidade, área, força, etc., ou pela tecnologia aplicada como restrição (orifício), turbina, vortex, ultra-sônico, magnético, etc (MILLER, 1996). 
- Instrumento primário de vazão: Instrumento montado internamente ou externamente ao canal do fluido que produz um sinal relacionado à vazão do fluido de acordo com leis físicas conhecidas relacionando a vazão do fluido à presença do elemento primário. $\mathrm{O}$ instrumento primário pode consistir de um ou mais elementos necessários para produzir o sinal do medidor.

- Instrumento secundário de vazão: Instrumento que responde ao sinal do instrumento primário e o converte para um mostrador local ou para um sinal de saída que pode ser traduzido para valor de vazão. O instrumento secundário pode consistir de um ou mais elementos necessários para traduzir o sinal do elemento primário em um sinal padronizado, ou não padronizado, de display ou unidades transmitidas (registrador, indicador, totalizador, etc). Por essa definição, o elemento primário de um medidor de vazão por restrição (orifício), inclui trechos reto à montante e à jusante, condicionador de fluxo, placa de orifício e tomadas de pressão. O transmissor de pressão diferencial, válvulas manifold, e conexões são elementos do instrumento secundário. A combinação desses dois instrumentos perfazem o medidor de vazão por restrição (orifício) (MILLER, 1996).

\subsection{Unidades de vazão}

As taxas de vazão são calculadas tanto em unidades de massa como em volume. A unidade de vazão mássica depende apenas do tempo, como em libras por hora, por segundo, ou por dia. No entanto, a unidade volumétrica pode ser calculada em litros, pés cúbicos, ou metros cúbicos por unidade de tempo na pressão e temperatura nas condições de escoamento ou a uma pressão e temperatura especificadas (base de pressão e temperatura). Vazões em líquidos são quase sempre calculados em unidades de volume (galões ou litros por minuto), e vazões em gases em pés ou metros cúbicos por hora. Vazão de vapor, como vapor de água e amônia, são geralmente calculadas em unidades de massa como quilos por hora (MILLER, 1996).

Relação entre unidades de volume e massa

Os medidores de vazão podem ser agrupados em quatro classes, de acordo com seu princípio de operação:

1. Medidor de velocidade (vortex, turbina, ultra-som, magnéticos) 
2. Medidor de volume discreto (deslocamento positivo)

3. Medidor dependente de velocidade e densidade (orifício, bocal, Venturi)

4. Medidor direto de massa

\subsubsection{Unidade normal e unidade padrão}

Nos Estados Unidos o pé cúbico padrão é o mais comumente usado como unidade de volume de gás. Essa unidade é padronizada na norma ISO 5024 (1981) para o gás de petróleo (gás natural) como o que corresponde ao volume que o gás ocupa à uma pressão de 14,69595 psia $(101,325 \mathrm{kPa})$ e à temperatura de $59^{\circ} \mathrm{F}\left(15^{\circ} \mathrm{C}\right)$. No entanto, outras pressões e temperaturas são mais comumente usadas para o gás natural, oxigênio, e nitrogênio. Os valores selecionados de base de pressão ou de temperatura dependem do tipo de indústria, das normas utilizadas no país e frequentemente de solicitações contratuais. Por exemplo, na Europa é comum usar metro cúbico padrão ou metro cúbico normal como uma unidade volumétrica. O metro cúbico padrão usa a temperatura base de $60{ }^{\circ} \mathrm{F}\left(15,56^{\circ} \mathrm{C}\right)$, a unidade metro cúbico normal usa a temperatura base de $32{ }^{\circ} \mathrm{F}\left(\mathrm{O}{ }^{\circ} \mathrm{C}\right)$ e a pressão base para ambas unidades é 14,69595 psia $(101,325 \mathrm{kPa})$ (MILLER, 1996).

Busca-se, sempre que possível, utilizar unidades que esclareçam como deve ser entendida a leitura da vazão:

A vazão mássica é medida em $\mathrm{kg} / \mathrm{h}$, ou outra unidade que seja massa dividida por tempo.

A vazão volúmica (ou volumétrica) é medida em $m^{3} / h$ ou outra unidade que seja volume dividido por tempo; a vazão volúmica pode ser medida nas condições de operação ou nas condições de referência: Observa-se que expressar a vazão em volume nas condições de referência é uma forma alternativa da representação em massa, salvo no caso particular dos gases úmidos. De fato, a vazão volúmica nas condições de referência é a vazão mássica dividida pela massa específica nas condições de referência, que é uma constante para um determinado fluido. Por exemplo, ler uma vazão de $1000 \mathrm{~m}^{3} / h\left(\mathrm{O}^{\circ} \mathrm{C}, 760 \mathrm{mmHg}\right)$ de ar seco é o mesmo que ler 1293 $\mathrm{kg} / \mathrm{h}$, já que a massa especifica do ar seco a $\mathrm{O}{ }^{\circ} \mathrm{C}$ e $760 \mathrm{mmHg}$ é $1,293 \mathrm{~kg} / \mathrm{m}^{3}$. No caso da vazão volúmica nas condições de referência, estas são geralmente diferentes das condições de escoamento (de fluxo). Por exemplo, um gás pode estar a uma pressão de 20 bar e a uma temperatura de $80^{\circ} \mathrm{C}$ (condições de fluxo) e o objetivo é ler a vazão equivalente a $\mathrm{O}{ }^{\circ} \mathrm{C}$ e $1 \mathrm{~atm}$, que 
são as condições normais de temperatura e pressão para um gás. Usa-se o $\mathrm{m}^{3} / h$ (condições de referência) para compressores, sopradores, ventiladores, objetivando obter leituras compatíveis com as especificações da máquina. A temperatura de referência, geralmente a $20{ }^{\circ} \mathrm{C}$, deve ser especificada. No caso da vazão volúmica atual, as condições de leitura são as mesmas que as de fluxo. Recomenda-se essa opção, em lugar da precedente, quando as condições de referência mudam o estado do fluido. Por exemplo: quando se mede um gás liquefeito de petróleo (GLP) a $35{ }^{\circ} \mathrm{C}$ e 20 bar, esse fluido não permanece na fase líquida a $20{ }^{\circ} \mathrm{C}$ e 1 atm. (outra condição de referência). Nessas condições, o GLP passa para a fase gasosa. Assim, a escolha recairá preferivelmente na vazão volúmica atual. Dá-se preferência à vazão mássica quando o objetivo da medição é uma leitura independente das condições de referência. Geralmente, a vazão de vapor d'água é expressa em vazão mássica (DELMÉE, 2003).

Os transmissores encarregados de fazer a leitura de pressão são divididos basicamente em duas partes:

- O sensor, que geralmente é um sensor piezorresistivo ou uma célula capacitiva.

- Uma placa eletrônica que faz a leitura do valor da pressão advinda do sensor e entrega o sinal de saída num padrão conhecido de mercado . Na década de 70, esse padrão utilizado era o 4-20 mA no qual uma faixa de valores, por exemplo, uma faixa de pressão diferencial de 0 a 10 mca (metros de coluna de água) é convertida para $4 \mathrm{~mA}$ para o valor de 0 mca e para 20 mA quando o valor da pressão é de 10 mca. Valores intermediários são linearmente convertidos entre esses limites de corrente. A comunicação em 4-20 é unidirecional.

No fim da década de 80 surgiu o protocolo HART, acrônimo de Highway Addressable Remote Transducer. Esse protocolo faz uso da técnica de Frequency Shift Keying (FSK) desenvolvida pelos laboratórios Bell para somar o sinal de comunicação digital ao sinal de 4-20mA. Nesse protocolo, um ciclo da frequência de $1200 \mathrm{~Hz}$ significa o código binário "1" e dois ciclos da frequência de $2200 \mathrm{~Hz}$ significam o código binário "0". Dessa forma, sequências de 0 e 1 podem ser transmitidas bidirecionalmente. A próxima Figura 2.1 ilustra a forma de onda desse protocolo.

A partir dessa comunicação bidirecional HART, os transmissores começaram a ser denominados de transmissores inteligentes. Os transmissores que fazem uso de protocolos foundation fieldbus e profibus também levam esse nome. Além da comunicação bidirecional, outras funções foram incorporadas a esses transmissores inteligentes. 


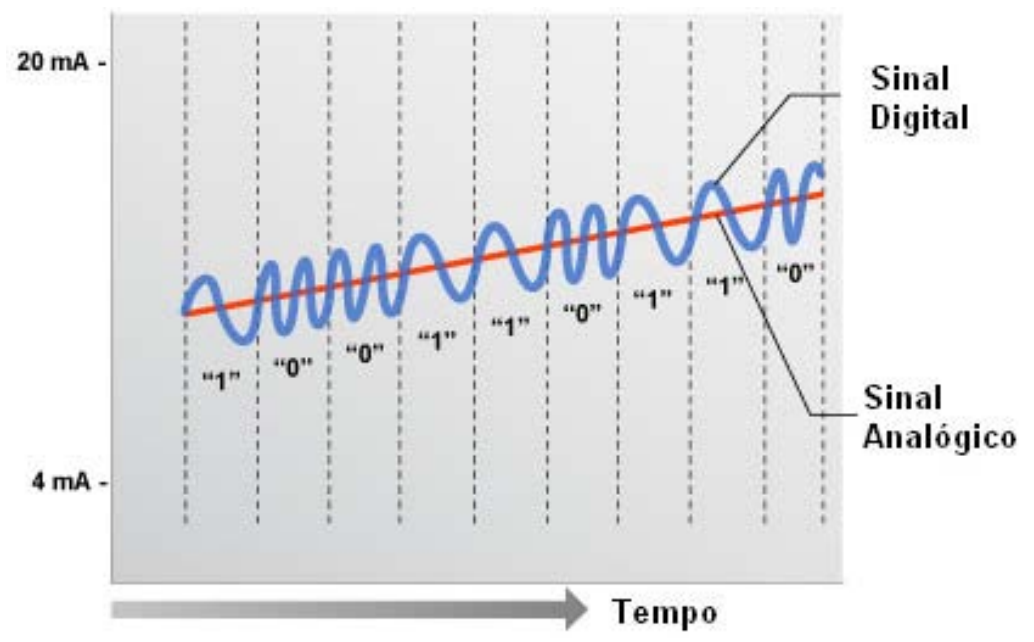

Figura 2.1: Sinal HART (SMAR, 2007).

\subsection{Transmissores inteligentes}

Os transmissores inteligentes foram inicialmente transmissores de pressão diferencial e de temperatura, mas agora incluem a pressão absoluta, pressão manométrica e transmissor de vazão, que combina todas as variáveis medidas usadas para computar a vazão. Vortex, eletromagnético, Coriolis, e outros tipos de medidores de vazão são também concebidos como medidores inteligentes. Em muitos sistemas, o sinal do sensor é digitalizado e então linearizado, tem a faixa reajustada, são realizadas conversões de unidades de engenharia, e a comunicação e diagnósticos são executados pelo microprocessador dedicado do transmissor. O sistema de comunicação é realizado através de um terminal remoto de mão que está ligado na malha padronizada de 4-20mA. Normalmente a saída do transmissor, o percentual da faixa, a supressão de zero, ou elevação, modelo, número de etiqueta, data da calibração, etc, podem ser exibidas remotamente. Os transmissores digitais são geralmente usados em aplicações que requerem um alto nível de desempenho em termos de estabilidade, diagnósticos, alta rangeabilidad£ (MILLER, 1996).

Com o advento dos transmissores inteligentes, foi possível enviar mais de uma variável, o que era impossível nos transmissores 4-20 mA puros. Devido à essa possibilidade da transmissão de mais de uma variável por transmissor, começaram a aparecer no mercado os transmissores hoje conhecidos como transmissores multivariáveis.

\footnotetext{
${ }^{1}$ Relação entre o maior e o menor valor lido respeitando-se uma dada precisão. Exemplo: Rangeabilidade de 100:1 com $0.075 \%$ de precisão na faixa de pressão.
} 


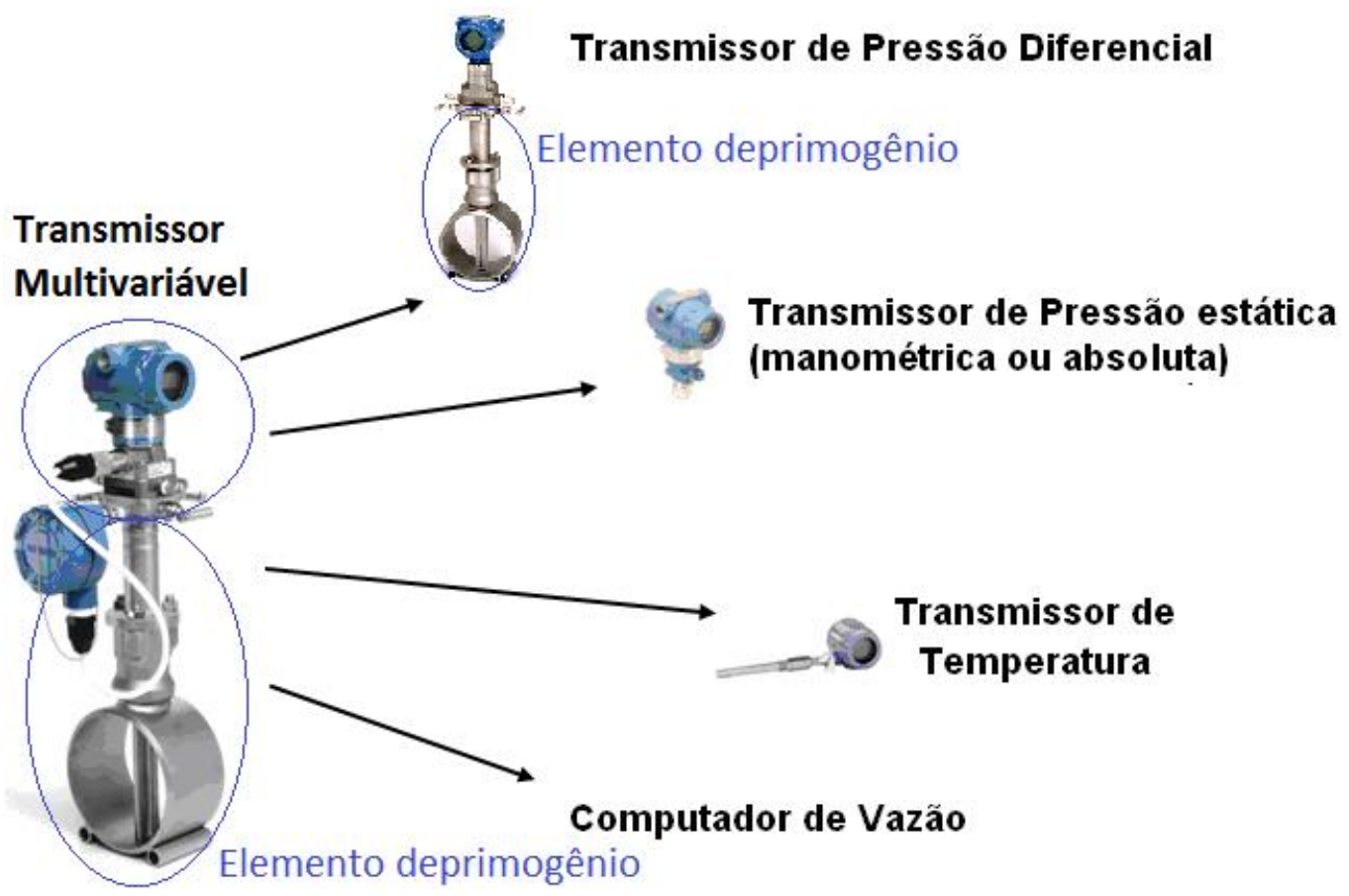

Figura 2.2: Transmissor multivariável acoplado a um elemento deprimogênio (annubar).

\subsection{Transmissores multivariáveis}

Os transmissores multivariáveis surgiram no final do século XX para aplicações em medição de vazão através de placas de orifício. Basicamente, esses transmissores são transmissores de pressão diferencial que possuem um transdutor interno de pressão estática. Um termorresistor pode ser ligado diretamente à eletrônica do transmissor. A parte eletrônica é um computador de vazão capaz de fazer os cálculos de acordo com as normas internacionais (AGA3, ISO5167) (DELMÉE, 2003).

Na Figura 2.2 é mostrada uma correlação entre o instrumento multivariável e sua equivalência quanto às funcionalidades dos transmissores discretos mais comuns. Ou seja, o instrumento multivariável substitui os transmissores de pressão estática, pressão diferencial, temperatura e realiza os cálculos de vazão. Na Figura 2.2, o transmissor multivariável e o transmissor de pressão diferencial aparecem acoplados a um averaging pitot tube modelo annubar que, como as placas de orifício, bocais e venturis é um elemento deprimogênid ${ }^{2}$. O sensor dos transmissores de pressão ou do multivariável são, em geral, do tipo célula capacitiva ou piezorresistivo.

A pressão diferencial gerada pelo elemento deprimogênio é levada até os diafragmas situados

\footnotetext{
${ }^{2}$ Gerador do valor da pressão diferencial a ser lida pelo sensor do transmissor.
} 


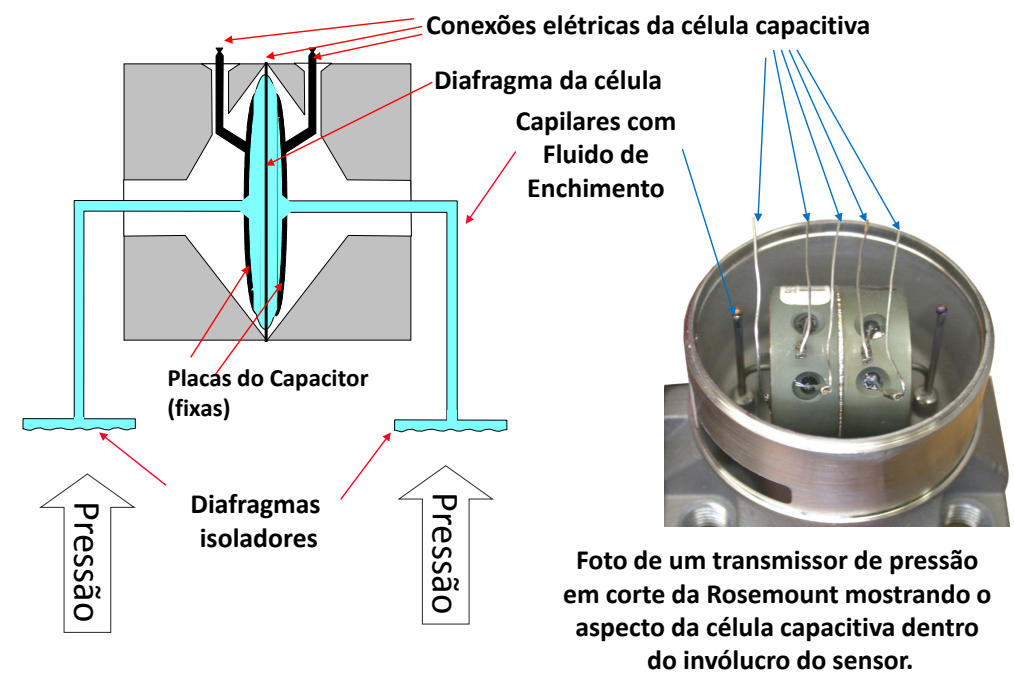

Figura 2.3: Célula capacitiva.

na parte inferior da célula capacitiva. O diafragma consiste de um disco fino e flexível, geralmente de aço inoxidável. As pressões são transmitidas através de um fluido de enchimento da célula indicado em cor azul (geralmente óleo silicone DC200) na Figura 2.3. Ainda nesta figura está ilustrada a célula capacitiva constituída de duas placas fixas e um elemento central que é flexível. Essa estrutura apresenta dois capacitores formados por uma das placas fixas e o diafragma central, sendo que este é compartilhado pelos dois capacitores. Dependendo da diferença entre as pressões, esse elemento central é defletido afastando-se da linha central, posição na qual o valor dos dois capacitores são praticamente idênticos. Esse diafragma central ao se mover, aumenta o valor de uma das capacitâncias (quando há a aproximação das placas), e diminui o valor da outra capacitância (quando há o afastamento das placas). O circuito eletrônico, por sua vez lê a diferença entre os capacitores, e dessa forma, consegue medir a diferença entre as pressões aplicadas ao transmissor diferencial. Essa mesma estrutura da célula capacitiva é também utilizada para medição de pressão manométrica e pressão absoluta. A diferença é que, para esses transmissores manométricos, uma das câmaras fica aberta para a pressão atmosférica local, e para os transmissores absolutos é realizado vácuo na câmara de referência.

Os sensores piezorresistivos são mais utilizados em transmissores de pressão estática, seja pressão manométrica ou absoluta. Esse tipo de sensor funciona segundo o princípio de que, quando uma força, originada pela pressão, deforma o corpo do sensor (geralmente de silício), a resistência elétrica desse corpo é modificada. Pela Figura 2.4 é possível verificar que a estrutura do sensor é montada num tipo de ponte de Wheatstone. O circuito eletrônico lê os valores de 


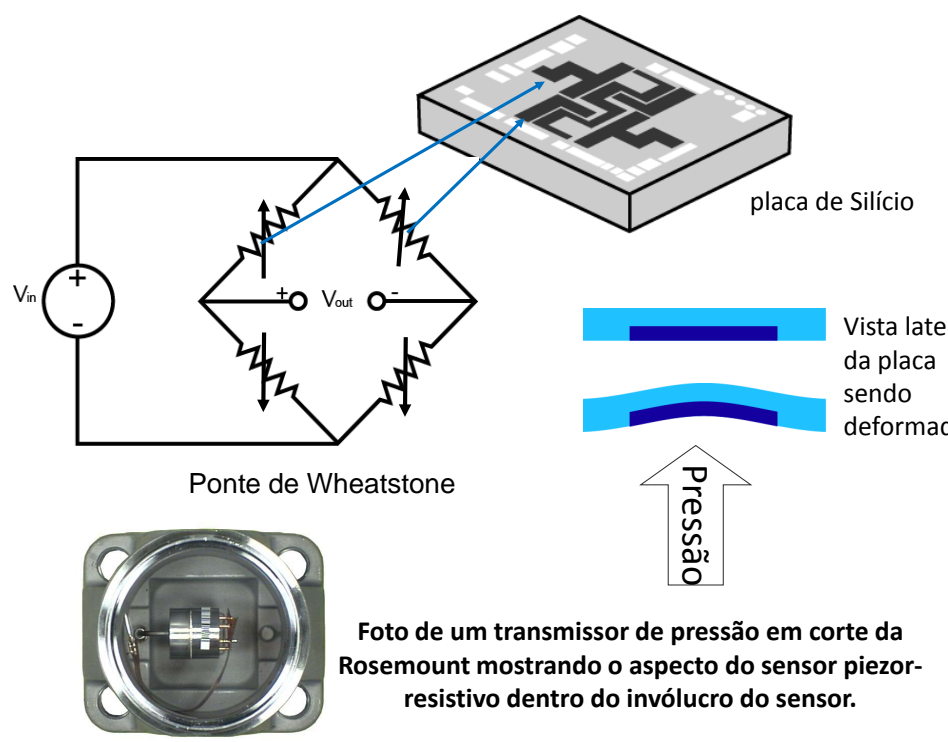

Figura 2.4: Sensor piezorresistivo.

resistência elétrica e, assim, consegue medir a pressão aplicada ao transmissor de pressão.

A transmissão do valor calculado da vazão é feita por via analógica ou por comunicação digital que permite também a transmissão de valores das outras variáveis como pressão diferencial, pressão estática e temperatura (DELMÉE, 2003).

Na Figura 2.5 é mostrado um detalhe de um fluxograma ilustrando as medições e o cálculo de vazão realizado. Esse desenho ilustra uma tubulação instrumentada. Há uma tomada para a medição da pressão estática da linha realizada pelo transmissor de pressão PT-001, uma placa de orifício conectada a um transmissor de pressão diferencial PDT-001 e um elemento sensor de temperatura TE-001 conectado a um transmissor de temperatura TT-001. Os sinais dos três transmissores são enviados a um $\mathrm{SDCD}^{3}$ ou CLP ${ }^{4}$ que perfaz os cálculos de indicação e totalização da vazão (FQI-001). Atualmente há no mercado alguns instrumentos multivariáveis como o 3095MV $\mathrm{MV}^{T M}$ e o 3051SMV ${ }^{T M}$ do fabricante Rosemount (ROSEMOUNT, 2009) (divisão da Emerson Process Management), o EJX910A ${ }^{T M}$ fabricado pela Yokogawa (YOKOGAWA, 2010), e o SMV3000 ${ }^{T M}$ da Honeywell (HONEYWELL, 1997).

Na Figura 2.6 é mostrado um módulo sensor do transmissor multivariável da Rosemount, modelo $3095 \mathrm{MV}^{T M}$. Os dois diafragmas isoladores ficam na parte inferior do módulo. As informações de pressão são enviadas até a célula capacitiva por capilares preenchidos, na maioria

\footnotetext{
${ }^{3}$ Sistema de controle distribuído.

${ }^{4}$ Controlador lógico programável.
} 


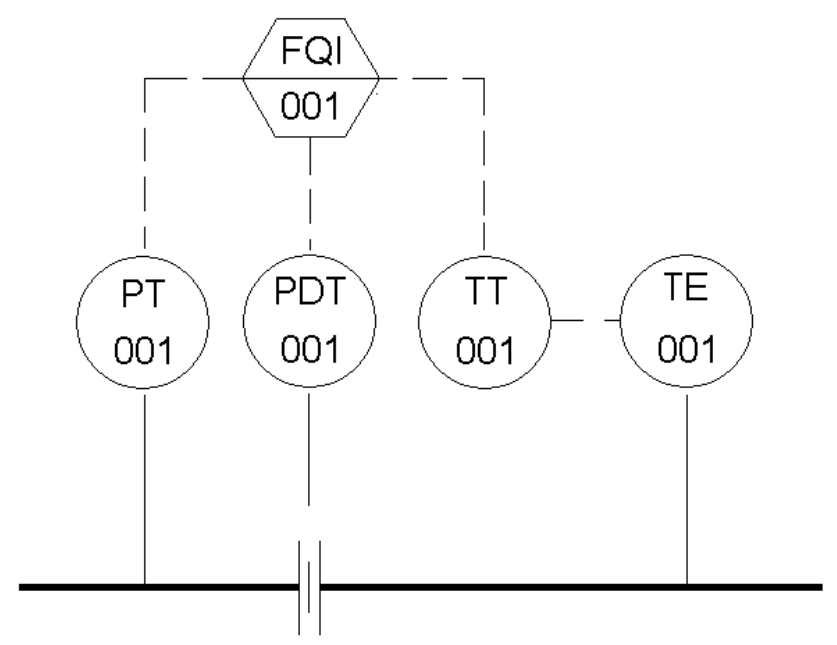

Figura 2.5: Detalhe da medição de um processo indicando a medição de vazão.

das vezes, por óleo silicone. Uma derivação no capilar do lado de alta pressão leva a informação até o sensor piezorresistivo, leitor da pressão estática. Dependendo do modelo do transmissor multivariável, esse sensor pode ler pressão absoluta ou manométrica. No experimento, o modelo utilizado foi o sensor de pressão absoluta. A placa eletrônica recebe os sinais dos sensores de pressão estática e diferencial e do cabo da termorresistência (sensor PT100) e trabalha a linearização desses sensores. O flat cable conduz as informações até a placa eletrônica principal onde são armazenadas as informações do fluido do processo, elemento primário de vazão e onde são realizados os cálculos de vazão.

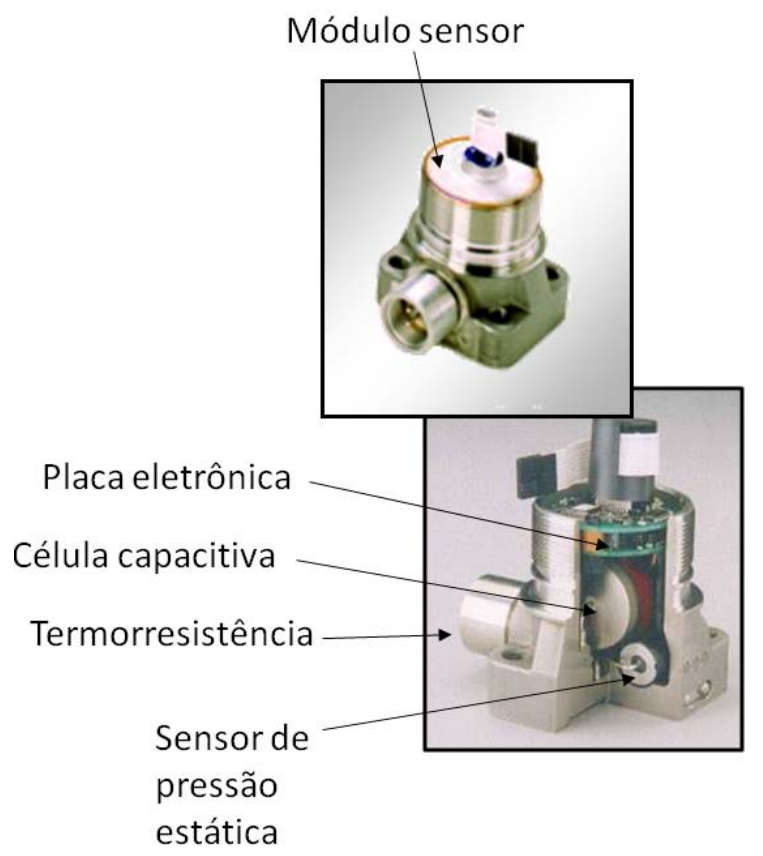

Figura 2.6: Módulo sensor do trasmissor multivariável. 
A Figura 2.7 ilustra as principais funções desenvolvidas no módulo sensor como conversão analógico digital e a linearização dos sensores. Na placa eletrônica central as principais funções desenvolvidas são os cálculos de vazão, escolha das unidades dos valores de pressão, temperatura, vazão, etc e a conversão digital analógico no caso do transmissor com saída de corrente 4 a 20 mA mais o protocolo HART. Para os transmissores com saída em foundation fieldbus não existe essa conversão porque a saída é transmitida digitalmente.

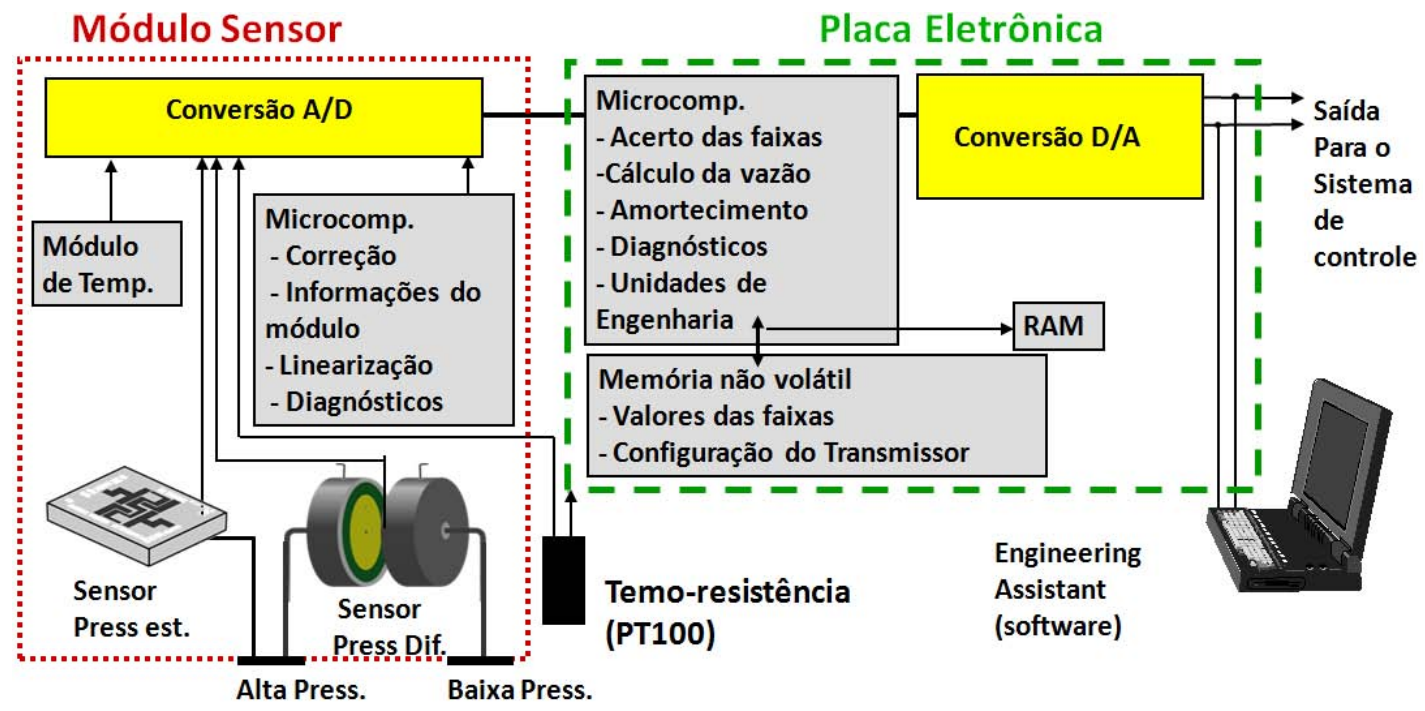

Figura 2.7: Diagrama de funções do transmissor multivariável.

A Figura 2.8 ilustra a região de operação (reta de carga) do transmissor multivariável em HART. A resistência elétrica comumente de $250 \Omega$ é necessária para a comunicação do sinal HART. 


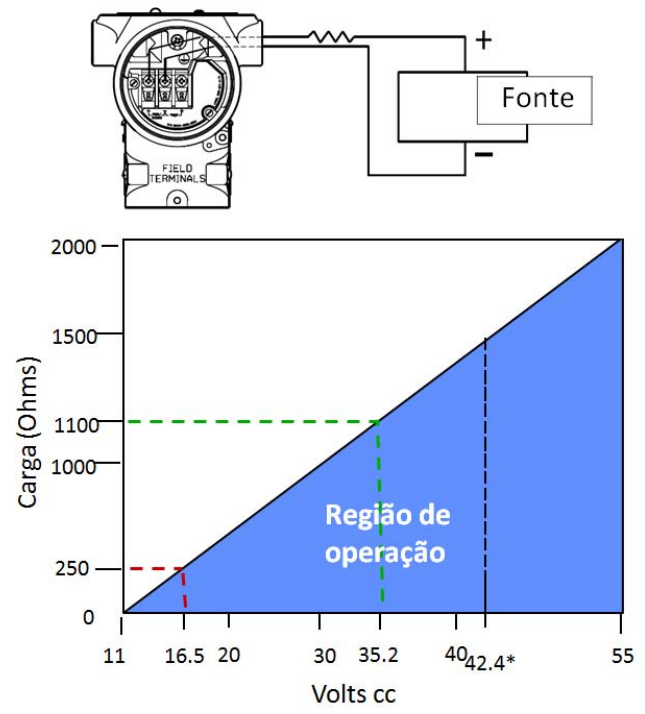

Figura 2.8: Limites de alimentação e reta de carga do transmissor multivariável.

A partir da leitura das variáveis dinâmicas de pressões e de temperatura adicionadas à algumas configurações como o tipo do elemento primário (placa de orifício, annubar, bocal de vazão, etc.), das dimensões desse elemento primário de vazão e da tubulação como o valor do diâmetro da tubulação, o valor de $\beta$, que é o valor do diâmetro do orifício da placa dividido pelo diâmetro do orifício da tubulação (MILLER, 1996), o instrumento multivariável realiza cálculos complexos e infere o valor da vazão onde o elemento primário foi instalado. Tais instrumentos são de significativa complexidade, possuem alta precisão na computação do valor da vazão, da ordem de 1\% da vazão mássica (ROSEMOUNT, 2009), e são instrumentos de custo elevado. São usados inclusive em aplicações de transferência de custódia 5 , por exemplo, de gás natural ou para avaliação de consumo de gases industriais ou hospitalares ou ainda, em aplicações em balanço de massa nas mais diferentes indústrias. Os medidores de vazão podem ser divididos segundo a Tabela 2.1 (DELMÉE, 2003).

\footnotetext{
${ }^{5}$ Transação comercial, na qual o fornecedor e o comprador controlam o fornecimento e o recebimento do produto, de acordo com o contrato firmado entre as partes interessadas.
} 
Tabela 2.1: Medidores de vazão.

\begin{tabular}{|c|c|c|c|c|c|c|c|}
\hline \multicolumn{2}{|c|}{ Geradores de $\Delta \mathrm{P}$} & \multicolumn{2}{|c|}{ Medidores Lineares } & \multicolumn{2}{|l|}{ Volumétricos } & \multicolumn{2}{|c|}{ Em canais abertos } \\
\hline Placa de Orifício & $\mathrm{T}$ & Área Variável & $\mathrm{A}$ & Diafragma & G & Calhas & $\mathrm{L}$ \\
\hline Bocal & $\mathrm{T}$ & Coriolis & $\mathrm{A}$ & Discos de Nutação & $\mathrm{L}$ & Vertedores & $\mathrm{L}$ \\
\hline \multirow[t]{2}{*}{ Venturi } & $\mathrm{T}$ & Eletromagnético & $\mathrm{LC}$ & Palheta & $\mathrm{L}$ & & \\
\hline & & Térmico & $\mathrm{A}$ & Pistão Oscilante & $\mathrm{L}$ & & \\
\hline \multicolumn{2}{|l|}{ Inserção } & Turbina & $\mathrm{A}$ & Pistões Recíprocos & $\mathrm{L}$ & & \\
\hline \multirow{3}{*}{$\begin{array}{c}\text { Pitot } \\
\text { Pitot de media }\end{array}$} & $\mathrm{T}$ & Ultra-sônico & $\mathrm{T}$ & & & & \\
\hline & $\mathrm{T}$ & Vortex & $\mathrm{T}$ & \multicolumn{2}{|l|}{ Rotor } & & \\
\hline & & \multicolumn{2}{|c|}{ Medidores Especiais } & Lóbulo & G & & \\
\hline \multicolumn{2}{|l|}{ Específicos } & Força & $\mathrm{A}$ & Engrenagem & $\mathrm{L}$ & & \\
\hline Centrífugos & $\mathrm{A}$ & Correlação & $\mathrm{E}$ & Semi-imerso & $\mathrm{G}$ & & \\
\hline Laminares & $\mathrm{G}$ & Laser & $\mathrm{G}$ & & & & \\
\hline Jato & $\mathrm{A}$ & & & & & & \\
\hline
\end{tabular}

\section{Legenda:}

T: líquidos, gases e vapor

G: Medição de gases, exclusivamente

L: Medição de líquidos exclusivamente

LC: Medição de líquidos condutores de eletricidade exclusivamente

A: Indica que não é usado para vapores, salvo excessão

E: Líquidos com sólidos em suspensão

Em seguida, alguns dos tipos mais comuns de medidores para aplicações industriais mostrados na Tabela 2.1 serão detalhados.

\section{Medidor volumétrico de vazão tipo turbina}

São medidores cuja vazão volumétrica é proporcional à frequência de rotação de um rotor posicionado no percurso do fluido dentro de um tubo. A rotação do rotor é transmitida por meios mecânicos ou elétricos para um contador de pulsos ou uma unidade eletrônica transformando a frequência em sinal digital ou analógico. 


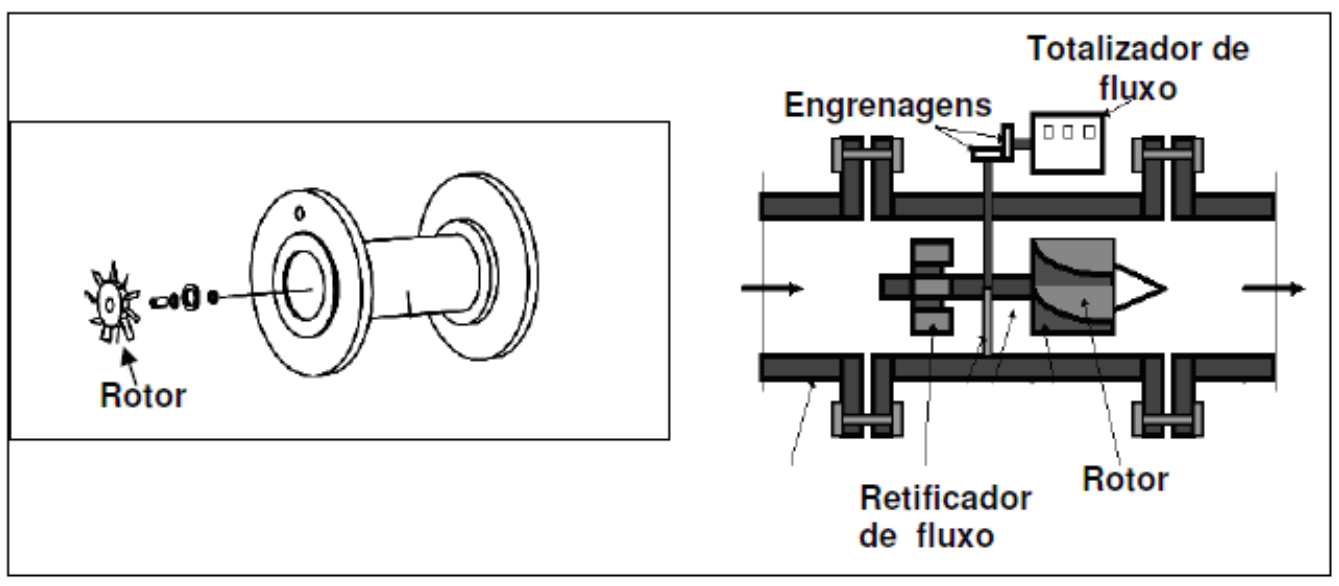

Figura 2.9: Medidor volumétrico de vazão tipo turbina (MELO, 2007).

A Figura 2.9 ilustra a construção típica de uma turbina (MELO, 2007) e (LIPTAK, 1995).

\section{Medição volumétrica de vazão tipo vortex}

Os vortex são medidores nos quais uma haste anti-aerodinâmica é colocada de forma a obstruir parcialmente o escoamento de um fluido, ocorrendo a formação de vórtices cuja frequência $f$ é proporcional a velocidade $V$ do fluido e também à forma e largura da haste representada pelo número de Strouhal (St) - Equação 2.1.

$$
f=S t \frac{V}{d}
$$

Transdutores (piezoelétricos, capacitivos e outros) são usados para transformar os esforços mecânicos exercidos sobre a haste em sinais elétricos de frequência.

A Figura 2.10 mostra o medidor tipo vortex em corte. Para baixas velocidades as linhas do fluxo contornam a haste com escoamento laminar, ou seja, sem formação de vórtices. Porém, à medida que a velocidade aumenta acima de um determinado limite, as linhas se descolam do canto da haste e formam vórtices alternados que geram esforços na haste. Cada pulso gerado é correspondente a um determinado volume fixo (MELO, 2007). O medidor tipo vortex é basedo no efeito descoberto por Von Karman. A frequência alternada dos vórtices é linearmente proporcional à vazão. Na Figura 2.11 é mostrado o fluido em cor azul atravessando o tubo do medidor tipo vortex. A alternância dos vórtices é captada pelo sensor. O sensor (elemento piezoelétrico) converte essas oscilações para um sinal elétrico alternado que é enviado para a placa eletrônica do transmissor. A frequência do sinal elétrico é proporcional à frequência de oscilação do shedder e linearmente proporcional à velocidade do fluido. 


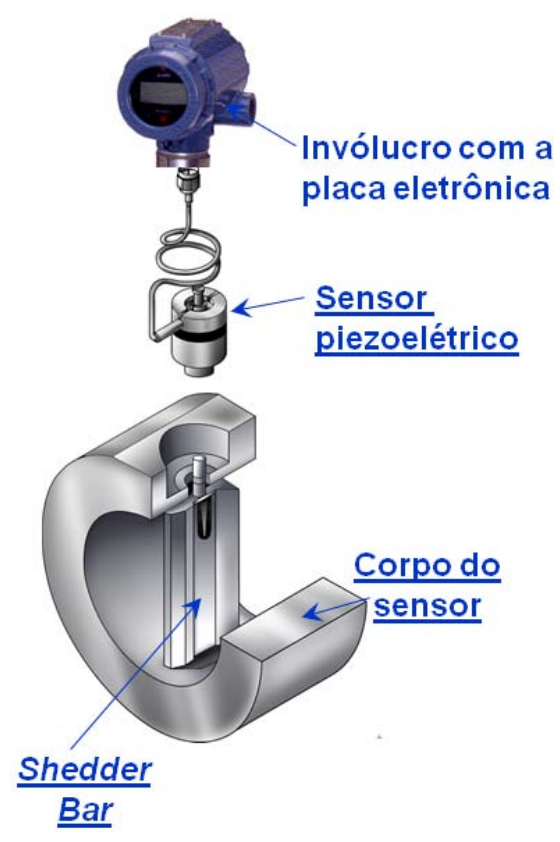

Figura 2.10: Principais componentes do medidor vortex.

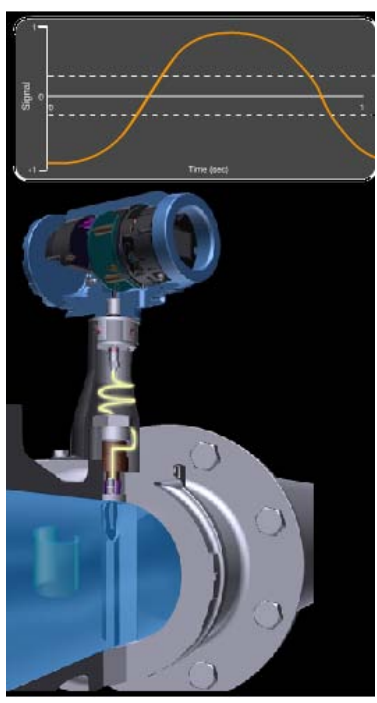

Figura 2.11: Princípio de funcionamento do medidor vortex. 


\section{Medição volumétrica de vazão tipo ultra-sônico}

São medidores cuja velocidade do fluido é obtida através da reflexão (efeito Doppler) ou retardo (tempo de trânsito) de sinais ultra-sônicos emitidos através do fluido.

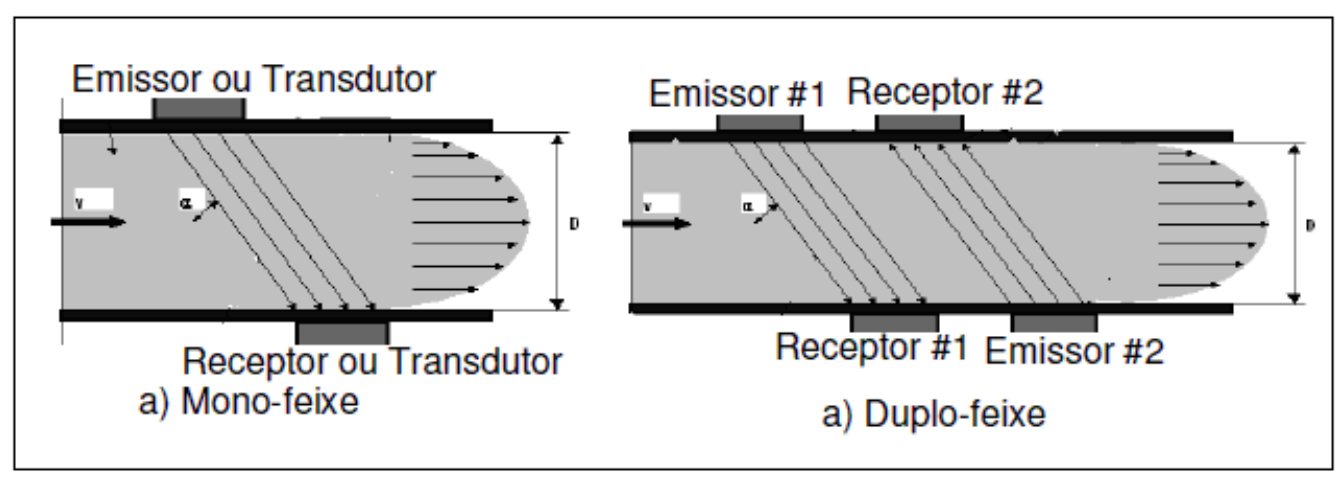

Figura 2.12: Medidores tipo ultra-sônicos (MELO, 2007).

A Figura 2.12 mostra os emissores e receptores de ondas ultra-sônicas em medidores monofeixe e duplo-feixe (MELO, 2007).

Os medidores multi-feixes (até 4 feixes) são usados para aumentar a confiabilidade, compensar efeitos de distorção no perfil de velocidades e diminuir a incerteza da medição.

\section{Medição volumétrica de vazão tipo ultra-sônica por efeito Doppler}

Nesses medidores a velocidade do fluido é proporcional à variação de frequência aparente, produzida pela reflexão de ultra-sons nas partículas móveis do fluido em movimento relativo ao emissor e ao receptor. Os sinais de ultra-som são refletidos pelas partículas do fluido que tem sua frequência alterada proporcionalmente à velocidade do fluido. Esses medidores são limitados a fluidos que contém partículas capazes de refletir ondas acústicas.

\section{Medição volumétrica de vazão ultra-sônica por tempo de trânsito}

Essa tecnologia utiliza medidores nos quais transdutores transmitem e recebem alternadamente trens de pulsos ultra-sônicos. A velocidade do fluido é proporcional à diferença entre os tempos de propagação no sentido do fluxo e no contra-fluxo. Esses medidores são limitados a fluidos limpos (sem partículas sólidas) e sem bolhas (MELO, 2007) e (LIPTAK, 1995). 


\section{Medidor tipo eletromagnético}

Esses medidores se baseiam no princípio eletromagnético descoberto por Faraday. Um fluido condutor de eletricidade (condutividade mínima de $5 \mu \mathrm{S}$ segundo o manual do fabricante Rosemount), ao fluir com uma certa velocidade por um trecho de tubo, corta as linhas do campo magnético gerado pelas bobinas presentes ao redor desse tubo. Esse fluido condutivo, ao cortar as linhas de campo, dão origem a uma tensão elétrica que é medida pela parte eletrônica do medidor. A partir da medição dessa tensão e do conhecimento do valor do campo magnético e do diâmetro da tubulação chega-se ao valor da velocidade e, consequentemente, da vazão que passa por aquela seção do tubo.

A Equação 2.2 ilustra a fórmula do princípio eletromagnético descoberto por Faraday.

$$
E=\vec{B} D \vec{V}
$$

O valor de tensão $E$ é dado em Volts, o campo magnético $\vec{B}$ em Tesla, $D$ em metros e a velocidade $\vec{V} \mathrm{em} m / s$.

A Figura 2.13 mostra um medidor eletromagnético.

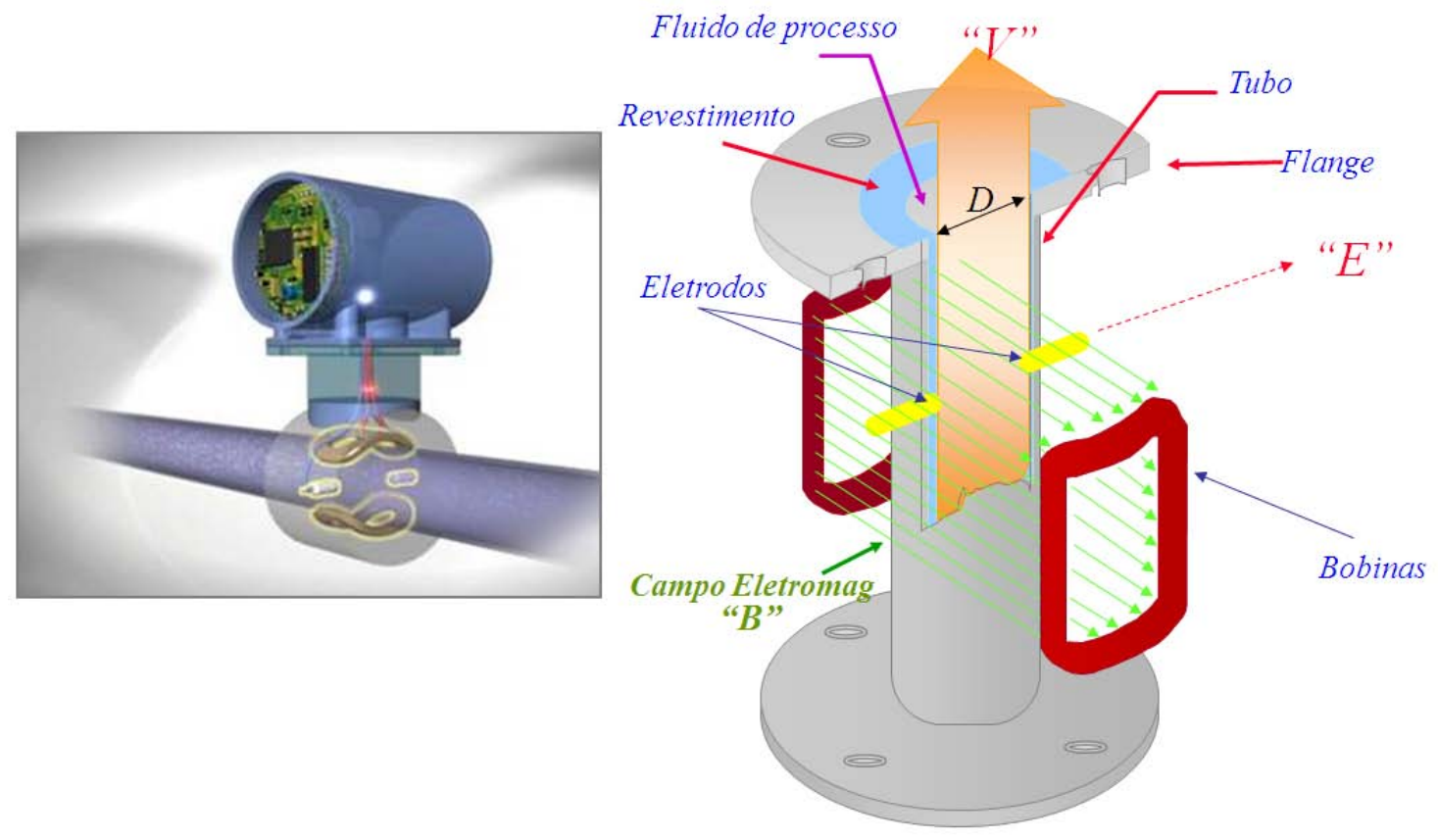

Figura 2.13: Medidores tipo eletromagnético. 

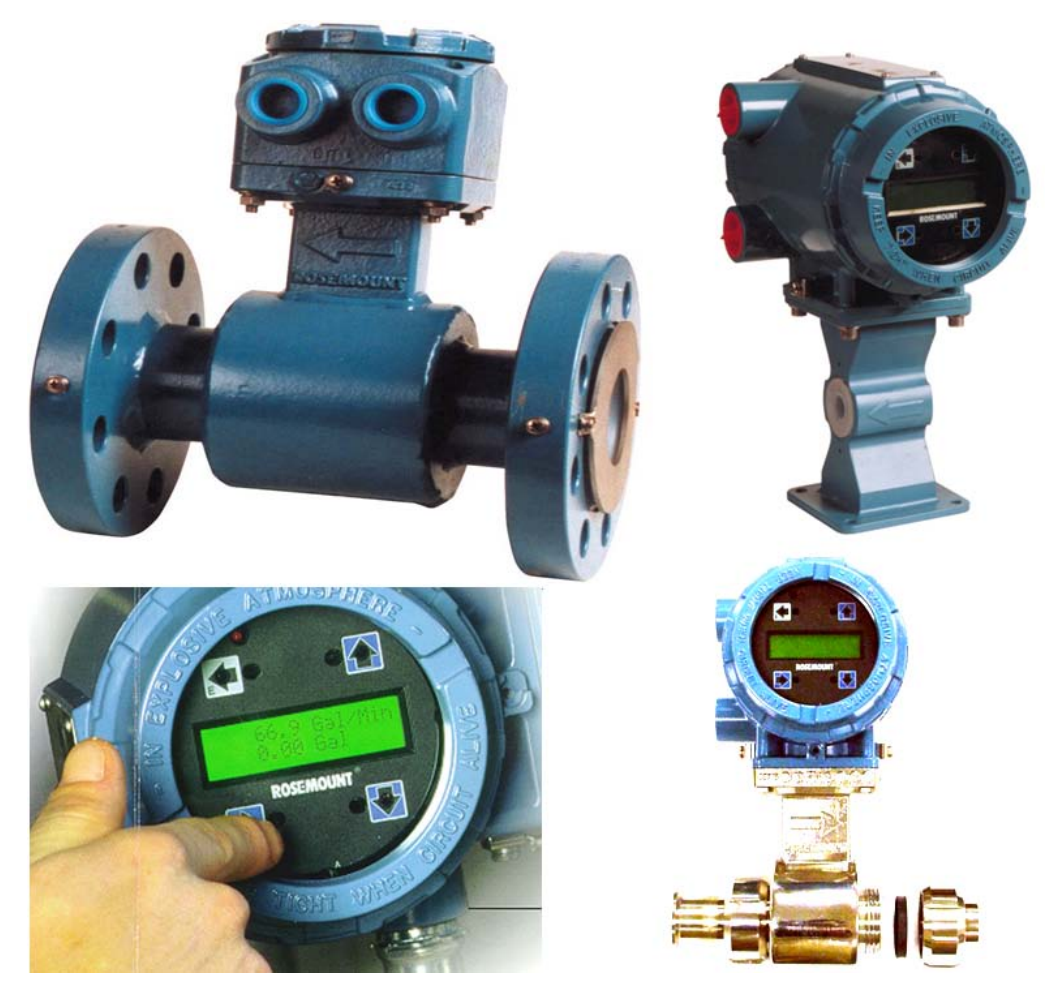

Figura 2.14: Aspecto físico dos medidores eletromagnéticos.

A Figura 2.14 mostra o aspecto físico de um medidor eletromagnético flangeado, um medidor tipo wafer, o invólucro de um transmissor e um medidor tipo sanitário.

\section{Medidor tipo Coriolis}

Esses medidores se baseiam no princípio descoberto por Gaspard Coriolis que estabelece que um corpo com uma determinada massa ao se deslocar num sistema giratório, sofre a ação de uma força segundo a fórmula:

$$
\overrightarrow{F_{c}}=2 m\left(\vec{w} \wedge \overrightarrow{v_{r}}\right)
$$

A Equação 2.3 foi estabelecida por Gaspard Coriolis.

Sendo $m$ a massa do fluido, $\overrightarrow{v_{r}}$ é a velocidade relativa a um sistema de referência, $\vec{w}$ é a velocidade angular. Essas duas últimas variáveis são grandezas vetoriais. O produto vetorial delas dá a direção da força de Coriolis $\vec{F}_{c}$.

O medidor tipo coriolis separa o fluido em dois tubos em "U". Esses dois tubos são colocados em vibração pela bobina impulsora e o sensoramento dessa vibração é realizado por duas bobinas sensoras. 


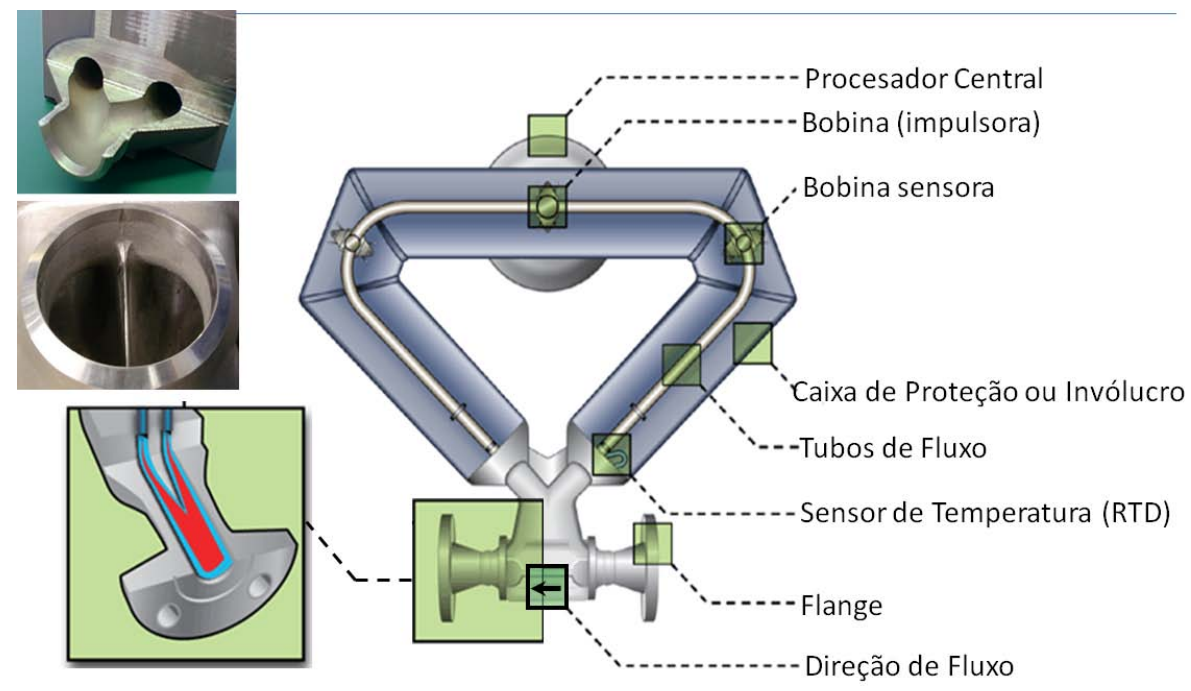

Figura 2.15: Elementos do medidor tipo coriolis.

A Figura 2.15 mostra os principais elementos do medidor tipo coriolis.

Quando não há vazão, as bobinas sensoras estão em fase. Quando há vazão, os tubos flexíveis se deformam quando o fluxo interno do tubo se afasta ou se aproxima do eixo de rotação (na figura é o eixo da tubulação) devido ao efeito de Coriolis. Com isso, as bobinas sensoras não estão mais em fase e pode-se medir eletronicamente a defasagem entre as duas senóides para se determinar a vazão que passa pelo medidor como pode ser visualizado na Figura 2.16 .

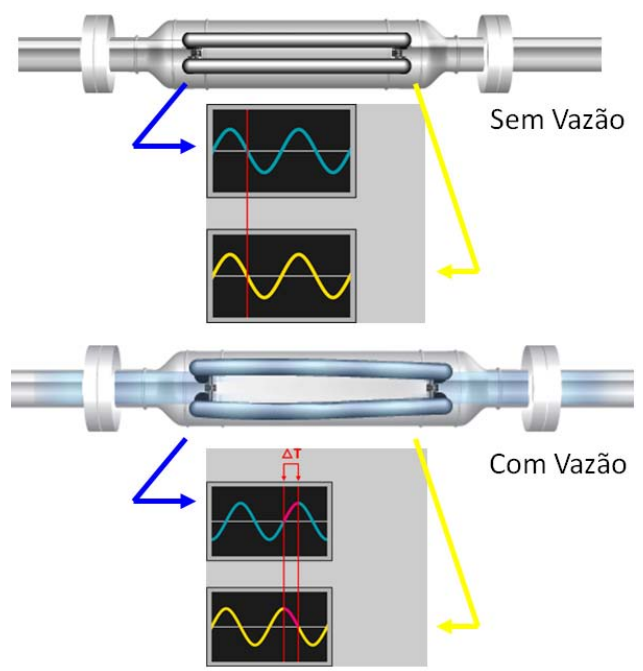

Figura 2.16: Funcionamento do medidor tipo coriolis. 


\subsubsection{Medidores por pressão diferencial}

\section{Placa de orifício}

O desempenho da placa depende criticamente da espessura e da planicidade da placa e do formato dos cantos de furo central. O desgaste do canto do furo, a deposição de sujeira no canto ou na superfície da placa e a curvatura na placa podem provocar erros grosseiros na medição da vazão. Por exemplo, quando há deposição, tornando o furo menor, tem-se uma maior pressão diferencial e portanto uma indicação maior que a vazão real. A espessura " $E$ " varia de $\frac{1}{8}$ a $\frac{1}{2}$ polegadas. A espessura da placa com furo de diâmetro $d$ é função do diâmetro $D$ da tubulação (ISO5167-2, 2003). A Figura 2.17 ilustra o perfil da placa.

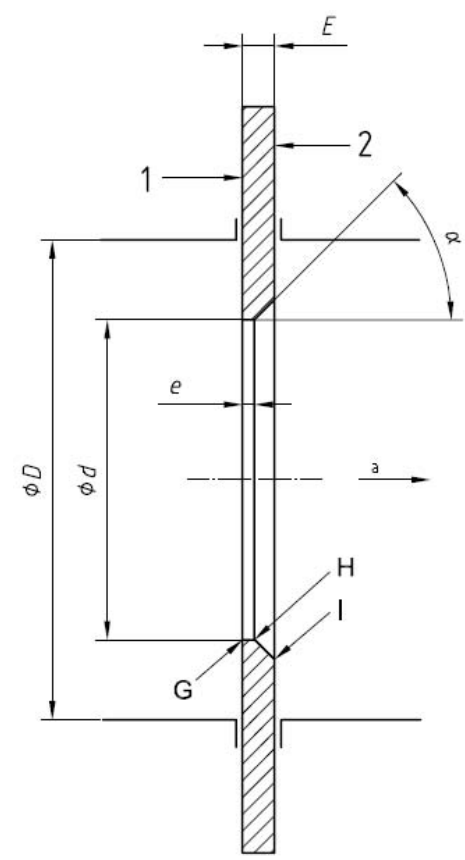

Figura 2.17: Placa de orifício em perfil (ISO5167-2, 2003).

No guia rápido de instalação (GUIDE, 2007) é encontrado o desenho explodido da placa de orifício entre as gaxetas e flanges. São mostradas também as conexões dos flanges ao transmissor de pressão diferencial ou transmissor multivariável na Figura 2.18 .

Ainda em (ISO5167-2, 2003), é possível ver o perfil do fluxo e ter uma noção de como a pressão e a temperatura variam ao longo da tubulação como ilustrado na Figura 2.19. Os índices 8 e 9 dessa figura ilustram a distribuição de pressão e de temperatura ao longo do eixo da tubulação. 


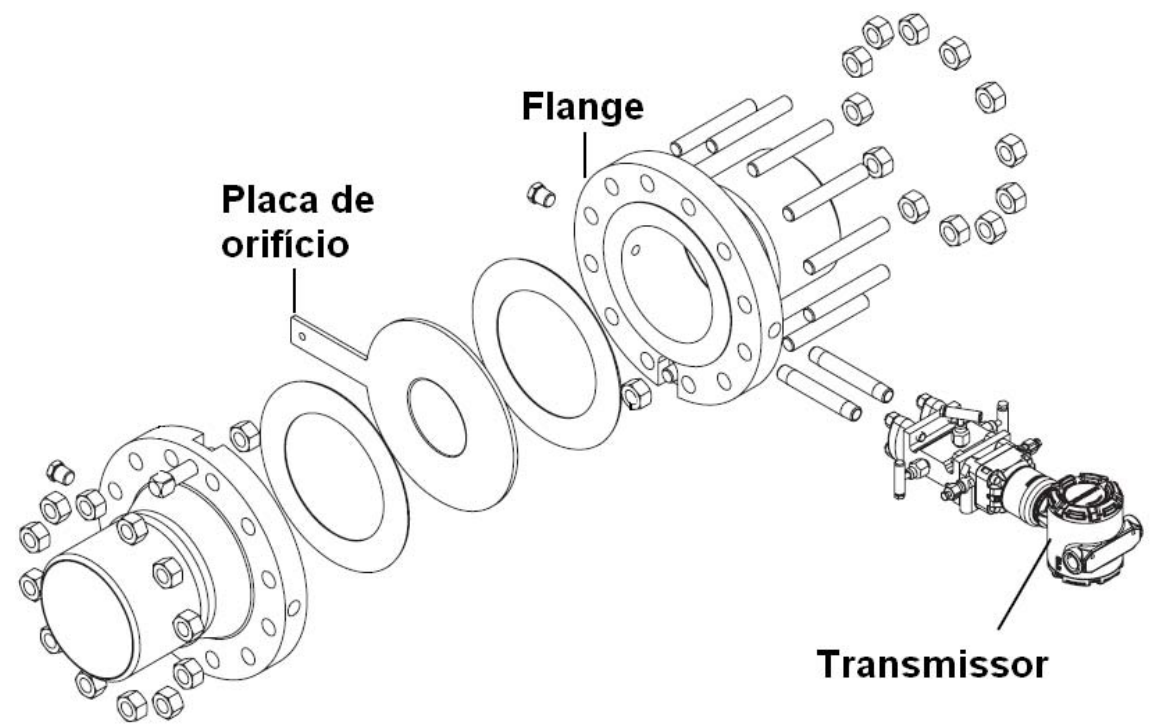

Figura 2.18: Montagem da placa de orifício (GUIDE, 2007).
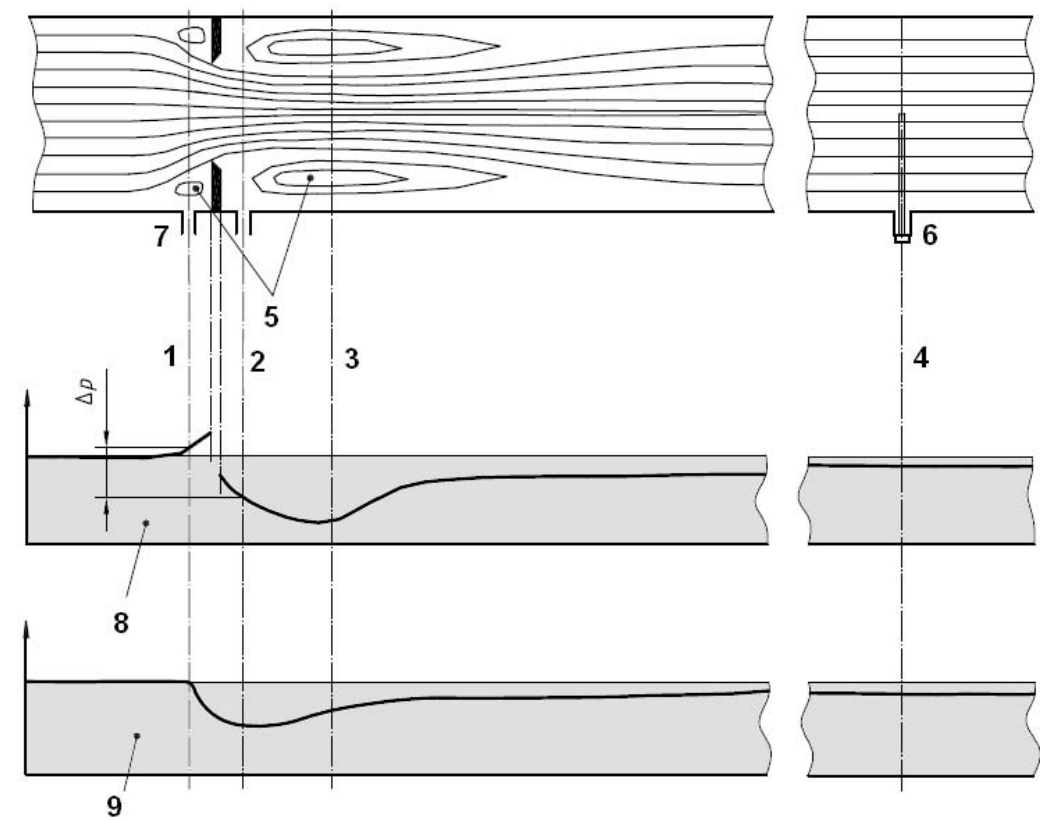

Figura 2.19: Perfil do fluxo na placa de orifício (ISO5167-2, 2003).

\section{Legenda:}

1. Plano das tomadas de pressão a montante da placa;

2. Plano das tomadas de pressão a jusante da placa;

3. Plano da "vena contracta" (velocidades mais altas);

4. Plano do sensor para medição de temperatura;

5. Regiões de vazão secundárias; 
6. Termopoço;

7. Tomadas de pressão;

8. Distribuição da pressão ao longo da parede da tubulação;

9. Distribuição da temperatura ao longo da parede da tubulação.

Este capítulo apresentou de forma objetiva os conceitos de vazão, as unidades mais comumente empregadas de vazão, a descrição funcional e os princípios de funcionamento dos principais medidores de vazão empregados em medições industriais.

No capítulo 3 será ilustrada a teoria de medição de vazão a partir da pressão diferencial. Essa técnica de medição de vazão merece ser abordada com maior detalhe do que a dos outros medidores dado que o sistema utilizado nos experimentos está baseado nela. 


\section{Capítulo 3}

\section{A teoria de medição de vazão a partir da pressão diferencial}

Esse capítulo tem o objetivo de apresentar ao leitor a técnica de medição de vazão a partir da medição de pressão diferencial, pressão estática e temperatura. Isso porque todo o trabalho desenvolvido com a rede neural artificial tomou por base esse princípio de medição de vazão utilizado na área industrial. Basicamente, a rede neural realizará o cálculo mostrado na Equação 3.16 mostrada ao fim desse capítulo.

Parte desse capítulo foi traduzida pelo autor e adaptada de um relatório técnico escrito por Steven Rogers ( Minnesota - EUA.

A Figura 3.1 ilustra um afunilamento da tubulação. Com essa diminuição do diâmetro do tubo, há um aumento na velocidade do fluido e, consequentemente, uma queda na pressão do fluido que será medida para se inferir o valor da vazão.

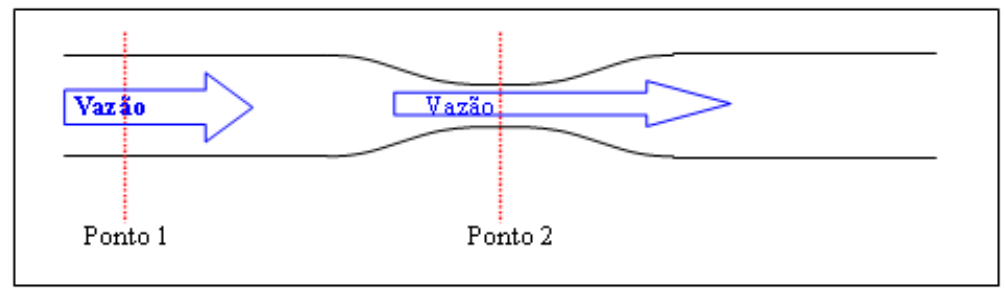

Figura 3.1: Representação de uma restrição na tubulação.

Em seguida será mostrada a origem da técnica da medição de vazão a partir da medição por pressão diferencial. 


\subsection{Equação de Bernoulli e a equação da continuidade}

A equação denominada DPflow, ou seja, a equação de vazão a partir de medidores que geram pressão diferencial, é baseada em Bernoulli, um balanço de energia para fluidos escoando por uma tubulação como ilustrado na Figura 3.1. A equação de Bernoulli estabelece que a soma da energia potencial, a energia cinética e energia de pressão é a mesma em qualquer ponto da tubulação. Está ilustrado abaixo os índices 1 e 2 que representam os pontos nos quais a Equação 3.1 se aplica.

$$
P_{1}+\frac{1}{2} \rho v_{1}^{2}+\rho g h_{1}=P_{2}+\frac{1}{2} \rho v_{2}^{2}+\rho g h_{2}
$$

A energia potencial do fluido em uma tubulação é o resultado do produto do peso deste pela sua altura no ponto 1 em relação à altura no ponto 2. Assumindo-se que o tubo está na horizontal, a altura do fluido nos pontos 1 e 2 é a mesma, assim, a energia potencial é a mesma. Por conseguinte, pode-se cancelar este termo. Em um tubo vertical, este termo é zerado na instalação do transmissor.

$$
\rho g h_{1}=\rho g h_{2}
$$

Se a equação de Bernoulli for resolvida para a pressão diferencial, $P 1-P 2$, pode-se verificar a relação entre a pressão diferencial e a energia cinética na Equação 3.3 . A energia cinética do fluido é o resultado da velocidade em que há o escoamento do fluido. Como o fluido acelera para passar pela restrição no ponto 2 , isso faz aumentar a energia cinética.

$$
\Delta P=P_{1}-P_{2}=\frac{1}{2} \rho v_{2}^{2}-\frac{1}{2} \rho v_{1}^{2}
$$

Em que $P_{1} \geq P_{2}$ e $v_{2} \geq v_{1}$

A energia de pressão é resultado da força que o fluido exerce sobre as paredes da tubulação. Se a energia cinética é maior no ponto 2 , e a soma das energias é a mesma nos pontos 1 e 2 , a energia de pressão deve ser menor no ponto 2. Tal queda de energia de pressão é medida para se determinar a taxa de vazão. O montante desta diminuição da energia de pressão será igual ao aumento da energia cinética.

A Equação 3.3 relaciona a pressão diferencial à velocidade no tubo, porém há duas incógnitas, 
$v_{1}$ e $v_{2}$, ambas não conhecidas.

Pode-se relacionar estas duas velocidades usando a equação da continuidade como segue.

$$
Q_{m 1}=Q_{m 2}
$$

A equação da continuidade, basicamente, afirma que a mesma quantidade de massa que flui através do ponto 1 , também passa pelo ponto 2 .

$$
\rho_{1} v_{1} A_{1}=\rho_{2} v_{2} A_{2}
$$

\section{Equação da continuidade desenvolvida}

Assumindo-se que a densidade dos líquidos é a mesma nos pontos 1 e 2 , a equação pode ser simplificada e chega-se à Equação 3.6

$$
v_{1} A_{1}=v_{2} A_{2}
$$

Isso estabelece uma relação entre cada uma das velocidades e as áreas do tubo e da restrição. Usando a fórmula para a área de um círculo, $A=\pi \frac{d^{2}}{4}$, pode-se resolver para a velocidade no ponto 1 , em termos da velocidade no ponto 2 , então chega-se a equação 3.7

$$
v_{1}=v_{2} \frac{d^{2}}{D^{2}}
$$

Nesta equação, o $d$ minúsculo é o diâmetro na restrição e o $D$ maiúsculo é o diâmetro da tubulação. Substituindo-se a Equação 3.7 na Equação 3.3 e resolvendo para $v_{2}$, temos a Equação 3.8. Esta equação descreve a velocidade no ponto $2 \mathrm{em}$ termos de diferencial de pressão, dos diâmetros do tubo e da restrição, e da densidade do fluido.

$$
v_{2}=\sqrt{\frac{2 \Delta P}{\rho\left[1-\frac{d^{4}}{D^{4}}\right]}}
$$

É importante notar que a densidade do fluido está presente nessa equação. Para calcular o fluxo, a densidade deve ser conhecida. A densidade também aparece nas equações de fluxo volumétrico na Equação 3.9 e a vazão em massa na Equação 3.10. Um medidor de vazão 
por pressão diferencial não é um medidor volumétrico ou mássico intrinsecamente. Pode ser considerado um híbrido dos dois medidores.

Normalmente é necessária uma equação para a vazão volumétrica ou mássica ao invés de velocidade. Se multiplicar ambos os lados da Equação 3.8 pela área transversal da restrição tem-se uma equação para o fluxo volumétrico mostrado na Equação 3.9 .

$$
Q_{v}=\frac{\pi}{4} d^{2} \sqrt{\frac{2 \Delta P}{\rho\left[1-\frac{d^{4}}{D^{4}}\right]}}
$$

Para obter vazão em massa, pode-se multiplicar ambos os lados da equação, pela densidade do fluido. Isso move esse termo do denominador para o numerador.

$$
Q_{m}=\frac{\pi}{4} d^{2} \sqrt{\frac{2 \Delta P \rho}{1-\frac{d^{4}}{D^{4}}}}
$$

\subsection{Correções para a equação teórica}

A Equação 3.10 é a equação teórica de vazão mássica para "DPFlow"e poderia ser utilizada diretamente se todos os pressupostos para criá-la fossem válidos. Mas eles não são. Quatro hipóteses foram feitas e não são válidas para medidores de vazão real.

1. Não há perdas por atrito através do medidor.

2. As tomadas de pressão para medir a queda de pressão são colocados em locais ideais imediatamente antes da contração do fluido começar e na restrição onde o diâmetro é conhecido exatamente.

3. O líquido não é viscoso (viscosidade $=0$ ). Isto criaria um perfil de velocidade que é perfeitamente laminar.

4. O fluido é incompressível. A densidade do fluido permanece constante à medida que flui através do medidor.

Para corrigir esses efeitos, dois fatores de correção foram desenvolvidos; o coeficiente de descarga, $C_{d}$, e o fator de expansão do gás, $Y_{1}$. O coeficiente de descarga corrige os efeitos decorrentes das três primeiras suposições. O fator de expansão do gás corrige os efeitos da quarta suposição. Como o próprio nome indica, este fator é usado somente para gases. Isso porque a 
suposição número 4 é válida para os líquidos (virtualmente incompressíveis).

\section{O Coeficiente de descarga}

O coeficiente de descarga é a relação entre o valor de vazão teórico e valor medido e é diferente para cada elemento primário. Esse coeficiente é derivado empiricamente de dados de vazão de laboratório. O exemplo a seguir ilustra como esse fator é determinado. Suponha que uma placa de orifício esteja instalada em um laboratório de vazão de modo que um fluxo contínuo de água pode ser recolhida em um tanque de pesagem. Um fluxo constante é observado por um período de tempo e é recolhido no tanque. Um cálculo de vazão com base na equação teórica mostra que 1.000 libras de água fluíram pelo orifício durante o período de teste. Durante o mesmo período, o tanque pesa apenas 607 libras de água. Isso significa que o coeficiente de descarga para o orifício foi 0,607 na taxa de fluxo contínuo que foi observada. Este coeficiente representa apenas um ponto dos dados no gráfico da Figura 3.2 .

$$
C_{d}=\frac{\text { Vazão Real }}{\text { Vazão teórica }}=\frac{607}{1000}=0,607
$$

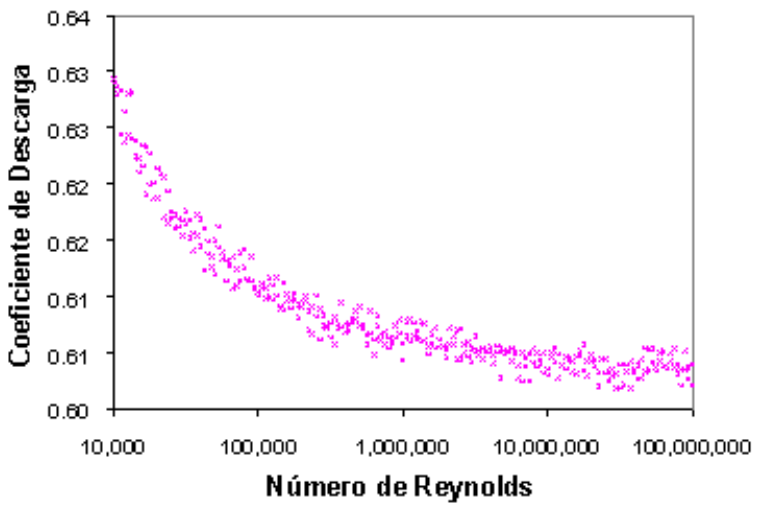

Figura 3.2: Variação do coeficiente de descarga com relação ao número de Reynolds.

Uma vez que este coeficiente de descarga para a maioria dos elementos primários varia de acordo com o número de Reynolds, este teste deve ser repetido centenas ou mesmo milhares de vezes a vários números de Reynolds e diversos valores de beta1. Este conjunto de dados caracteriza o coeficiente de descarga em uma ampla gama de condições de escoamento para os

\footnotetext{
${ }^{1}$ Valor do diâmetro do orifício dividido pelo diâmetro da tubulação.
} 
orifícios similares.

Depois que todos os dados são coletados, uma equação pode ser desenvolvida para se ajustar à curva dos dados, como representado pela linha azul na Figura 3.3 . Esta equação pode então ser usada para prever o coeficiente de descarga de qualquer elemento primário geometricamente semelhante. Desta forma, a equação serve como uma calibração constante, para que os elementos primários de construção similar não precisem ser calibrados em um laboratório.

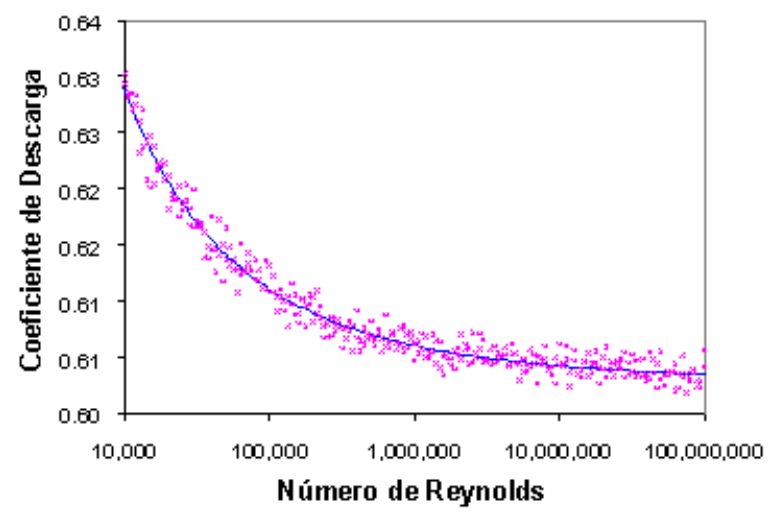

Figura 3.3: Variação empírica do coeficiente de descarga com relação ao número de Reynolds.

Geralmente há um limite de incerteza associado a essa equação, que é baseado em quanto os dados de teste desviam da equação. O coeficiente de descarga para qualquer elemento primário, construído com geometria similar, espera-se que esteja dentro desse limite de incerteza. Essa "incerteza do coeficiente de descarga" é a especificação de precisão para o elemento primário. Isso se aplica a qualquer elemento primário que esteja dentro dos limites dos dados de teste conforme ilustra a Figura 3.4 .

\section{O fator de expansão dos gases}

A suposição inválida número 4 é corrigida pelo fator de expansão dos gases. Como um gás escoa por uma restrição, a queda em pressão faz com que ele se expanda (queda na densidade). Como a densidade diminui, a velocidade no ponto 2 será ligeiramente maior do que o previsto pela suposição de que a densidade seria constante. Isso também fará com que a pressão diferencial seja ligeiramente maior. 


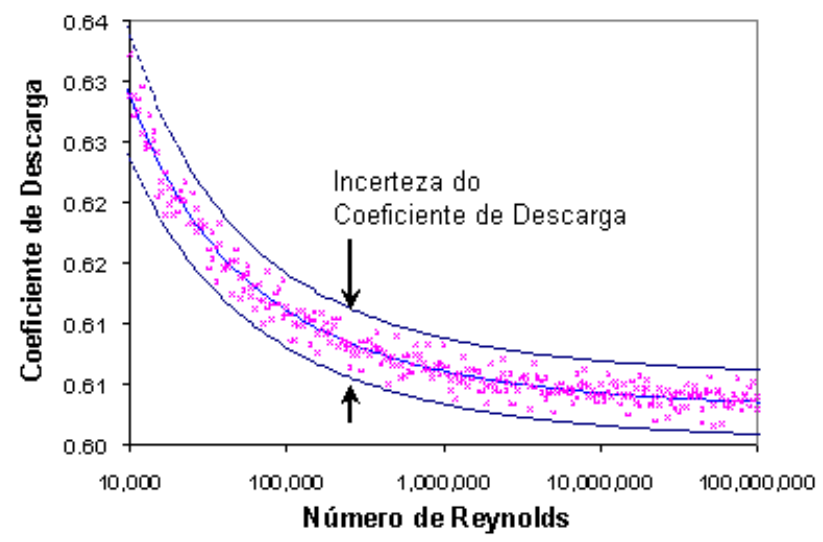

Figura 3.4: Incerteza do coeficiente de descarga com relação ao número de Reynolds.

A quantidade dessa suave queda na densidade será proporcional à mudança percentual na pressão absoluta da linha. A relação é utilizada como base para se comparar o fator de expansão dos gases desde que essa relação representa o percentual de variação na pressão da linha.

Para placas de orifício ou pitots de média (averaging pitot tubes), o fator de expansão dos gases é determinado empiricamente, de forma análoga ao que é feito para o levantamento do coeficiente de descarga. Pode-se pensar no mesmo experimento descrito com o líquido já discutido para a determinação do coeficiente de descarga.

\section{Variação empírica do coeficiente de descarga com relação ao número de Reynolds}

Reavendo os testes anteriores para a determinação do coeficiente de descarga num experimento com um elemento primário idêntico e com o mesmo número de Reynolds, mas agora com gás como fluido, se chegará ao fator de expansão dos gases. Qualquer diferença observada no valor da vazão entre o teste do experimento anterior (líquido) e o atual (gás) será devido ao fator de expansão dos gases já que o coeficiente de descarga será o mesmo. No experimento do gás, não se tem o coeficiente de descarga quando se divide a vazão real pela vazão teórica. $\mathrm{O}$ que se tem é o produto do coeficiente de descarga pelo fator de expansão dos gases. Porém, pode-se chegar ao fator de expansão dos gases dividindo-se esse produto (0.601) pelo coeficiente de descarga que fora encontrado no experimento com o líquido (0.607).

$$
Y_{1}=\frac{C_{d} Y_{1}}{C_{d}}=\frac{0,601}{0,607}=0,990
$$


Como no caso da determinação do coeficiente de descarga, esse teste encontrará o fator de expansão dos gases apenas para um ponto. Esse teste deve ser repetido numerosas vezes para caracterizar o fator de expansão do gás sobre uma ampla faixa de relações de $\frac{\Delta P}{P_{a b s}}$ e valores de beta como ilustrado na Figura 3.5 .

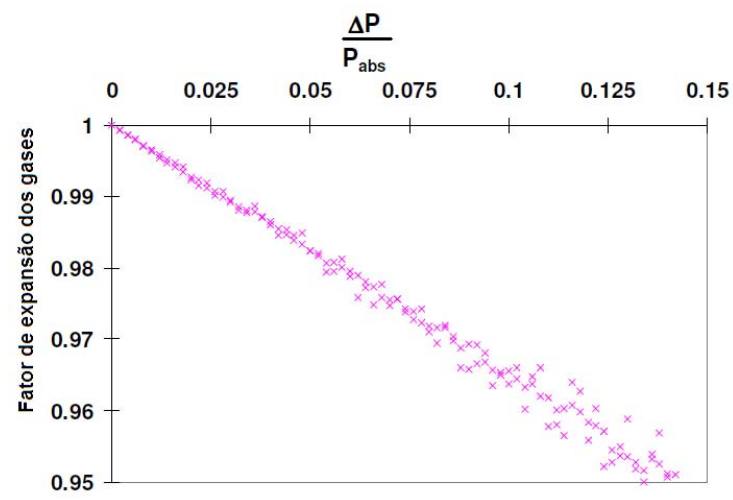

Figura 3.5: Variação empírica do fator de expansão dos gases com relação a $\frac{\Delta P}{P_{a b s}}$.

Uma vez que os dados foram coletados, pode-se desenvolver uma equação e ajustar uma reta como indicado na Figura 3.6. Tal como acontece com o coeficiente de descarga, também pode-se determinar os limites de incerteza (limite de variabilidade), os quais indicam o quão perto o fator de expansão do gás está da equação.

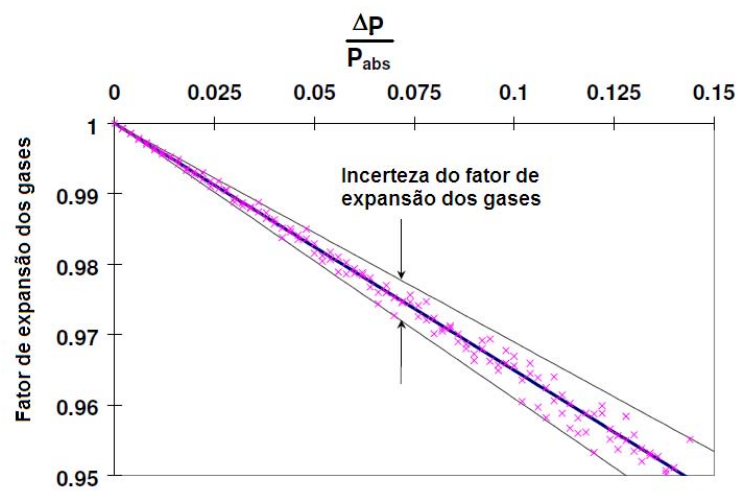

Figura 3.6: Incerteza do fator de expansão dos gases. 


\subsection{A equação completa para DPFL $O W$}

Incluindo o coeficiente de descarga e o fator de expansão do gás na Equação 3.10, tem-se a Equação 3.13 .

$$
Q_{m}=\frac{\pi}{4} C_{d} Y_{1} d^{2} \sqrt{\frac{2 \Delta P \rho}{1-\frac{d^{4}}{D^{4}}}}
$$

O fator da velocidade de aproximação, definido na Equação 3.14, é geralmente retirado da equação e indicado como " $E$ ", na equação da vazão.

$$
E=\frac{1}{\sqrt{1-\frac{d^{4}}{D^{4}}}}
$$

A fim de se harmonizar as unidades de cada lado da equação, um fator de conversão de unidades " $N$ ", está incluído. Esse fator será diferente para diferentes combinações de unidades de densidade, pressão diferencial, diâmetro, e as unidades de vazão. Como os coeficientes $\frac{\pi}{4}$ e $\sqrt{2}$ são puramente numéricos, eles são incluídos nas unidades de fator de conversão.

$$
N=\frac{\pi}{4} \sqrt{2}(x)
$$

sendo que o fator $x$ contempla os coeficientes de ajuste das unidades de pressão, temperatura, densidade e fatores de correção da vazão.

Com o fator de velocidade de aproximação e as unidades de fator de conversão incluídos, chega-se na Equação 3.16. A equação básica de vazão utilizada pela maioria dos medidores de vazão por princípio de pressão diferencial é mostrada nessa Equação 3.16. Esta é a equação utilizada no instrumento multivariável $3095 \mathrm{MV}^{T M}$ e com pequenas modificações, pode ser usada para todos os elementos primários.

$$
Q_{m}=N C_{d} E Y_{1} d^{2} \sqrt{(\Delta P \rho)}
$$

Sendo:

$Q_{m}=$ Vazão mássica (dimensão de massa por unidade de tempo)

$N=$ conversor de unidades (admensional)

$C_{d}=$ Coeficiente de Descarga (admensional)

$E=$ Fator de velocidade de aproximação (admensional) 
$Y_{1}=$ Fator de expansão dos gases (admensional)

$d=$ diâmetro do orifício (dimensão de comprimento)

$\rho=$ densidade do fluido (dimensão de massa por unidade de volume)

$\Delta P=$ pressão diferencial (dimensão de força por unidade de área - tipicamente dado em polegadas ou milímetros de água à uma temperatura específica). 


\section{Capítulo 4}

\section{Utilização de técnicas de inteligência artificial para medição de vazão em sistemas de automação}

Para o presente trabalho foram realizadas pesquisas nas bases científicas com quatro palavras chave: neural networks, fieldbus, flow measurement e soft sensors além de pesquisas em alguns livros. Este capítulo apresenta os principais trabalhos pesquisados.

A seguir estão descritos os trabalhos mais voltados à medição da vazão e condicionadores de fluxo.

O texto do trabalho Delajoud (2005) cita que a medição de vazão de gases na faixa de até $50 \mathrm{~g} / \mathrm{s}$ é importante para uma ampla gama de processos industriais. No início da faixa de vazão, medidores que lidam com escoamento laminar (baixo número de Reynolds) tem sido empregados com sucesso. Para faixas altas de vazão, os tubos toroidais Venturi para vazão crítica são utilizados. O texto cita um novo medidor tipo Venturi que cobre desde 0.02 até 50 $\mathrm{g} / \mathrm{s}$. Esse novo elemento combina o tubo Venturi com condicionamento de fluxo numa mesma montagem, o que simplifica a operação e maximiza a repetibilidade da medição de vazão.

No trabalho Zanker e Group (2005) é relatado que cotovelos, redutores, filtros, válvulas, trocadores de calor afetam sobremaneira o perfil de vazão, o que altera o desempenho dos medidores de vazão. Uma solução para isso é aumentar o trecho reto à montante do medidor. Os efeitos de fricção nas paredes da tubulação estenderão as velocidades do fluxo para o centro da tubulação gerando um perfil de velocidades totalmente desenvolvido. Na prática, tal medida, 
muitas vezes é inviável porque se necessitaria de centenas de diâmetros da tubulação. Algumas soluções são a escolha ou desenvolvimento de medidores menos sensíveis ao perfil da vazão ou o uso de condicionadores de fluxo que produzem bons perfis de velocidade em trechos extremamente mais curtos de trechos retos da tubulação. Para a medição de vazão, a componente axial é a que importa. As vazões radiais não contribuem para a saída, mas distorcem o perfil de velocidades. O texto cita duas placas condicionadoras, que são combinações da placa de orifício e condicionador de fluxo num único dispositivo. É citado ainda que a placa condicionadora da Rosemount com 4 orifícios parece ser mais prática que a da Texas ${ }^{T M}$ A \& M com 48 ranhuras.
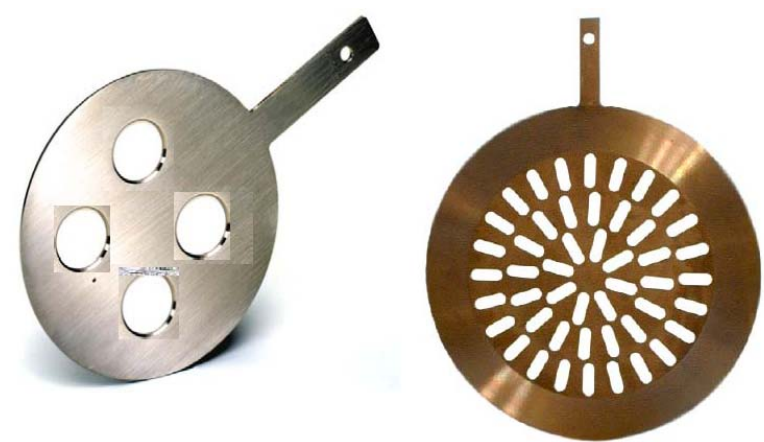

Figura 4.1: Placas condicionadoras (ZANKER e GROUP, 2005).

O trabalho Brown et al. (2009) relata que com o aumento da demanda por energia e com a queda das reservas de óleo, a produção de óleo pesado tem se tornado cada vez mais comum. A viscosidade alta dos óleos pesados trazem desafios para a maioria dos medidores. Por exemplo, limita a vazão máxima em medidores por pressão diferencial, reduz a rangeabilidade de turbinas e podem resultar em erros de medição em medidores tipo coriolis. O trabalho citado explica os desafios técnicos quando um medidor ultra-sônico para alta viscosidade / baixo número de Reynolds é utilizado. Um bom resultado foi conseguido com um ultra-sônico dotado de um bocal com $\beta$ de 0,64 usado para estabilizar o perfil de velocidades. Isso não só melhora a medição na transição do escoamento laminar para o turbulento, mas também melhora o desempenho em termos de repetibilidade.

Os próximos trabalhos estão mais voltados à aplicações de soft sensors.

Os resultados de recentes estudos em aplicações industriais e simulações de plantas destacam a crescente utilização de sistemas inteligentes como um soft sensor, ou seja, um sensor baseado preferencialmente em software, ao invés de hardware (WILLIS, 1992).

A pesquisa Petrovic et al. (2003) elucida que fatores chaves de especificação de produtos numa coluna de destilação a vácuo são principalmente a densidade, a viscosidade e a cor. Desses 
fatores, a viscosidade é geralmente a que tem maior limitação em qualidade. Embora existam medidores de viscosidade online no mercado, seus preços são muito altos e a confiabilidade pode é geralmente baixa. No trabalho supra citado, a solução apresentada foi o desenvolvimento de um soft sensor para o cálculo da viscosidade.

No trabalho Caponetto et al. (2009), um soft sensor utilizando redes neurais foi desenvolvido para lidar com um problema de pequena quantidade de dados na identificação de um modelo não linear para estimar o ponto de congelamento de querosene numa unidade de destilação atmosférica na Sicília - Itália. Um soft sensor baseado em redes neurais que estima o valor da viscosidade a partir de outras variáveis facilmente mensuráveis é proposto.

Outra aplicação de soft sensor é mostrada em Devogelaere (2002) no modelamento de processos e controle na indústria de cana-de-açúcar e etanol.

Os trabalhos a seguir tratam de assuntos mais direcionados às aplicações de redes neurais em ambientes industriais.

Ainda em Devogelaere (2002) uma rede neural foi treinada tomando como base os dados históricos para prever as variáveis de qualidade dos processos de modo que se possa substituir o processo de teste de laboratório. Um benefício imediato da construção de sensores inteligentes é que a rede neural pode prever a qualidade do produto em tempo curto o suficiente para fazer as correções necessárias no processo de fábrico. Se o produto não atende aos requisitos e, portanto, uma correção é necessária, os sensores inteligentes permitem antecipar as ações de controle, o que pode evitar a contínua fabricação de produtos de má qualidade.

Segundo o trabalho Wang (2009) a medição tradicional de vazão por ultrassom não é precisa. Sua saída varia com características do fluido, temperatura e pressão entre outros. Uma compensação efetiva da temperatura deve ser feita pra assegurar precisão e sensibilidade à medição. A rede neural é habilidosa ao tratar modelamento não linear, mapeamento complexo não linear e auto aprendizagem. Os dados comparados no referido trabalho mostram que o erro na medição é reduzido de 5,2 para $3 \%$ depois do treino com a utilização de redes neurais.

De acordo com o trabalho Fernandes (2007), em sistemas dinâmicos, falhas podem causar alterações em parâmetros críticos do sistema, ou mesmo alterações em sua dinâmica, Para se evitar prejuízos e acidentes, é vital que estados não desejáveis ou não permitidos sejam detectados. O sistema de Fernandes (2007) foi desenvolvido em duas fases. O primeiro é a identificação do sistema de níveis por redes neurais. A segunda fase é a detecção da falha e isolação. Em 
simulações reais, o sistema foi capaz de detectar e isolar falhas no sistema de medição de nível.

Segundo o trabalho Guixue et al. (2009), um soft sensor baseado em regras fuzzy para medição de vazão mássica de carvão pulverizado é estudado. Isso soluciona uma deficiência de medição do sensor eletrodinâmico. Uma rede neural RBF foi utilizada em conjunto com lógica fuzzy. Diferentes arranjos de treinamento foram feitos para os modelos neurais obtidos a partir dos dados somados à um ruído branco com uma variância fixa para aumentar a diversidade dos dados nos padrões de aprendizagem. Com isso, foi possível a programação de um FPGA (Field Programmable Gate Array) com alta precisão para a finalidade de obtenção do ponto de congelamento da querosene.

Na pesquisa Costa et al. (2005) é mencionado que durante o processo de extração de informação gerado por sensores instalados na rede de campo, a adição de ruído é muito comum. Se o ruído e a informação estiverem na mesma faixa de frequência, isso torna a utilização de filtragem seletiva mais difícil de ser efetuada. Essa situação é caracterizada como um problema de separação cega de fonte, BSS (Blind Source Separation) onde o objetivo é recuperar um conjunto original de fontes independentes da mistura de sinais obtidos dos sensores da rede. $\mathrm{O}$ termo "cego" indica que as fontes e a forma como estão combinadas são desconhecidos.

Algoritmos baseados em análises de componentes independentes (Independent Component Analysis - ICA) proveem soluções pra problemas tipo BSS, e tem sido aplicados com sucesso em diversos campos como processamento de imagem, processamento de sinal biomédico, sistemas de telecomunicações, entre outros.

De acordo com o trabalho Devogelaere (2002), as variáveis difíceis de medir no contexto de indústrias de açúcar e etanol, geralmente são as de qualidade ou as diretamente relacionadas com os interesses econômicos de produção. Estas variáveis de qualidade são frequentemente observadas a partir de amostras de produtos em laboratório. Atrasos consideráveis numa faixa de uma a dez horas podem ocorrer, e dessa forma, pode ser tarde demais para qualquer ajuste necessário na qualidade do produto.

Os próximos trabalhos indicam a utilização de redes foundation fieldbus em aplicações industriais. Ainda neste capítulo será explicado o que é o foundation fieldbus e como este foi utilizado no contexto de medição de vazão.

O trabalho Silva et al. (2005) mostra a aproximação de uma ampla gama de funções matemáticas através de redes neurais trabalhando com blocos padrão do Foundation Fieldbus. O 
treinamento das redes neurais foi desenvolvido fora do ambiente foundation fieldbus e, então, a topologia da rede neural mais os parâmetros de aprendizagem como os pesos sinápticos e limiares foram transportados para blocos funcionais em foundation fieldbus sendo que os principais blocos foram o aritmético e o caracterizador.

O principal objetivo do trabalho Machado et al. (2010) foi criar uma arquitetura multiagente que permite incorporar nas redes industriais foundation fieldbus, aplicações inteligentes baseadas nos blocos funcionais de dispositivos de campo. Essa arquitetura viabiliza a alocação de recursos (algoritmos) em sensores e atuadores que permitem realizar algumas tarefas para auxiliar os supervisores a detectar e solucionar alguns problemas na rede como filtragem de ruído, predição e calibração. Isso tudo conduz à uma melhoria no suporte a decisão em ocorrências no nível da planta e permite um funcionamento ainda mais independente de intervenção humana. Ressaltase que para a aprendizagem foram utilizadas redes neurais.

Considerando as leituras desses artigos, é possível se concluir que há uma tendência cada vez maior do uso de redes de comunicação entre os instrumentos de campo e, entre elas, uma das que mais se destaca é a foundation fieldbus.

Deve-se considerar que os cálculos de vazão para fluidos compressíveis são bastante complexos como se pode ver pela Figura 4.2. A fórmula mostra a vazão mássica, porém o texto a seguir vale também para o cálculo da vazão volumétrica, basta que se divida a equação pelo valor da densidade.

O valor do diâmetro da placa de orifício se altera de acordo com a variação da temperatura e do coeficiente de dilatação da placa que está relacionado ao material do qual a placa é feita (quase sempre se utiliza aço inox 316). Essa variação do diâmetro do orifício também ocorre com o diâmetro da tubulação e consequentemente provoca uma variação no valor do $\beta$. A variação dos valores da temperatura e pressão também resultam em variações na densidade e viscosidade do fluido, isso acarretará uma variação no número de Reynolds que irá, por sua vez, provocar mudanças no valor do coeficiente de descarga. As variações na velocidade do fluido causam variação no valor da pressão diferencial medida pelo sensor do transmissor multivariável. Os cálculos do fator de velocidade de aproximação, do fator de expansão do gás envolvem termos exponenciais e quadráticos que não podem se realizar em blocos padrões de cálculos em ambiente foundation fieldbus, porém as redes neurais se mostram uma excelente ferramenta para lidar com cálculos complexos e sistemas não lineares que é o caso do cálculo de vazão mássica. Podese considerar ainda que a utilização de redes neurais artificiais reduz o esforço computacional 
porque, basicamente, trabalha-se com multiplicação matricial em vez de equacionamentos não lineares. Também é importante notar que a utilização de redes neurais artificiais aumentam a velocidade de processamento (não de treinamento, que é feito previamente em outro ambiente computacional, nesse caso o Matlab $\left.{ }^{T M}\right)$.

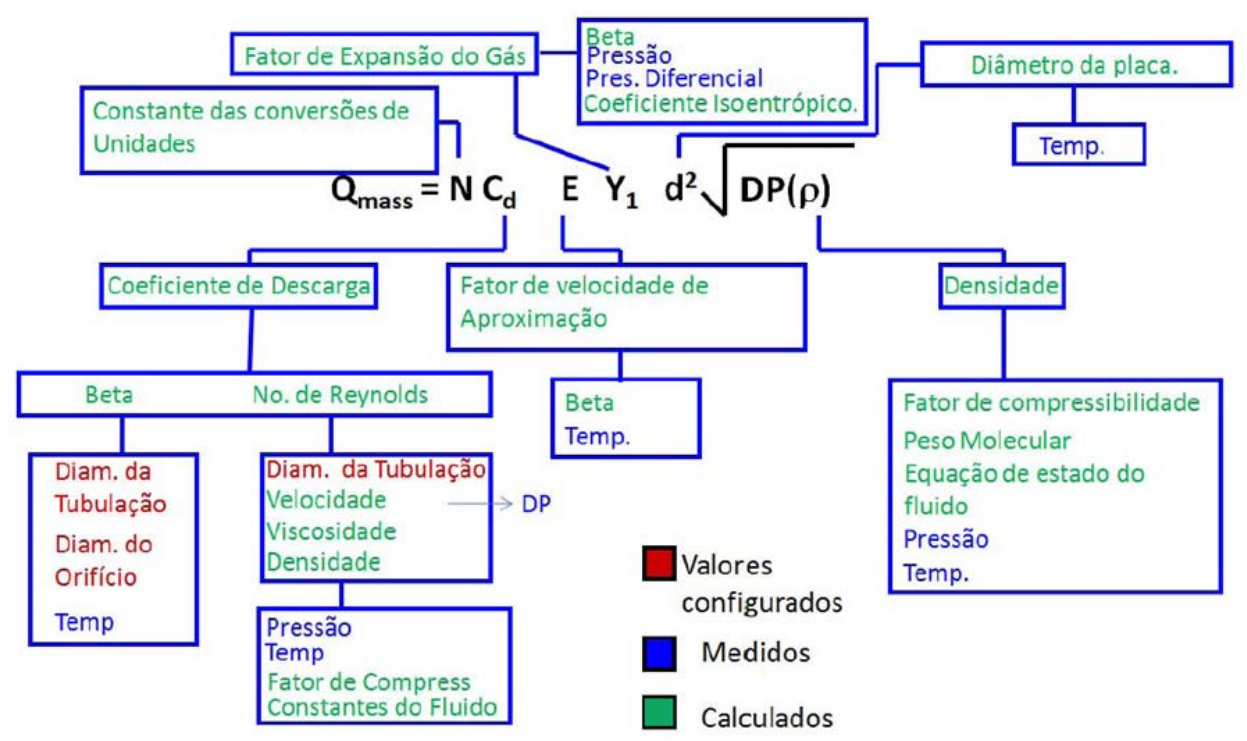

Figura 4.2: Complexidade do cálculo de vazão.

Com as justificativas do parágrafo anterior reforçadas pelos trabalhos de Costa et al. (2005) e Machado et al. (2010) que trabalharam com redes neurais num ambiente foundation fieldbus, foi possível propor a implementação de uma rede neural em ambiente foundation fieldbus utilizando blocos funcionais padrões para a computação de vazão simulando o conjunto de cálculos realizados por um instrumento multivariável com placa de orifício como elemento deprimogênio.

Uma vantagem obtida com a técnica proposta frente ao modo tradicional para a computação de vazão pelo uso de instrumentos multivariáveis é a relação de custo entre ambas soluções, que seria muito baixo considerando que o usuário muitas vezes já dispõe de um sistema em foundation fieldbus e recebe as informações das variáveis de pressão diferencial e estática, e da temperatura do seu processo por meio de instrumentos de campo.

Este trabalho visa, portanto, descrever a solução proposta para o problema mencionado, a metodologia adotada e sua validação experimental.

Estão relacionados os principais passos nos algoritmos de treinamento e operação na Figura 4.3. Na fase de treinamento, os padrões de treinamento são adquiridos e aplicados a um programa de redes neurais desenvolvido no software $\operatorname{Matlab}^{T M}$. Nesse software os dados são primeiro 
normalizados entre -1 e 1. Então várias topologias são testadas e quando um valor aceitável de erro médio é encontrado, os valores de pesos e limiares (aprendizado da rede) são armazenados. O procedimento utilizado para o cálculo do erro médio foi desenvolvido numa programação dentro do software Matlab ${ }^{T M}$. Em primeiro lugar, são calculados os erros relativos de cada uma das saídas da rede neural com relação aos padrões de testes em valores absolutos como ilustrado na Equação 4.1. Após esse cálculo individual de cada valor de erro relativo, é feita uma somatória de todos os valores de erros relativos e divide-se esse resultado pelo número total de padrões de testes.

$$
E R=\left|\frac{\text { saida_rna }- \text { padrao_teste }}{\text { padrao_teste }}\right| * 100
$$

Depois de vários testes com cada topologia, o aprendizado da melhor rede é transmitido para uma estrutura de blocos de função em ambiente foundation fieldbus, que reproduz da forma mais fiel possível os cálculos do passo forward da rede perceptron multicamadas elaborada no toolbox do Matlab ${ }^{T M}$. Para a fase de Operação, os dados são normalizados como será explicado mais adiante. Os padrões são aplicados, os cálculos são realizados e a saída (valor da vazão) é desnormalizada. 

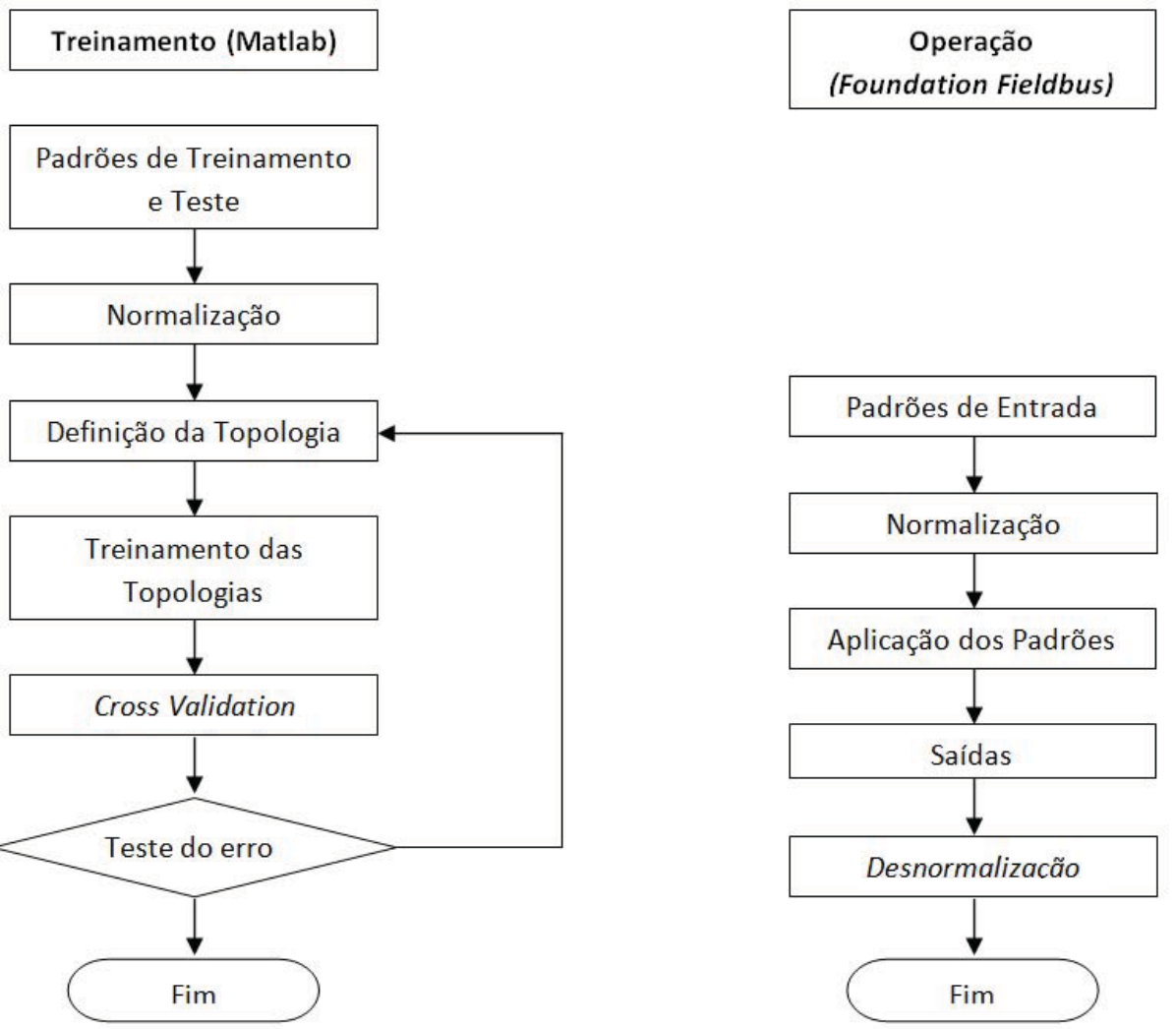

Figura 4.3: Algoritmo simplificado. 


\section{O foundation fieldbus como uma ferramenta de implementação da rede neural}

O foundation fieldbus é um sistema de comunicação totalmente digital e bidirecional que conecta equipamentos "fieldbus" tais como sensores, atuadores e controladores. O fieldbus é uma rede local (LAN) para automação e instrumentação de controle de processos, com capacidade de distribuir o controle no campo. Ao contrário dos protocolos de rede proprietários, o fieldbus não pertence à nenhuma empresa, ou é regulado por um único organismo ou nação.

A tecnologia é controlada pela Fieldbus Foundation - uma organização não lucrativa que consiste em mais de 100 dos principais fornecedores e usuários de controle e instrumentação do mundo.

O foundation fieldbus mantém muitas das características operacionais do sistema analógico 4-20 mA, tais como uma interface física padronizada da fiação, os dispositivos alimentados por um único par de fios e as opções de segurança intrínseca, mas oferece uma série de benefícios adicionais aos usuários (SMAR, 2007).

Os principais benefícios são a interoperabilidade e uma quantidade maior de informação ao usuário: Com a interoperabilidade, um dispositivo fieldbus pode ser substituído por um dispositivo similar com maior funcionalidade de um outro fornecedor na mesma rede fieldbus, mantendo as características originais. Isto permite aos usuários mesclar dispositivos de campo e sistemas de vários fornecedores. Dispositivos individuais fieldbus podem também transmitir e receber a informação de multivariáveis, comunicando-se diretamente um transmissor com o outro sobre o barramento fieldbus, permitindo que novos dispositivos sejam adicionados ao barramento sem interromper o controle.

Com o foundation fieldbus, as variáveis múltiplas de cada dispositivo podem ser trazidas ao sistema de controle da planta para a análise, arquivo, análise de tendência, estudos de otimização de processo e geração de relatórios. Este acesso aos dados mais exatos e de alta resolução, permite um ajuste fino do processo para melhor operação, reduzindo o tempo ocioso da planta. Estas características permitem um maior desempenho do sistema (SMAR, 2007).

A linguagem de programação no ambiente fieldbus é feita através de interligações de blocos funcionais. Esses blocos realizam as funções de cálculos e de controle. Pode-se citar brevemente dois deles, o bloco aritmético e o bloco caracterizador que são fundamentais na aplicação de uma rede neural. 


\section{O bloco aritmético}

O propósito do bloco aritmético é ser usado no cálculo das medições e combinações de sinais dos sensores (BERGE, 2004).

Esse bloco tem 5 entradas. As duas primeiras são dedicadas a uma função de extensão da faixa. As três entradas restantes são combinadas com a $P V$ (process variable) em uma seleção de quatro funções de termos matemáticos que são úteis para uma variedade de medições (SMAR, 2007). O aspecto de um bloco aritmético padronizado pela Fieldbus Foundation é mostrado na Figura 4.4.

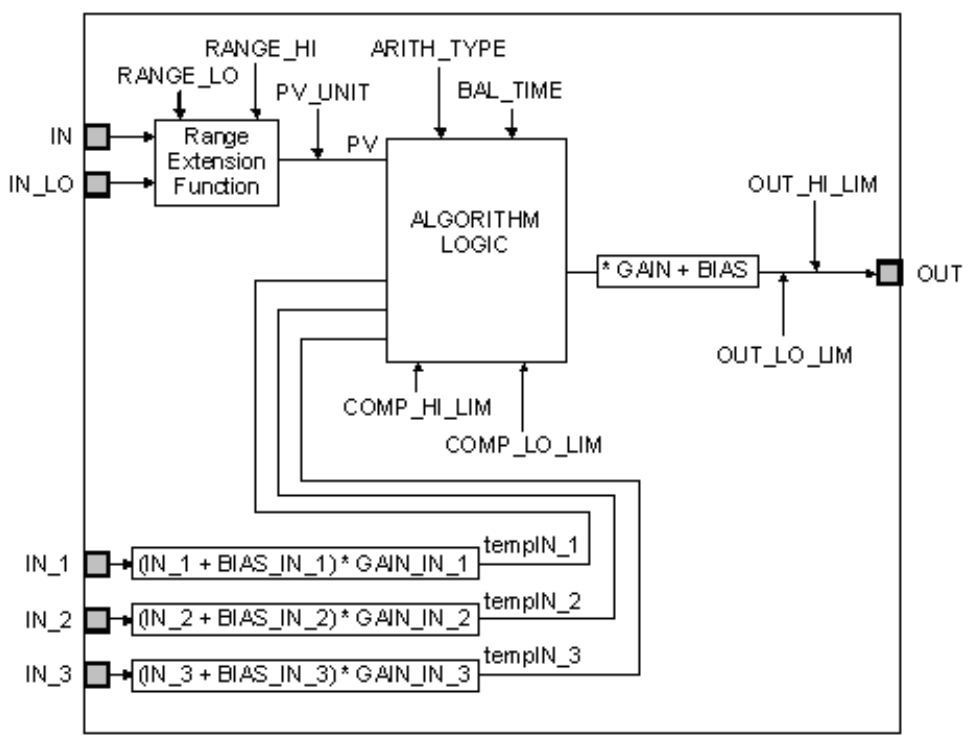

Figura 4.4: Esquema interno do bloco aritmético.

O Bloco aritmético foi usado para realizar as multiplicações das entradas pelos pesos da rede neural e também para somatórias.

\section{O bloco caracterizador}

O bloco caracterizador de sinal tem duas seções, cada uma com uma saída que é uma função não-linear da entrada respectiva.

A função é determinada por uma consulta a uma tabela única com as coordenadas $(x, y)$ de 21 pontos cada uma (SMAR, 2007). Na Figura 4.5 é mostrado o aspecto de um bloco caracterizador.

O bloco calcula $O U T_{1}$ a partir de $I N_{1}$ e $O U T_{2}$ a partir de $I N_{2}$, usando as curvas dadas pelos pontos: $[x 1 ; y 1],[x 2 ; y 2], \ldots,[x 21 ; y 21]$ onde $x$ corresponde à entrada e $y$ corresponde à saída. 


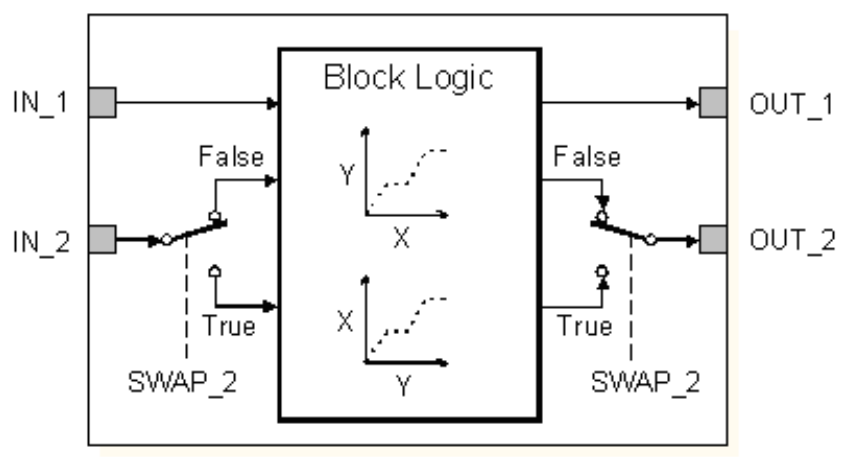

Figura 4.5: Esquema interno do bloco caracterizador.

\subsection{Redes neurais artificiais}

Embora os primeiros trabalhos em redes neurais artificiais (RNA) tenham sido publicados há mais de 50 anos, esse tema começou a ser fortemente pesquisado a partir dos anos 90. As aplicações que utilizam sistemas considerados inteligentes são as mais variadas possíveis como a avaliação de imagens captadas por satélite, classificação de padrões de escrita e de fala, reconhecimento de faces em visão computacional, controle de trens de grande velocidade, previsão de ações no mercado financeiro, identificação de anomalias em imagens médicas, identificação automática de perfis de crédito para clientes de instituições financeiras, controle de aparelhos eletrônicos e eletrodomésticos, como máquinas de lavar roupa, fornos de microondas, geladeiras, cafeteiras, fritadeiras, filmadoras, etc. (SILVA, 2010).

Está ilustrada na Figura 4.6 um neurônio (perceptron) proposto por McCulloch \& Pitts em 1943 (SILVA, 2010). Cada entrada do sistema $x 1, x 2, \ldots, x n$ são multiplicadas pelos seus respectivos pesos $w 1, w 2, \ldots, w n$. Esses pesos quantificam a importância de cada entrada relativamente às outras entradas. É realizada uma somatória dos produtos de cada produto da entrada pelo seu peso sináptico juntamente com o limiar de ativação do neurônio. O resultado dessa somatória é passado como argumento para a função de ativação que produzirá a saída y do neurônio.

Para a rede multiperceptron utilizada nessa dissertação, a função de ativação escolhida foi a tangente hiperbólica.

Conforme ainda mencionado na literatura, os textos de Willis (1992), Caponetto et al. (2009), Devogelaere (2002), Machado et al. (2010), Haykin (2008), Wang (2009), Fernandes (2007), Petrovic et al. (2003) e Goedtel et al. (2009), as redes neurais demonstram ser uma excelente 


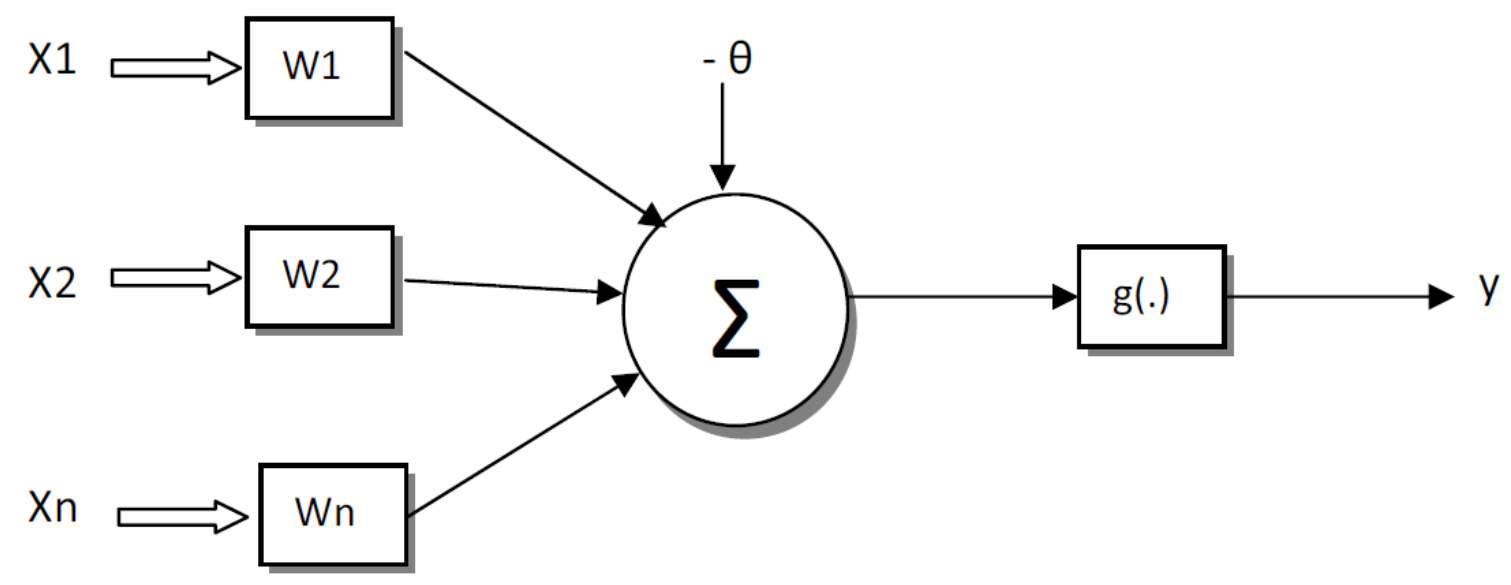

Figura 4.6: Esquema de um neurônio tipo perceptron.

ferramenta para lidar com cálculos complexos e não lineares, sendo uma tendência cada vez maior em aplicações de redes de comunicação entre instrumentos de campo, entre elas, foundation fieldbus.

O cálculo do valor da vazão por métodos convencionais são não lineares e se utilizam de inúmeras funções exponenciais, tornando impraticável a implementação por meio de blocos funcionais padrão foundation fieldbus. Em contrapartida, as RNA's apresentam um baixo custo computacional e simplicidade de implementação.

A computação envolvida em uma RNA do tipo perceptron multicamadas se reduz a simples multiplicações de matrizes e indexação de tabela (look-up table), desde que o processo de treinamento offline já esteja realizado (GOEDTEL et al., 2009) e (HAYKIN, 2008).

No próximo capítulo que descreve a etapa experimental deste projeto, é explicado como foram adquiridos os valores de entrada (Pressão estática, Pressão diferencial e Temperatura).

Esses pontos foram adquiridos e salvos numa planilha eletrônica. Esse arquivo foi lido pelo programa elaborado no Matlab ${ }^{T M}$. Foram realizados dois cenários explicados no próximo capítulo. Para o primeiro cenário os padrões foram separados em dois grupos:

O grupo de treinamento da rede, que contou com 523 padrões, e o grupo de treinamento com 93 pontos. Os valores de temperatura variam de 20 a $40{ }^{\circ} \mathrm{C}$, Pressão de 1 a 5 Bar abs e Pressão diferencial de 0 a $1000 \mathrm{mmH}_{2} 0$ a $68{ }^{\circ} \mathrm{F}$.

Para o segundo cenário, a pressão diferencial variou de 10 a $1840 \mathrm{mmH}_{2} 0$ a $68{ }^{\circ} \mathrm{F}$, a temperatura de 60 a $120{ }^{\circ} \mathrm{C}$ e a pressão de -5 a 60 Bar abs. Para a faixa de pressão diferencial foram tomados valores de $10 \mathrm{em} 10 \mathrm{mmH}_{2} 0$ a $68^{\circ} \mathrm{F}$, para temperatura e pressão estática foram 
tomados intervalos de 5 em $5\left({ }^{\circ} \mathrm{C}\right.$ e Bar abs) resultando em 33487 padrões de entrada. Durante a fase de treinamento foram utilizados 28703 desses padrões e 4784 foram utilizados para os testes.

Esses valores foram normalizados entre -1 e 1 para todas as entradas e a saída foi normalizada entre os valores de -100 e 100 .

A rede neural foi treinada e simulada com diferentes valores de neurônios. Pode se concluir que com 8 neurônios a rede teve um desempenho satisfatório apresentando um baixo erro relativo médio.

A função de ativação utilizada foi a tangente hiperbólica para os neurônios da camada escondida e para a camada de saída, composta por apenas um neurônio, foi utilizada a função identidade.

A partir do treinamento da rede foi possível utilizar os valores dos pesos e limiares para configurar os blocos funcionais conforme explicado no próximo capítulo. 


\section{Capítulo 5}

\section{Experimentos, desafios e resultados}

Este capítulo visa explicar como foi realizada a aquisição de dados, como foram trabalhados os dados adquiridos e ilustrar os resultados obtidos.

Num primeiro momento foi criado um cenário com determinado elemento primário e fluido de processo que tinha por objetivo a avaliação da possibilidade de se reproduzir da maneira mais fiel possível o desenvolvimento da rede neural desenvolvida no Matlab ${ }^{T M}$. Ainda para esse primeiro cenário também foi importante a análise do erro. Se este fosse muito elevado, por exemplo, da ordem de $20 \%$ ou maior referente ao valor da vazão, embora houvesse a demonstração de que era possível se fazer essa migração dos cálculos da rede para o ambiente foundation fieldbus, essa metodologia não seria viável devido ao alto erro para aplicações práticas. Como o resultado para esse primeiro cenário foi positivo, ou seja, foi demonstrado que é possível elaborar uma estratégia de blocos padrões foundation fieldbus e que os valores resultantes apresentados refletiram um erro relativo médio de $1,43 \%$ do valor da vazão comparado aos resultados calculados pelo instrumento multivariável, foi possível elaborar um segundo cenário com uma quantidade sensivelmente maior de padrões com outras características de elemento primário e de fluido do processo, que visava aperfeiçoar o método anterior de forma a obter um cálculo mais preciso, e que apresentasse um erro relativo médio menor que o obtido no primeiro experimento. Esse intuito foi alcançado com algumas alterações na forma de se calcular a tangente hiperbólica e com algumas alterações na topologia da rede neural.

A montagem experimental consiste, como ilustrado na Figura 5.1, de uma fonte de alimentação de 24 Vcc em série com um resistor de 250 ohms que alimenta o transmissor multivariável $3095 \mathrm{MV}^{T M}$, um hart modem conectado aos terminais do transmissor em paralelo com a alimen- 
tação, e em sua outra extremidade conectado à porta USB do microcomputador que contém o software Engineering Assistant ${ }^{T M}$ do fabricante Rosemount, utilizado para a configuração do transmissor multivariável.

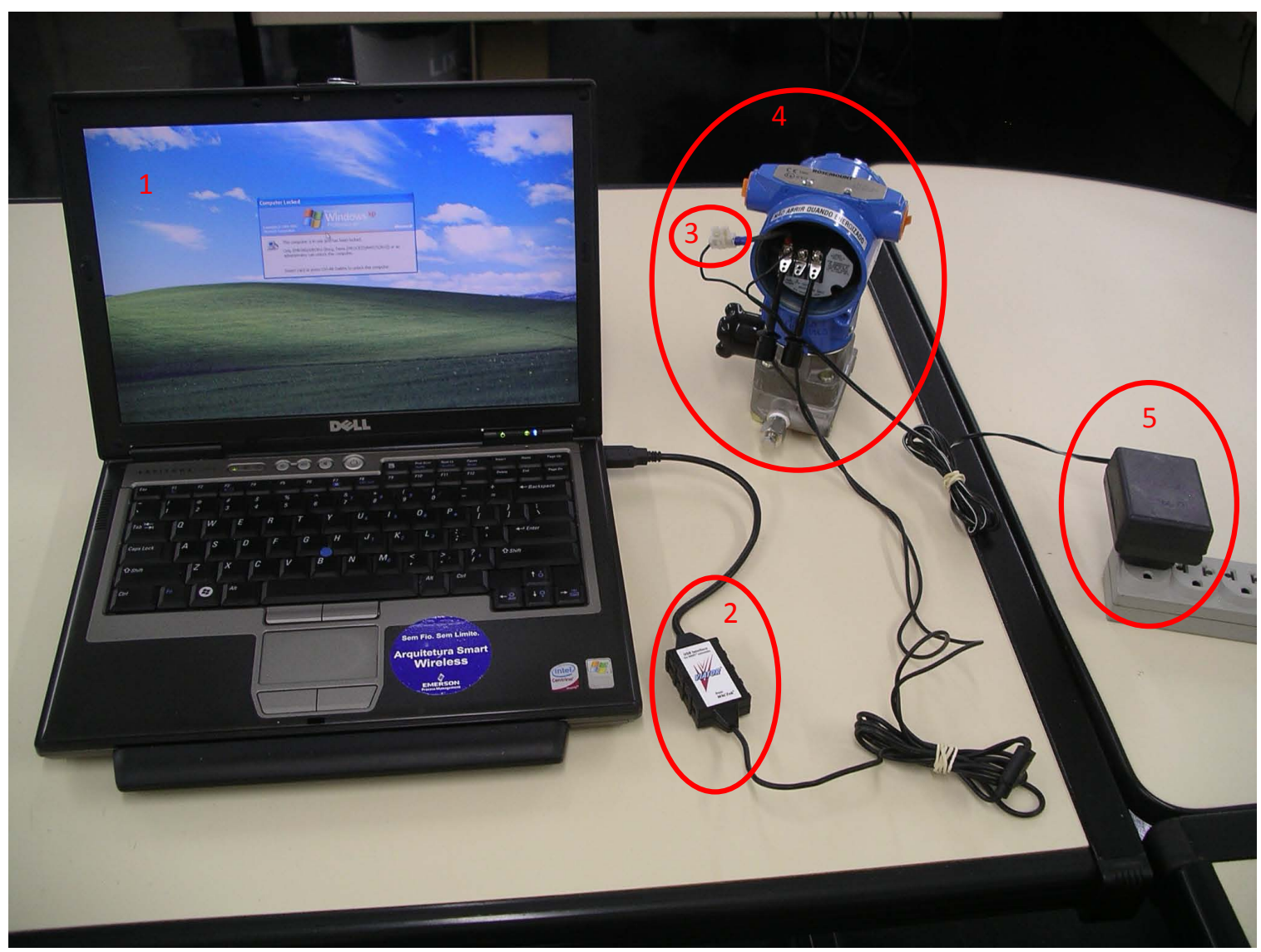

Figura 5.1: Bancada com os elementos para a aquisição dos dados.

Ítens constituintes da bancada de aquisição dos dados:

1. Microcomputador com o software Engineering Assistant ${ }^{T M}$;

2. Hart modem: O hart modem conecta o laptop ao transmissor multivariável e torna possível a comunicação bidirecional entre esses dispositivos. O hart modem é conectado à porta serial do laptop ou à porta USB nos modelos mais atuais e tem um cabo com terminais tipo garra pra facilitar a conexão ao transmissor multivariável;

3. Resistor de $250 \Omega$ para permitir a comunicação HART entre o hart modem e o transmissor multivariável;

4. Transmissor multivariável modelo $3095 \mathrm{MV}^{T M}$ fabricado pela Rosemount;

5. Fonte de alimentação $24 \mathrm{Vcc} 1 \mathrm{~A}$; 


\subsection{O primeiro cenário}

A partir da montagem da bancada de testes descrita anteriormente, o instrumento multivariável foi alimentado com uma fonte de $24 \mathrm{Vcc}$ em série com um resistor de $250 \Omega$. Um microcomputador com o software EA (Engineering Assistant) ${ }^{T M}$ da Rosemount instalado foi utilizado para a comunicação com um $3095 \mathrm{MV}^{T M}$ através de um hart modem do fabricante MACTek. A comunicação HART foi iniciada entre o 3095MV ${ }^{T M}$ e o microcomputador.

É importante salientar que foi utilizado um transmissor HART e não um foundation fieldbus apenas para o levantamento dos padrões que serviram de treinamento para a rede neural. Isso foi feito porque, como será visto mais adiante, existe uma ferramenta de software integrada ao EA chamada test calculation, que permite a simulação de valores de vazão digitando-se as variáveis de entrada. Essa ferramenta está disponível apenas para a versão HART por enquanto, por isso não foi utilizado o 3095MV em foundation fieldbus. Mas os algoritmos internos de cálculos de vazão do multivariável são exatamente os mesmos para HART e foundation fieldbus.

As próximas seis telas a seguir foram capturadas do software EA e ilustram as configurações que servem de base para o algoritmo embarcado no transmissor multivariável calcular a vazão. As telas mostradas a seguir retratam as configurações para o segundo cenário abordado mais adiante. Como as telas são idênticas, com exceção da tela dos dados de cromatografia, pode-se evitar o repetimento das mesmas para o primeiro e segundo cenários e o motivo de se mostrar as telas do segundo cenário é devido ao fato destas trazerem mais informações que as do primeiro cenário. Como exemplo pode se citar a tela da Figura 5.4 de composição do fluido do processo, que não é necessária (inexistente) quando é feita a configuração para o primeiro cenário. Para fluidos puros como ar (fluido utilizado no primeiro cenário), nitrogênio e hidrogênio, essa tela não é necessária. Para fluidos com composições variadas como gás natural (fluido utilizado no segundo cenário) ou mistura de gases, essa tela é automaticamente solicitada durante o processo de configuração. Essas diferenças são evidenciadas pelas informações contidas nas próximas figuras.

A seguir é ilustrada a sequência dos dados solicitados para a configuração do transmissor multivariável.

A Figura 5.2 mostra as telas principais do software EA necessárias para a configuração do transmissor multivariável. Os pontos mais importantes serão descritos com algum detalhe a seguir. 


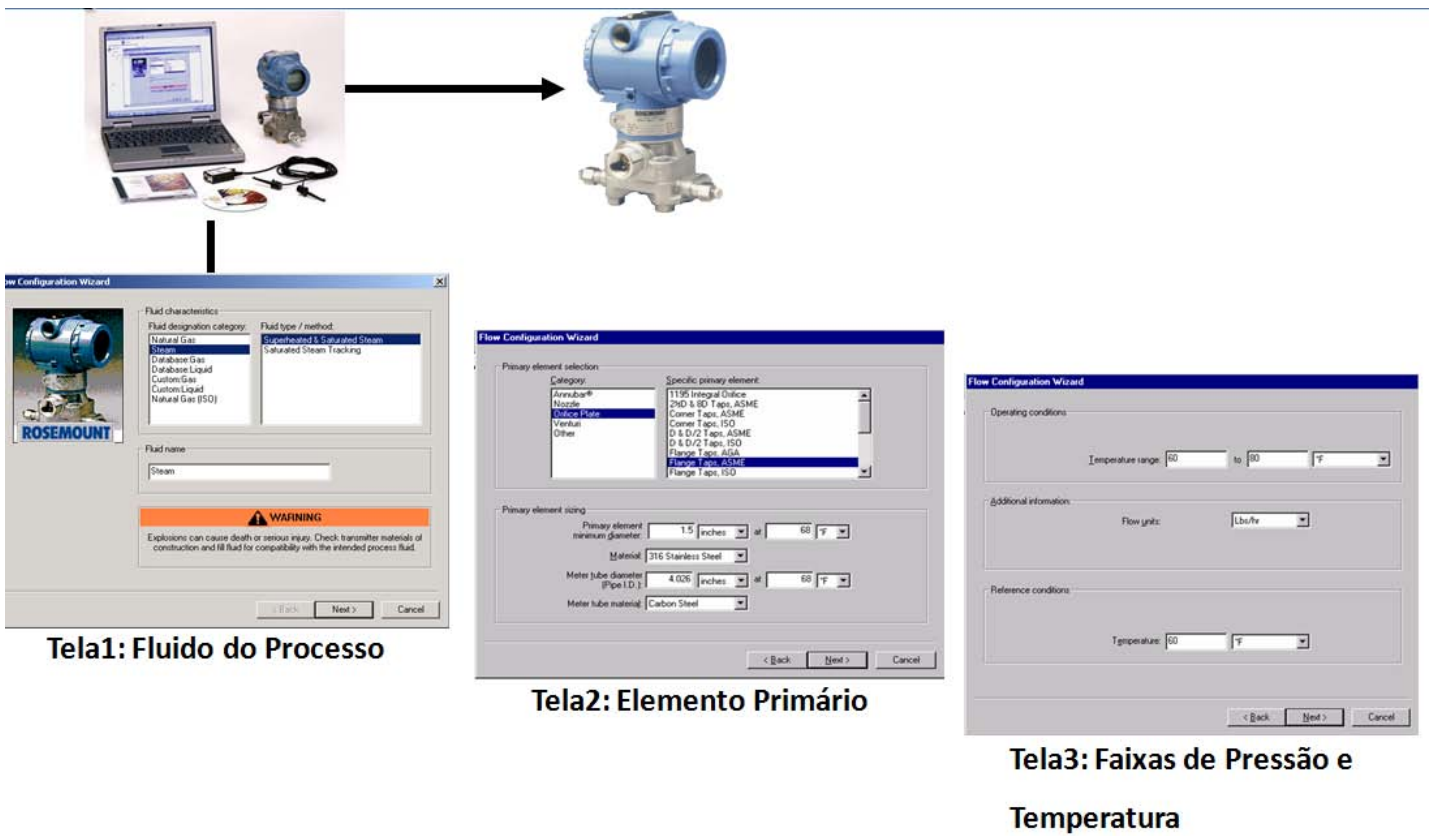

Figura 5.2: Sequência de telas principais na configuração do transmissor multivariável.

A primeira tela do software EA, é utilizada para a escolha do fluido do processo, que para a Figura citada (cenário 2), é gás natural. Para o primeiro cenário foi escolhido "ar" como fluido do processo.

$\mathrm{Na}$ ilustração 5.4 pode ser verificada a tela de composição do gás natural. Essa tela é inexistente para outros tipos de fluido como ar ou vapor de água. Ela é necessária para o gás natural devido às grandes alterações de composição que esse tipo de fluido apresenta. Esses dados de composição são retirados de relatórios de cromatografia do gás natural seja em laboratório, seja em cromatógrafo online instalado.

A tela da Figura 5.5 é utilizada para a configuração do elemento primário de vazão. Nesse caso é utilizada uma placa de orifício comum flange taps, ou seja, as tomadas de pressão estão localizadas nos flanges como mostrado na Figura 2.18 do capítulo 2, com beta 0,5. Os materiais da tubulação e da placa de orifício, bem como a informação da temperatura na qual as dimensões do elemento primário foram medidas também são importantes. O algoritmo embarcado no multivariável tem informação dos coeficientes de dilatação desses materiais, possibilitando recalcular as dimensões destes elementos que são atualizadas para os cálculos da vazão, ao se medir a temperatura do fluido do processo.

Na tela ilustrada na Figura 5.6, os valores mínimos e máximos das faixas de pressão e temperatura são informados. Outra informação importante nessa tela é a unidade da vazão. Neste 


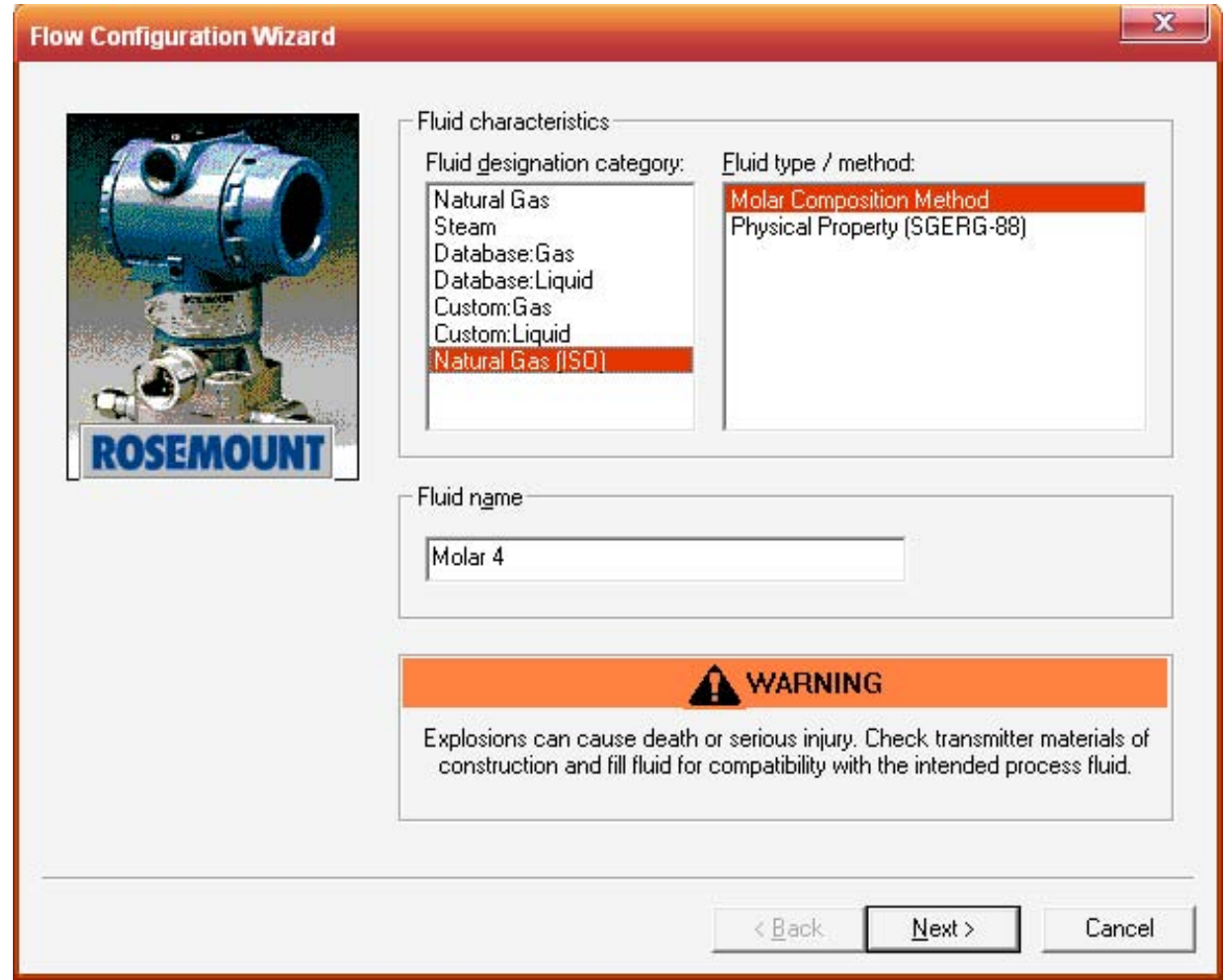

Figura 5.3: Tela de escolha do fluido do processo.

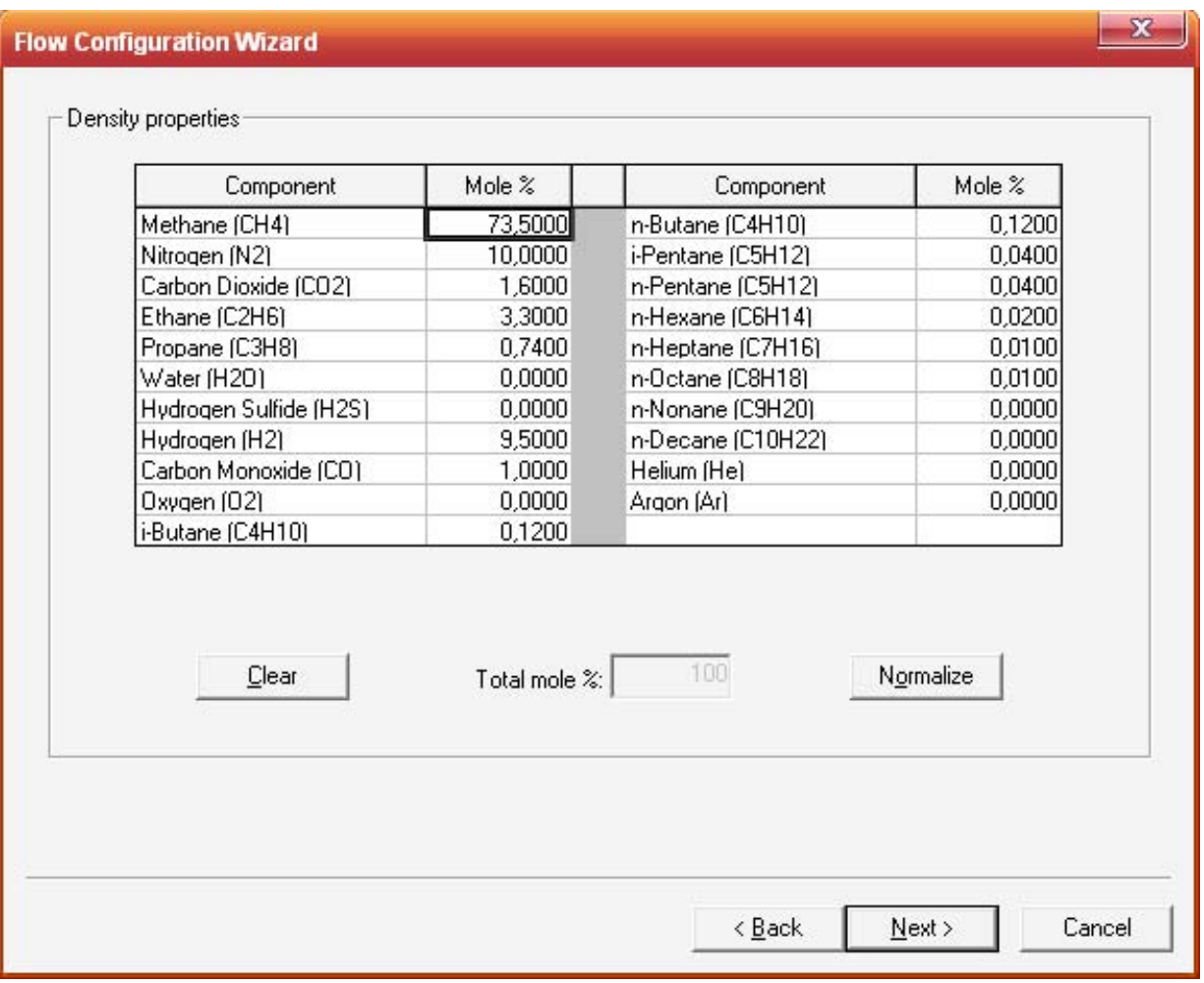

Figura 5.4: Tela de entrada da composição do gás natural. 


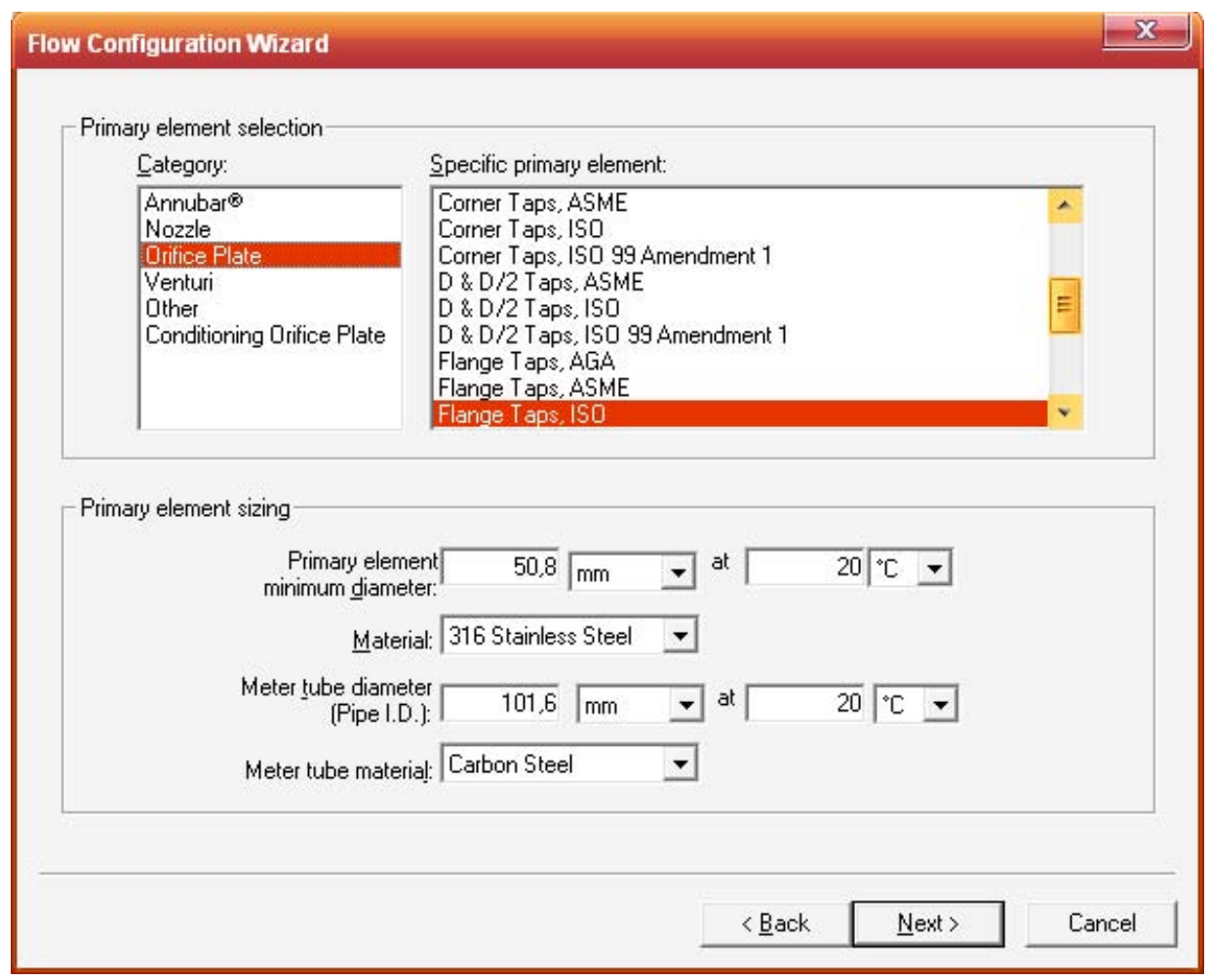

Figura 5.5: Tela de escolha do elemento deprimogênio e sua configuração.

exemplo está em $\mathrm{Kg} / \mathrm{h}$. As demais informações dessa tela não influenciarão nos resultados dado que o valor mostrado no campo atmospheric pressure é utilizado apenas quando o transmissor tem um sensor de pressão manométrica. Se fosse esse o caso, o software adicionaria o valor digitado no campo citado (atmospheric pressure) ao valor medido de pressão para que a soma (pressão absoluta) fosse utilizada na fórmula de cálculo da vazão. O transmissor multivariável utilizado tem um sensor absoluto e o software despreza o valor digitado no campo atmospheric pressure. As informações das condições de referência também não são utilizadas quando o valor da vazão é expresso em unidades de massa $(\mathrm{Kg} / \mathrm{h})$.

Na tela da Figura 5.7, são mostrados alguns valores tabelados que o software utiliza internamente para o cálculo da vazão. Esses valores são calculados de acordo com as equações de estado internas ao multivariável. Esses valores dependem da cromatografia do fluido de processo e das faixas de pressão e de temperatura. Todas essas informações já foram alimentadas no software nas telas imediatamente anteriores e enviadas via um processo chamado de download para a eletrônica do multivariável.

Na Figura 5.8 , é mostrado a tela test calculation que é utilizada para a simulação do valor 


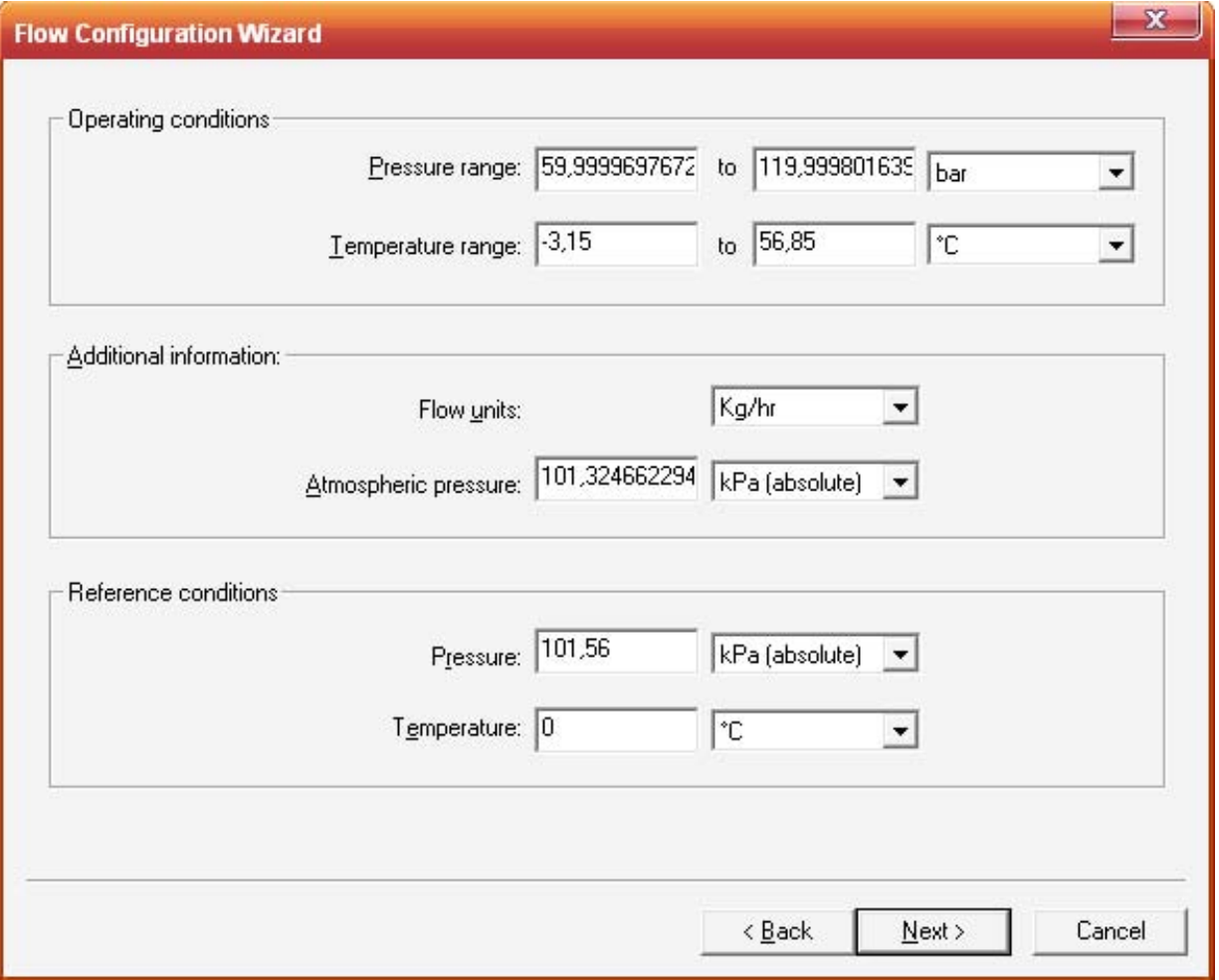

Figura 5.6: Tela de limites de pressão, temperatura e unidades de medidas.

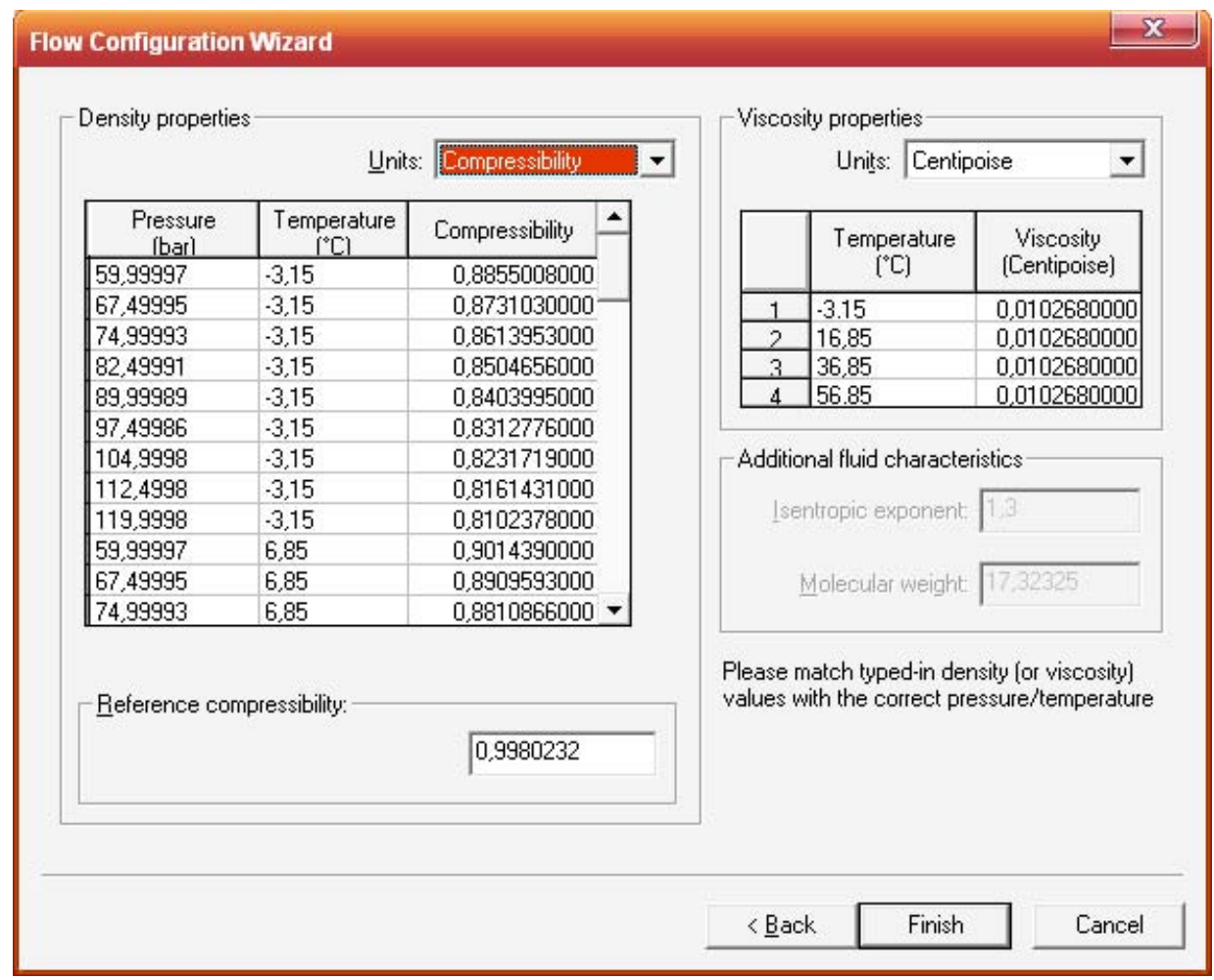

Figura 5.7: Tela dos valores calculados de densidade e viscosidade do fluido. 
de vazão a partir dos dados configurados do fluido, do elemento primário e dos valores digitados de pressão diferencial, pressão estática e temperatura. Os valores digitados são enviados via comunicação HART para a eletrônica do 3095 que processa os dados e depois de alguns segundos, o resultado do cálculo da vazão retorna da eletrônica do multivariável também via comunicação HART e é mostrado na mesma tela. O resultado do cálculo da vazão depende das entradas e da configuração residente na memória do transmissor multivariável. Para cenários diferentes de fluido de processo ou de elemento primário de vazão ou ainda de limites diferentes de faixas de pressão e temperatura, uma nova configuração do software EA é necessária.

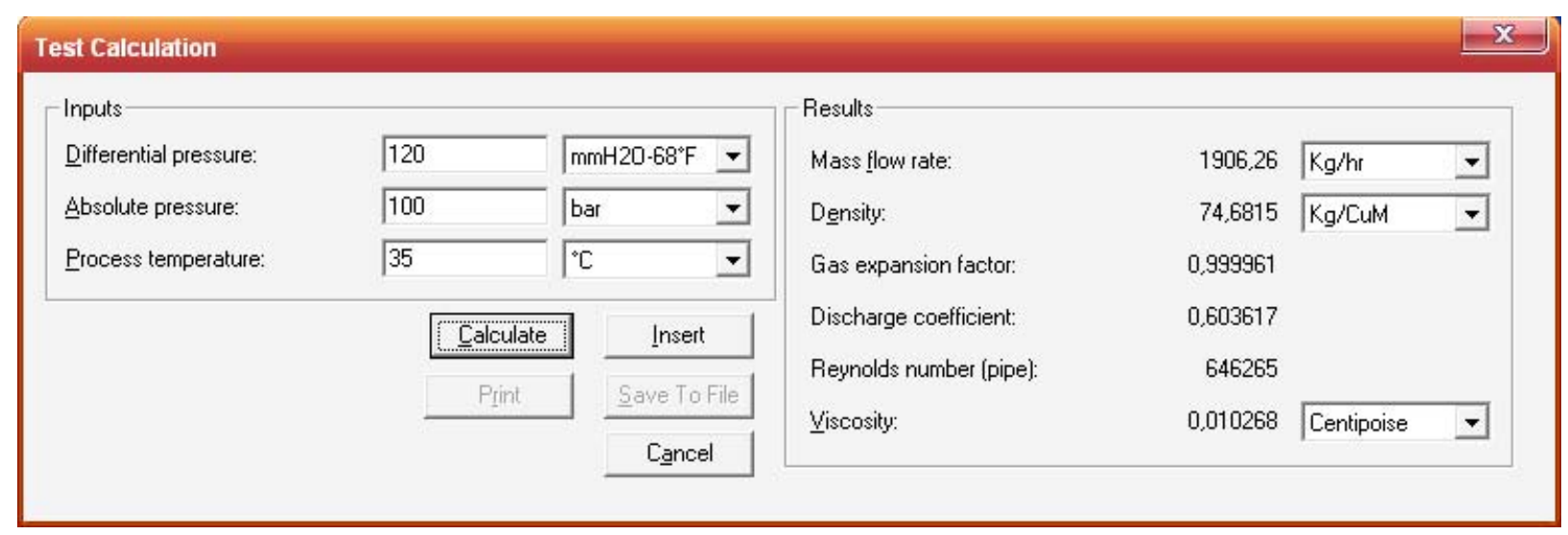

Figura 5.8: Tela de simulação: Test calculation.

No primeiro cenário, após a configuração ter sido elaborada e enviada à eletrônica do multivariável, os padrões de entrada foram digitados um a um na tela do test calculation. O botão calculate foi pressionado e após aproximadamente 8 segundos, o valor da vazão aparecia na mesma tela. Dessa forma os valores de entrada (pressão diferencial, pressão estática e temperatura) foram anotados seguidos do valor de vazão. Foram mantidos fixos os valores de duas das três entradas e incrementou-se o valor da terceira dentro de uma determinada faixa de valores. Para esse primeiro cenário, os valores de temperatura variam de 20 a 40 Celsius, os de pressão de 1 a 5 Bar abs e os de pressão diferencial de 0 a $1000 \mathrm{mmH}_{2} 0$ a $68^{\circ} \mathrm{F}$. Uma vez planilhados os dados de entrada, esses foram separados em dois grupos. O grupo de treinamento da rede, que contou com 523 padrões, e o grupo de testes com 93 padrões, totalizando 616 padrões.

Os dados utilizados para o treinamento das redes neurais e validação da mesma para o primeiro cenário podem ser visualizados na tabela A.1 no Apêndice.

A Figura 5.9 resume os procedimentos realizados para a aquisição de dados. Os valores informados nessa figura retratam os ensaios para o primeiro cenário. 


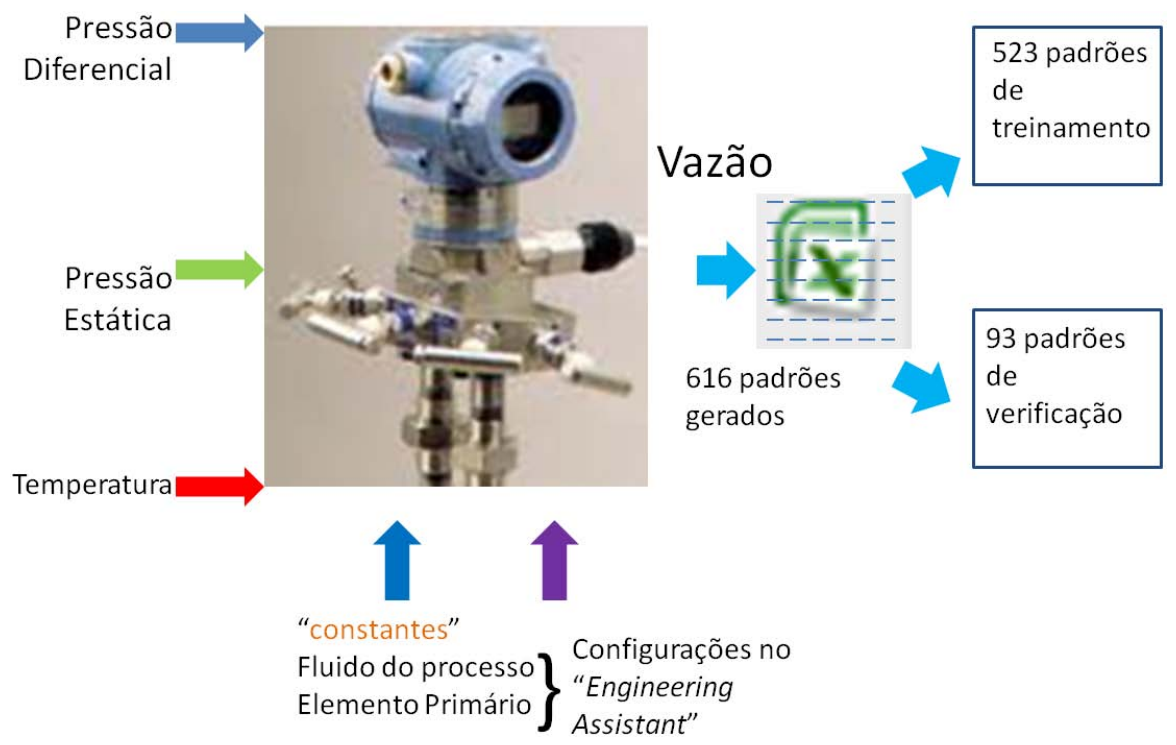

Figura 5.9: Aquisição de dados.

\subsection{Utilizando os dados adquiridos para o treinamento da rede neural}

Após a separação dos dados em grupos de treinamento e de testes, uma programação foi realizada utilizando-se para tanto o software Matlab ${ }^{T M}$ para o treinamento, validação da rede e verificação do desempenho da mesma.

Utilizando o Matlab ${ }^{T M}$ foram montadas redes neurais com 5, 8, 10, 20, 30, 50 e 100 neurônios. Através da análise dos resultados, a rede de 8 neurônios foi escolhida. O critério utilizado foi a procura de uma topologia de rede que permitisse um erro relativo médio menor que $2 \%$ e que tivesse o menor número de neurônios possível para simplificar a implementação da rede no ambiente foundation fieldbus. A incerteza de medição de vazão do transmissor multivariável é da ordem de $1 \%$. Uma incerteza da ordem de $2 \%$ pode se aplicar à uma ampla gama de aplicações de medição de vazão como medições de vazão de ar e gases combustíveis para controle de processo de fornos e caldeiras.

No capítulo 4 foi mostrado o algoritmo utilizado para o desenvolvimento do programa em Matlab $^{T M}$ para se realizar o treinamento das redes.

A Figura 5.10 ilustra o aspecto do estimador neural de vazão.

Mediante as simulações descritas na seção anterior, adquiriram-se os valores de entrada, ou seja, pressão estática, pressão diferencial e temperatura; e seus respectivos valores de vazão, os 


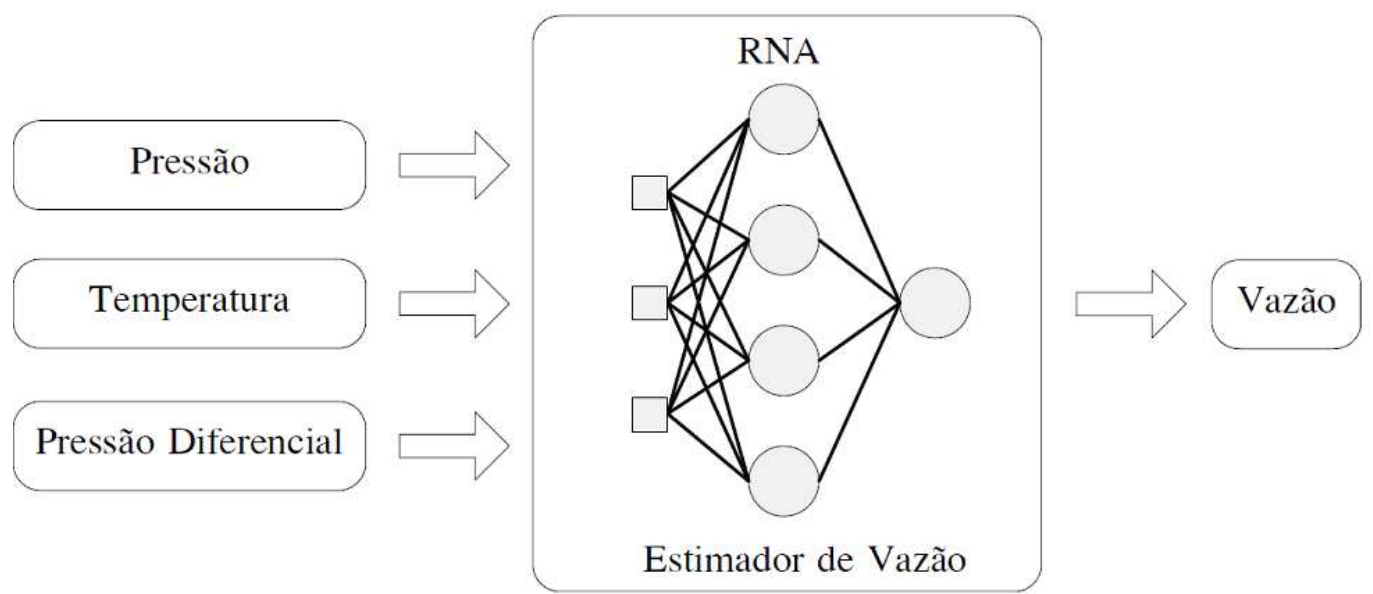

Figura 5.10: Estrutura do estimador neural de vazão.

quais foram empregados como base de dados de treinamento da rede neural.

A partir desses valores foi desenvolvida uma programação no software Matlab ${ }^{T M}$ para treinamento de uma rede neural que simulasse os valores de saída a partir dos valores de entrada utilizados com o multivariável. Em outras palavras, para as mesmas condições de elemento primário e fluido do processo, a intenção é que a rede neural possa trabalhar como se fosse um instrumento multivariável virtual.

A topologia de rede neural empregada para estimar a vazão é do tipo Perceptron multicamadas com algoritmo de treinamento backpropagation de Levenberg-Marquardt. A arquitetura da rede neural foi determinada por métodos empíricos variando-se o número de neurônios e de camadas neurais. A função de ativação dos neurônios da camada oculta foi a tangente sigmóide para mapear o comportamento não linear, enquanto que a função linear foi escolhida para o neurônio de saída em virtude do seu baixo custo computacional.

A metodologia proposta exige que o treinamento da rede neural, etapa em que se exige um esforço computacional relativamente elevado, seja realizado de forma offline. Após o treinamento, utiliza-se o conjunto de dados de testes para avaliar a capacidade de generalização da rede neural para dados que não participaram do treinamento.

Uma vez que arquitetura da rede neural estava avaliada e definida, extraiu-se a matriz de pesos e limiares para serem inseridos no software compatível com a rede foundation fieldbus. Foi utilizado o ambiente do software Delta $\mathrm{V}^{T M}$ do fabricante Emerson. Neste contexto, a rede neural implementada com os blocos funcionais realizará apenas o passo forward da rede perceptron multicamadas. 


\subsection{Os pesos sinápticos}

A estrutura da rede neural com os valores dos pesos sinápticos e limiares foram utilizados para a montagem da rede foundation fieldbus. Na Figura 5.11 são mostrados um bloco aritmético e parte de sua configuração, no caso, os pesos sinápticos.

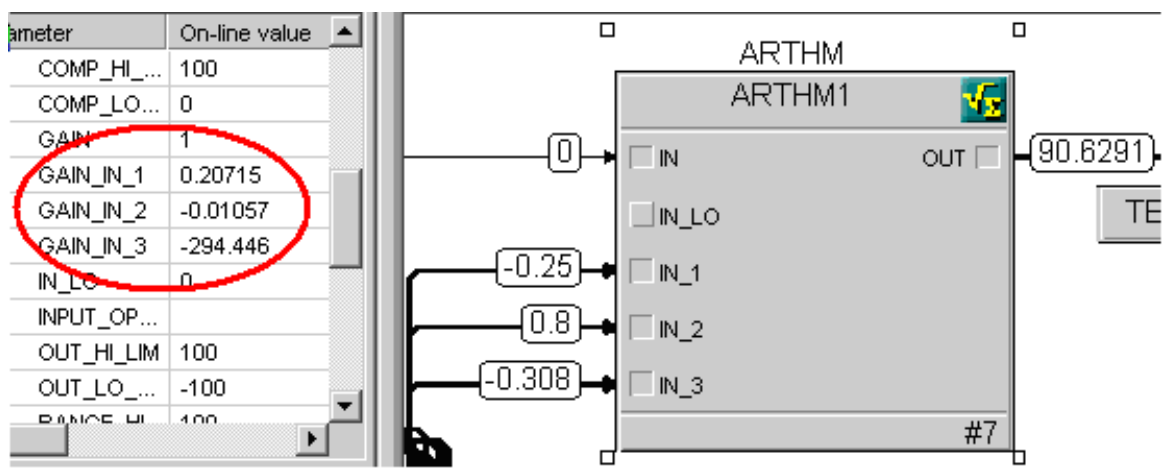

Figura 5.11: Tela com valores dos pesos configurados no bloco aritmético.

Foram utilizados blocos aritméticos para os cálculos dos pesos e limiares e blocos caracterizadores para se encontrar o valor da tangente hiperbólica. Na Figura 5.12 é possível visualizar parte dos parâmetros configurados para a função da tangente hiperbólica.

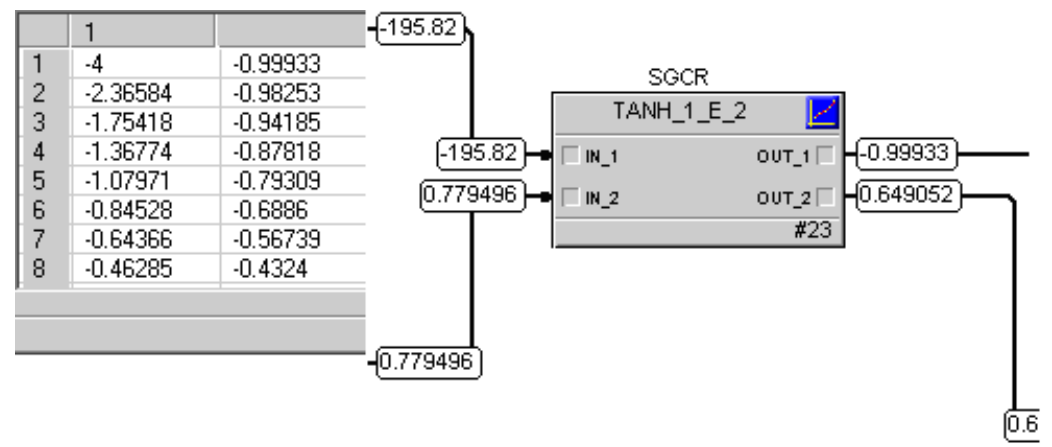

Figura 5.12: Tangente hiperbólica configurada via tabela de 21 pontos no bloco caracterizador.

Para a construção das curvas de tangente hiperbólica, foi utilizado o bloco caracterizador que permite a montagem de 21 pontos no formato de tabela (x,y) e dessa forma, pontos intermediários são obtidos por interpolação dos segmentos de reta entre os pontos configurados.

\subsection{Tangente hiperbólica}

Mapeamento dos pontos dentro do bloco caracterizador 
A precisão da tangente hiperbólica é um elo importante dentro dos cálculos da vazão. Como há uma limitação de número de pontos por bloco caracterizador, há a necessidade de se mapear os pares de pontos $(\mathrm{x}, \mathrm{y})$ dentro do bloco caracterizador de forma a se ter a melhor precisão possível.

O trabalho Silva et al. (2005) utilizou algoritmos genéticos para o mapeamento dos pontos da tangente.

Foi desenvolvido uma programação dentro do Matlab ${ }^{T M}$ com a finalidade de se fazer uma varredura dentro dos valores de -4 até +4 (eixo x) gerados com 10.000 intervalos e esse método exaustivo procura sequencialmente qual seria o próximo ponto em que a diferença seja maior ou igual ao erro digitado. Quando o programa encontra esse ponto, é escolhido o ponto imediatamente anterior para se garantir que o erro será menor que o limite configurado. Então a varredura continua até que se encontre o próximo ponto para essa condição de erro e assim sucessivamente até mapear os pontos. Embora esse método de varredura pareça pouco atraente, ele se mostrou bastante prático porque ele é executado apenas uma vez e demora cerca de 4 segundos num computador pessoal. Depois que os pontos são escolhidos e transferidos para a tabela de pontos do bloco, não há mais a necessidade de se mapear novamente esses pontos. Esse método atingiu os objetivos esperados para esse projeto.

Como o bloco tem apenas 21 pontos, quando era encontrado um número maior de pontos, foi necessário aumentar o erro até que se conseguisse trabalhar com apenas 21 pontos. O gráfico da tangente com 21 pontos e o erro associado serão mostrados na próxima seção.

Além dos blocos utilizados para a função da tangente hiperbólica tabelada, outros blocos aritméticos foram adicionados para a normalização dos valores de entrada e saída. Também foram adicionados blocos somadores e multiplicadores. O aspecto dessa estratégia na tela é ilustrado na figura 5.13. Esse arranjo de blocos foi montado para o primeiro cenário.

Foram utilizados alguns blocos reduzidos como os blocos somadores e multiplicadores apenas para simplificação da estratégia. Esses blocos são blocos aritméticos de apenas duas entradas destinados para operações de adição (ou subtração) e multiplicação (ou divisão), mas poderiam ser utilizados os blocos aritméticos comuns sem qualquer prejuízo para o funcionamento da rede. Foi interessante a utilização desses blocos reduzidos para que a tela com os blocos interligados ficasse esteticamente mais limpa com um número menor de interligações entre os blocos. 


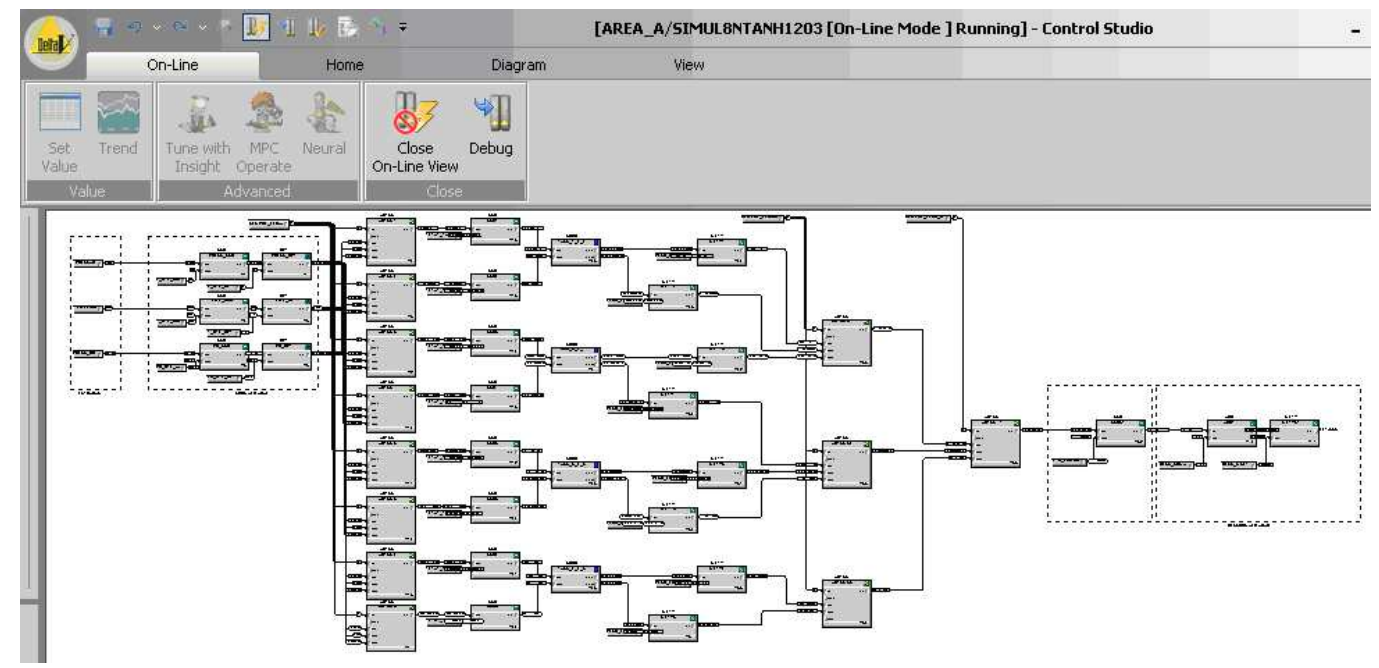

Figura 5.13: Visão geral do control studio (Delta $V^{T M}$ ) mostrando a tela dos blocos interligados.

\subsection{Normalização e desnormalização}

A normalização e desnormalização realizadas em ambiente foundation fieldbus seguem os princípios do teorema de Thales como ilustrado na Figura 5.14.

$$
Z=\frac{2 x-x_{\max }-x_{\min }}{x_{\max }-x_{\min }}
$$

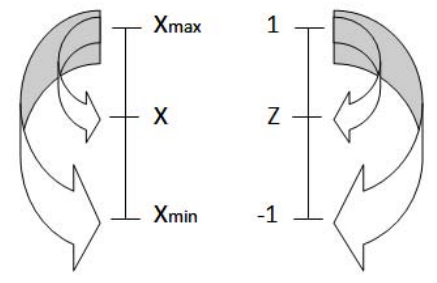

Figura 5.14: Rede neural no ambiente foundation fieldbus.

Depois da aplicação dos valores, foi observado que são suficientes uma subtração e uma divisão em cada uma das entradas para se realizar a normalização e que são necessárias uma soma seguida de uma multiplicação para a desnormalização. Dessa forma, nas figuras 5.15 e 5.16 estão mostrados como foram realizadas essas operações nos blocos de função. Por exemplo, a entrada de temperatura que varia de 60 a 120 Celsius. Substituindo-se esses valores na equação 5.1 e simplificando, chega-se à equação 5.2 .

$$
Z=\frac{x-90}{30}
$$


Portanto as operações realizadas para os padrões de entrada de temperatura são de subtração pelo valor de 90 unidades seguido de uma divisão pelo valor de 30 unidades. As Figuras 5.15 e 5.16 ilustram o aspecto dos blocos e dos links que são as interligações entre os blocos utilizados.

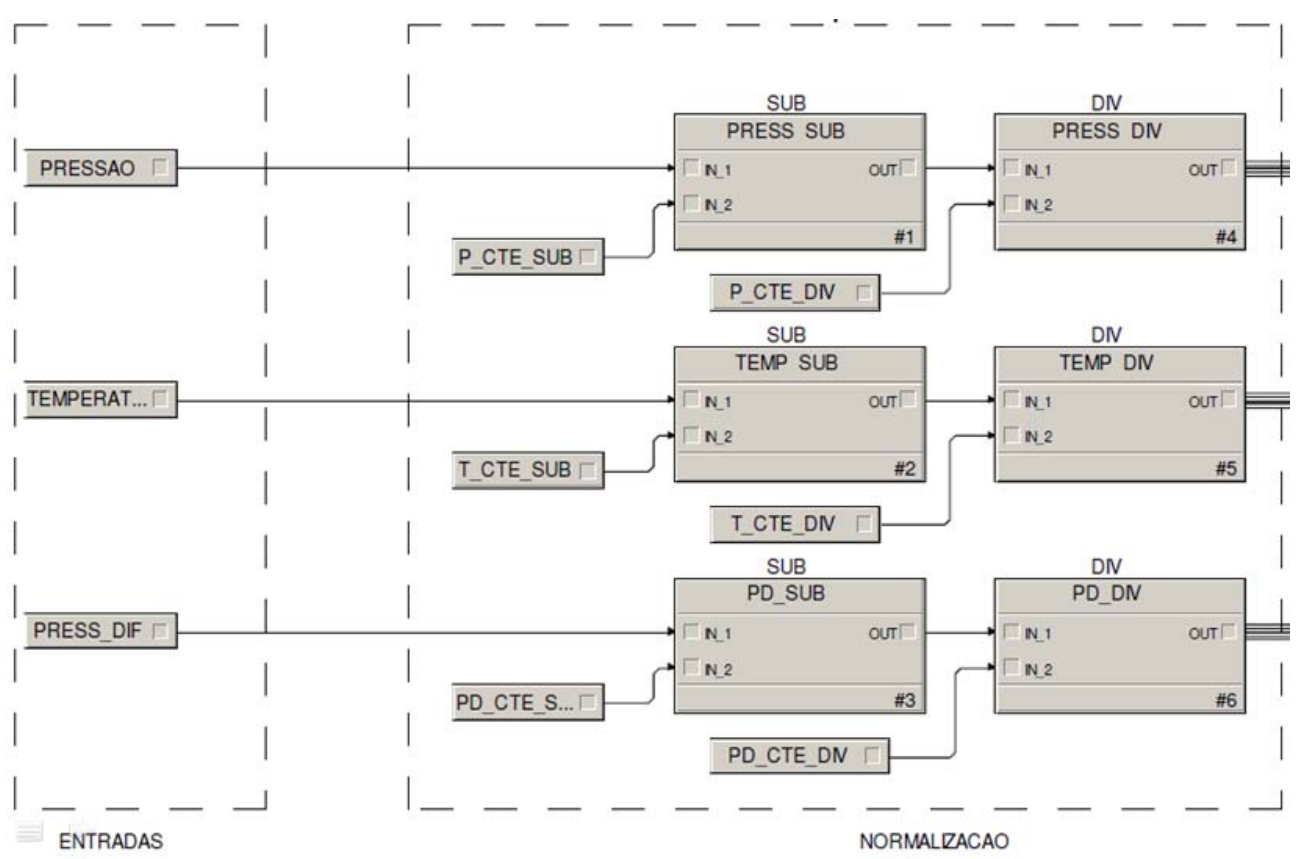

Figura 5.15: Normalização.

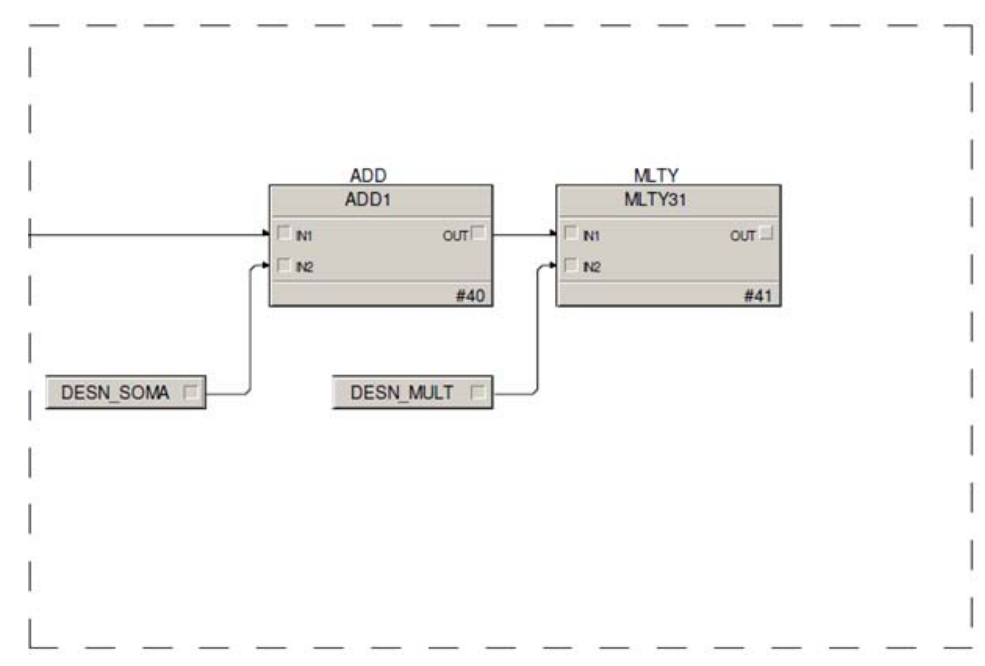

Figura 5.16: Desnormalização. 


\subsection{Desafios na implementação da rede neural no ambiente foun- dation fieldbus}

Num primeiro momento, as redes neurais no Matlab ${ }^{T M}$ foram testadas com 5, 8, 20, 30, 50 e 100 neurônios.

Para os primeiros testes, uma rede neural com 12 neurônios foi escolhida entre as simulações com os números de neurônios citados. A partir disso, o aprendizado da rede, ou seja, os valores dos pesos sinápticos e dos limiares foram transportados para uma estrutura de blocos de função no ambiente foundation fieldbus. Os primeiros resultados apresentaram erros muito grandes, da ordem de $60 \%$.

Numa segunda análise, foi verificado que que os pequenos erros decorrentes da tangente hiperbólica são multiplicados pelos pesos. Os pesos de valores altos acabam provocando um aumento no erro que são acumulados na saída da rede neural.

Uma forma de se melhorar isso seria seria aumentar o número de pontos da Tabela de 21 pontos utilizados no bloco caracterizador foundation fieldbus . Como as tabelas são limitadas em 21 pontos, uma forma de se fazer isso seria aumentar o número de blocos por curva de tangente. Com isso poderia se melhorar a definição dos pontos. Esse estudo foi realizado e implementado no segundo cenário. Nesta mesma seção também foi ilustrado o mapeamento ótimo dos blocos (mapeamento dos pontos) com a finalidade de se obter uma melhor precisão para a tangente hiperbólica tabelada.

Realizou se um estudo novamente no Matlab ${ }^{T M}$ simulando redes com menor número de neurônios e vários treinamentos foram feitos a fim de se conseguir valores de pesos sinápticos e de limiares que pudessem apresentar erros menores. Uma outra fonte de erro observada nessa última fase citada acima de reavaliação da rede foundation fieldbus, foi que nos blocos aritméticos existem parâmetros limitantes de valores da saída OUT LO LIM e OUT HI LIM que são, por padrão, configurados como 0 e 100. Isso faz com que valores abaixo de 0 ou acima de 100 calculados pelo bloco aritmético sejam ceifados e o valor de saída do bloco fique em zero no primeiro caso e em 100 para o segundo caso. Esses valores de parametrização foram alterados para -10000 e 10000 em todos os blocos aritméticos para evitar que a influência não desejável nos cálculos explicada acima ocorresse e invalidasse o estudo.

Os gráficos a seguir foram obtidos via Matlab ${ }^{T M}$ e é possível analisar que alguns erros ficaram muito acima da média. Provavelmente se esses pontos forem passados pra dentro do conjunto de 
treinamento ou se o número de neurônios for aumentado, é possível a redução do erro relativo médio que está em 1,43\%. Embora esse valor não contemple as imprecisões dos sensores nas medições de pressão, pressão diferencial e de temperatura que se somariam à esse erro, pode-se julgar que esse erro atenderia à uma ampla gama de aplicações ao compararmos com o erro nominal apresentado na folha de dados do transmissor multivariável de $1 \%$ sobre o valor da vazão.

Na Figura 5.17 são mostrados os erros relativos em dois subgráficos, comparando-se o erro que utiliza a função da tangente hiperbólica comum calculada (no Matlab ${ }^{T M}$ ) e a função hiperbólica simulada com segmentos de reta com 21 pontos trabalhando com interpolações (como é realizado pelo bloco caracterizador). Pode se constatar que os erros, como esperado, são maiores para o segundo subgráfico (tangente tabelada).
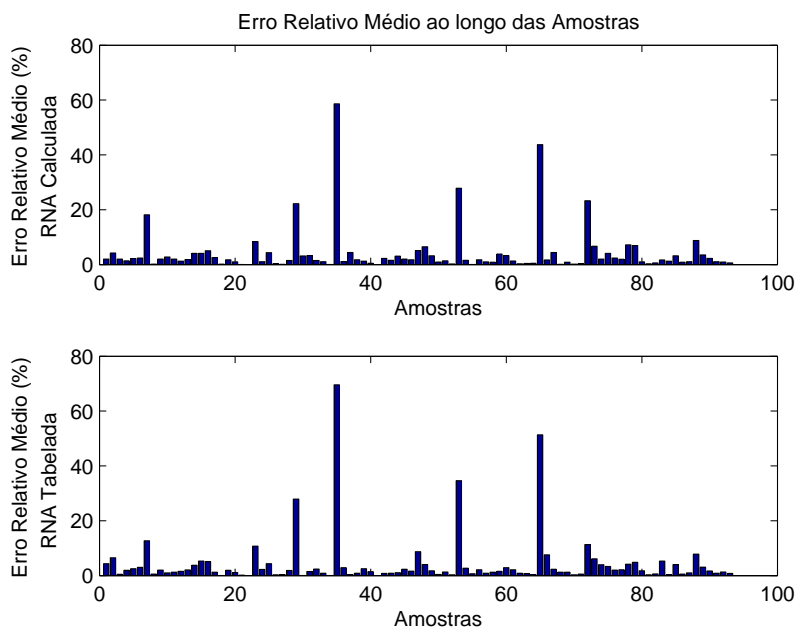

Figura 5.17: Gráfico comparativo - rede de 5 neurônios.

Os erros relativos médios das tangentes calculada e tabelada para a Figura 5.17 são respectivamente de 4,1624 \% e de 4,3288 \%. Foram utilizadas 265 épocas para esse treinamento.

Os erros relativos médios das tangentes calculada e tabelada para a Figura 5.18 são respectivamente de 3,0914 e de 4,2351\%. Foram utilizadas 560 épocas para o treinamento dessa rede neural.

Para o treinamento com 10 neurônios ilustrado na Figura 5.19, os erros relativos médios das tangentes calculada e tabelada são de 0,6937 e 0,9291 \%. Houve 566 épocas épocas para o treinamento dessa rede.

Para o treinamento com 15 neurônios ilustrado na Figura 5.20, os erros relativos médios das 

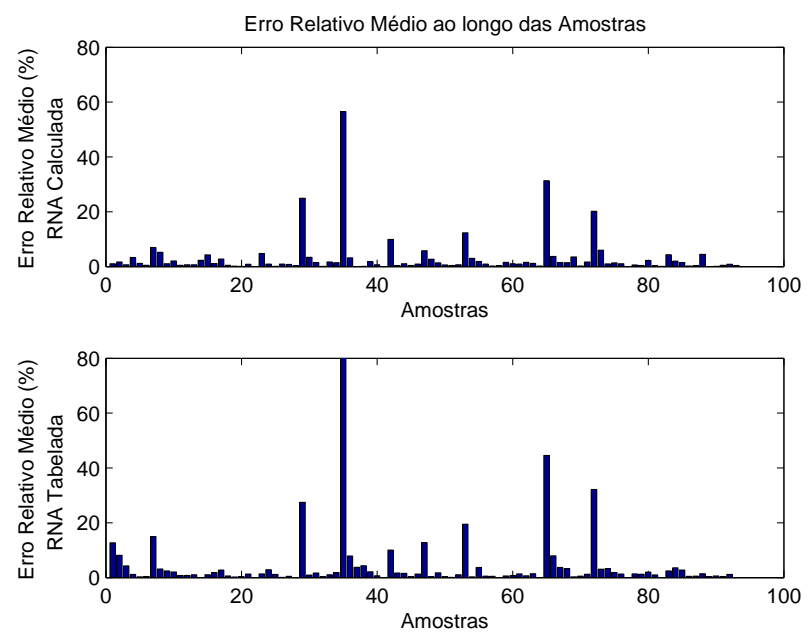

Figura 5.18: Gráfico comparativo - uma das redes treinadas com 8 neurônios.
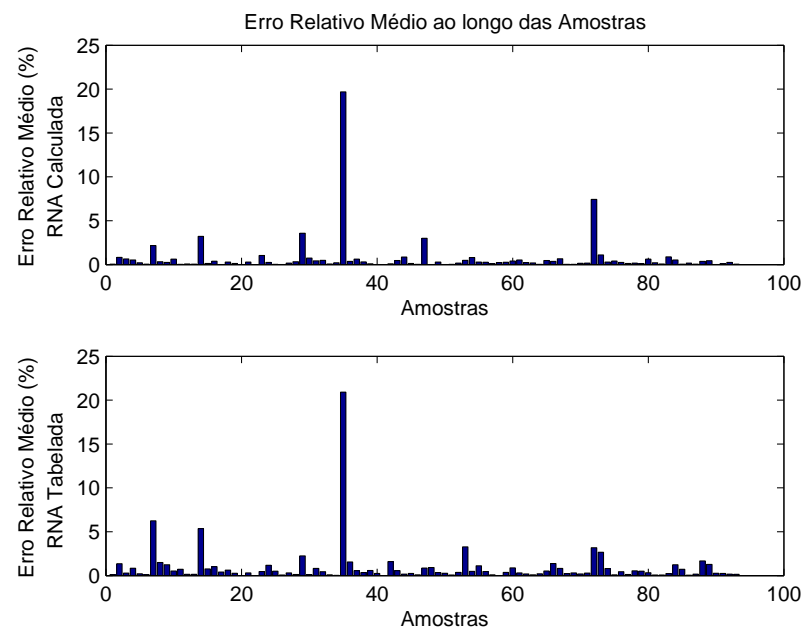

Figura 5.19: Gráfico comparativo - rede de 10 neurônios.
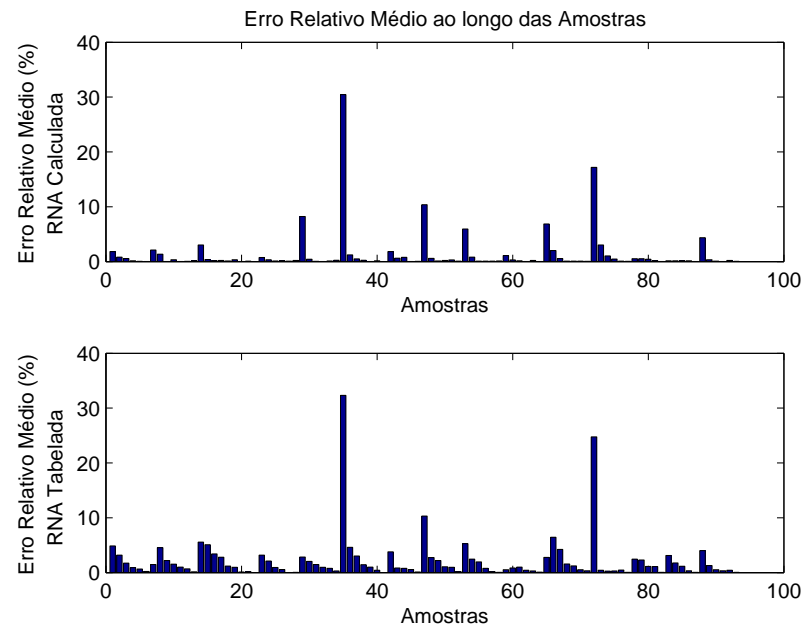

Figura 5.20: Gráfico comparativo - rede de 15 neurônios. 
tangentes calculada e tabelada são de 1,2926 e de 2,2116 \%. Foram utilizadas 1000 épocas para esse treinamento.
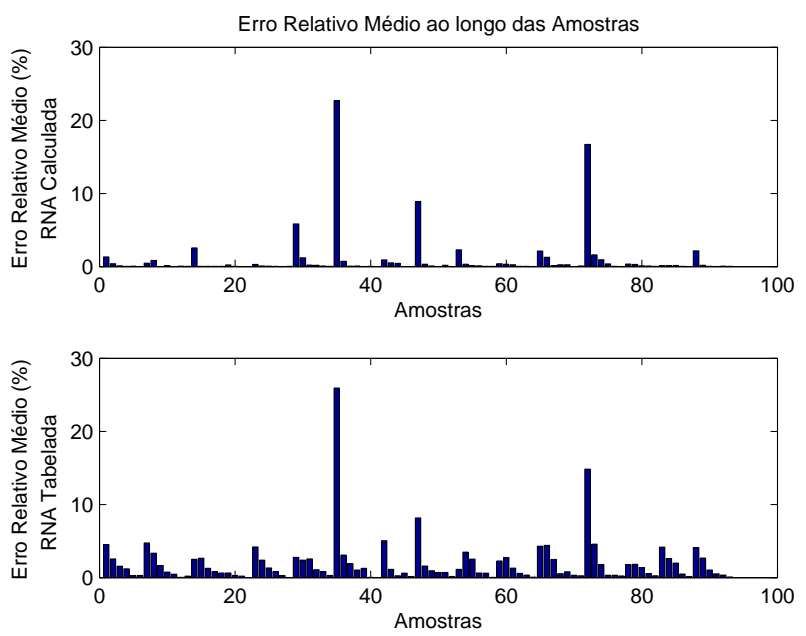

Figura 5.21: Gráfico comparativo - rede de 20 neurônios.

O treinamento da Figura 5.21 foi realizado com 20 neurônios, os erros relativos médios das tangentes calculada e tabelada são de 0,8898 e de 1,9432 \%. Esse treinamento utilizou 2000 épocas.
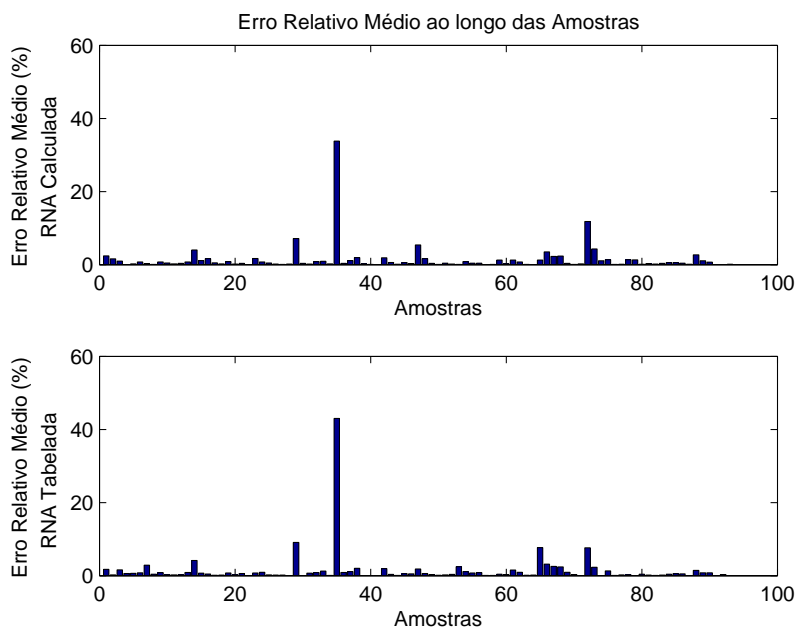

Figura 5.22: Gráfico comparativo - rede escolhida de 8 neurônios.

Após vários treinamentos com 8 neurônios, foi escolhido o treinamento cujo gráfico de erro relativo médio pode ser visto na Figura 5.22. Os erros relativos médios das tangentes calculada e tabelada são de 1,3591 e de 1,4258 \%. Como relatado anteriormente, essa rede com 8 neurônio foi a escolhida por ter apresentado um erro menor que $2 \%$ e um número menor de neurônios facilita a programação da rede neural em ambiente foundation fieldbus. 
Na figura 5.23 é possível se observar o gráfico de desempenho do treinamento da rede neural efetuado pelo toolbox de redes neurais do Matlab ${ }^{T M}$.

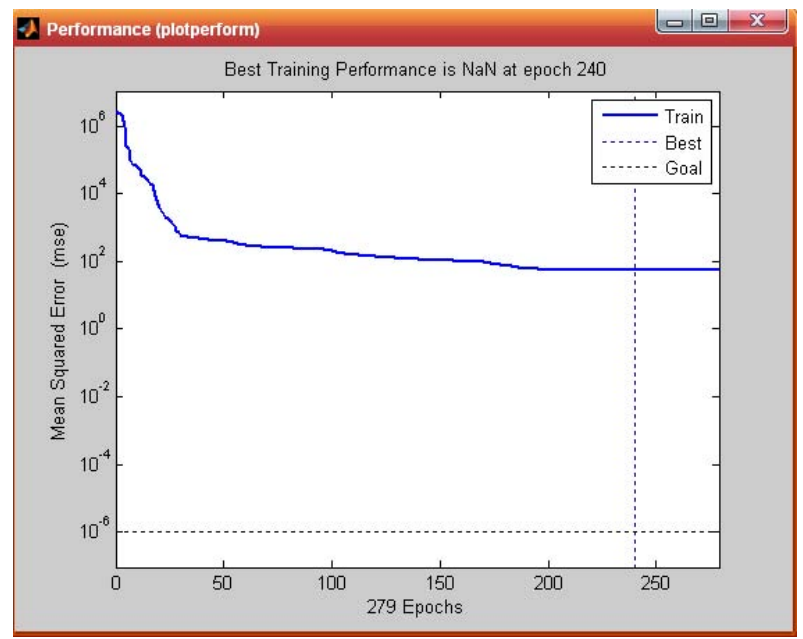

Figura 5.23: Desempenho do treinamento da rede neural

\subsubsection{O segundo cenário}

Para o segundo cenário, o objetivo era conseguir um erro relativo menor. Poucas alterações foram feitas na programação desenvolvida no Matlab ${ }^{T M}$ e procurou se chegar a um erro da ordem de $0,2 \%$. Também houve a preocupação de se manter a busca pelo menor número de neurônios possível.

O procedimento para o segundo cenário foi bastante semelhante, mas houve uma automatização através de software para se escrever as entradas e para se tomar os valores da vazão. Isso será explicado em pormenores na próxima seção. O número dos padrões gerados foi incrementado consideravelmente.

No segundo cenário foi utilizada também uma placa de orifício de 4 polegadas, porém, com beta de 0,5 e o fluido do processo é gás natural. Esse cenário retrata uma condição real de medição de gás natural realizada pela empresa Braskem na Bahia.

A mesma bancada de testes foi utilizada para o segundo cenário. As Figuras 5.3, 5.4, 5.5, 5.6, 5.7 5.8 ilustram a sequência de configurações realizadas no software EA para o transmissor multivariável.

Os valores de pressão diferencial variam de 10 a $1840 \mathrm{mmH}_{2} 0$ a $68^{\circ} \mathrm{F}$, os valores de temperatura de 60 a 120 Celsius e os da pressão estática de -5 a 60 Bar abs. Para a faixa de pressão 
diferencial foram tomados valores de 10 em $10 \mathrm{mmH}_{2} 0$ a $68{ }^{\circ} \mathrm{F}$, para temperatura e pressão estática foram tomados intervalos de 5 em 5 (Celsius e Bar abs). Essas faixas são limites reais de operação industrial. A configuração do software EA foi elaborada e enviada para o instrumento multivariável de forma similar ao que foi realizado para o primeiro cenário.

Para o segundo cenário, era necessário uma quantidade maior de pontos para revalidar o método desenvolvido. Haveria um gasto enorme de tempo para se adquirir os dados da mesma forma anotando os à mão como foi feito para o primeiro cenário.

Utilizou-se para tal finalidade o software gratuito AutoIt de forma a se automatizar esses procedimentos de escrita dos valores de entrada e leitura do valor da vazão calculada pelo software Engineering Assistant ${ }^{T M}$. Este software tem a capacidade de ler e escrever em campos de janelas abertas de outros softwares. Também é possível guardar informações em formato de texto. Um programa foi elaborado no AutoIt para automatizar a escrita de um padrão por vez, ou seja, os valores de pressão diferencial, pressão estática e de temperatura eram escritos diretamente nos campos mostrados na tela do test calculation que permanecia aberta, o botão calculate era pressionado, sendo essa ação disparada por outro comando dentro do software AutoIt e depois de aproximadamente 12 segundos, o valor da vazão que aparecia na tela do test calculation era guardada ao lado dos valores das entradas num arquivo tipo texto (.txt). As informações eram salvas nesse arquivo e uma nova linha era iniciada com outro padrão de entradas / saída. Isso possibilitou a simulação de uma grande quantidade de pontos. O microcomputador ficou ligado por volta de 7 dias e 6 noites para a tomada desses valores. Dessa forma, obtiveram-se 33487 padrões de entrada. Durante a fase de treinamento foram utilizados 28703 desses padrões e 4784 foram utilizados para os testes.

\subsubsection{Número de blocos e melhoria da precisão da tangente tabulada}

Quanto maior o número de pontos para se discretizar a curva da tangente, maior a precisão. Porém, um dos problemas de se aumentar o número de pontos é a necessidade de se aumentar o número de blocos caracterizadores e também a adição de outros blocos para tratar o mecanismo de seleção e de distribuição. Por exemplo, para direcionar qual bloco caracterizador vai trabalhar com qual parte da curva da tangente. Depois há que se combinar de alguma forma as saídas desses blocos caracterizadores para se recompor a curva tangente. Essa tarefa não é fácil de ser implementada porque as estruturas de decisão clássicas como (if... then... else) ou (while... do) ou ainda (do... until) não estão incorporadas em blocos padrão. Existe uma estrutura 
do bloco ISEL - Input Selector, mas a decisão tem que ser tomada previamente por alguma outra estrutura. O bloco ISEL apenas faz o chaveamento entre 2 entradas (ou mais) e envia a saída para um outro bloco. Será ilustrado mais adiante como foi feita a escolha de dois blocos caracterizadores e como foi resolvida a lógica de seleção entre eles.

O estudo feito variado-se o número de pontos do mapeamento da curva tangente, e, por conseguinte dos blocos caracterizadores é mostrado a seguir nas Figuras 5.24(a) e 5.24(b).

Na Figura 5.25 é ilustrada uma comparação dos erros das duas tangentes tabeladas acima. Utilizando apenas um bloco caracterizador com 21 pontos tem-se um erro de 0,61\% com relação a tangente calculada. Isso foi utilizado para o primeiro cenário. Para o segundo cenário, foram utilizados dois blocos caracterizadores e 39 pontos da tabela. Com isso conseguiu-se um erro de $0,166 \%$. Com o valor mais preciso da tangente hiperbólica, que é um elo muito importante nos cálculos da rede neural, isso acarretará uma melhor precisão no cálculo da vazão, como será visto mais adiante.

O primeiro bloco trabalha a parte negativa da tangente e o segundo bloco trabalha a parte positiva. Depois um bloco aritmético faz a somatória das saídas dos dois blocos. Dessa forma a transição entre as tabelas sob o valor zero que é o centro da curva. Foi estudada a montagem com três blocos ou mais, mas a complexidade da estrutura da lógica de seleção e fluxo de dados aumenta drasticamente quando se utiliza apenas blocos padrão.

O aumento da precisão da curva da tangente influencia no aumento da precisão dos cálculos da vazão. Teoricamente tem se 42 pontos para trabalhar, mas alguns pontos tem que ser sobrepostos na transição de um bloco para o outro. Dessa forma, foi possível trabalhar com 39 pontos. Foi criada uma estratégia com blocos caracterizadores para verificar a diferença de precisão da tangente hiperbólica desenvolvida em blocos foundation fieldbus.

A Figura 5.26 ilustra essa diferença entre os valores das duas tangentes tabeladas com $21 \mathrm{e}$ 39 pontos. O primeiro bloco caracterizador contém toda a curva da tangente discretizada em 21 pontos. Foi esse modelo o utilizado para o primeiro cenário. No segundo cenário, os dois blocos caracterizadores trabalham em paralelo. O primeiro deles trabalha a parte negativa da tangente e o segundo trabalha a parte positiva. Um bloco somador no final desses blocos faz a junção das duas metades trabalhadas separadamente e volta a constituir a curva total da tangente agora discretizada em 39 pontos.

A Tabela A.8 do Apêndice ilustra essa diferença entre os valores das duas tangentes tabeladas 


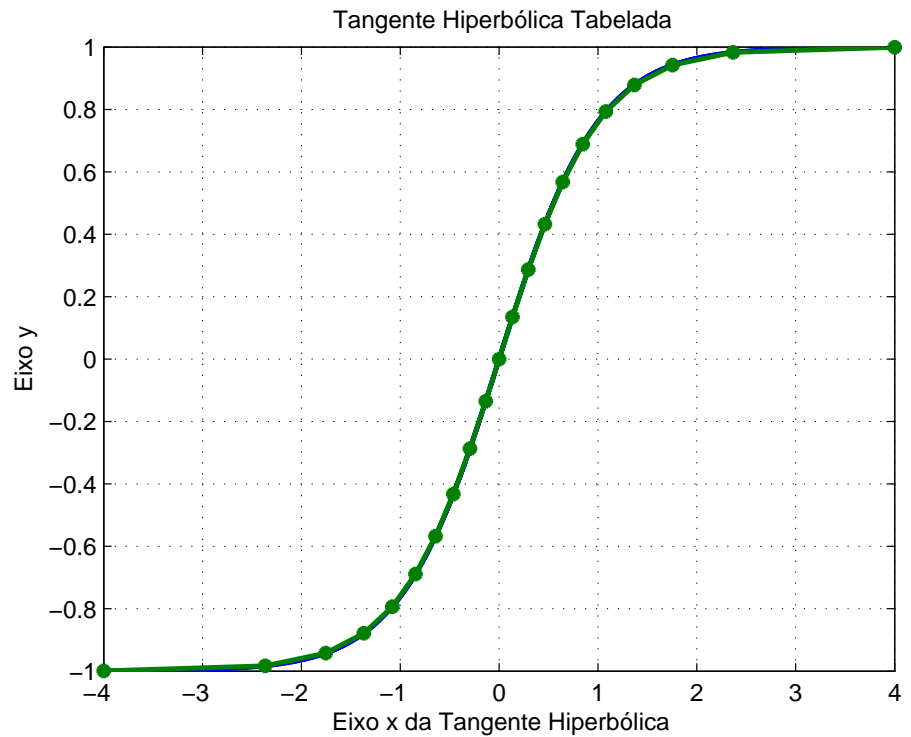

(a) Tangente com 21 pontos.

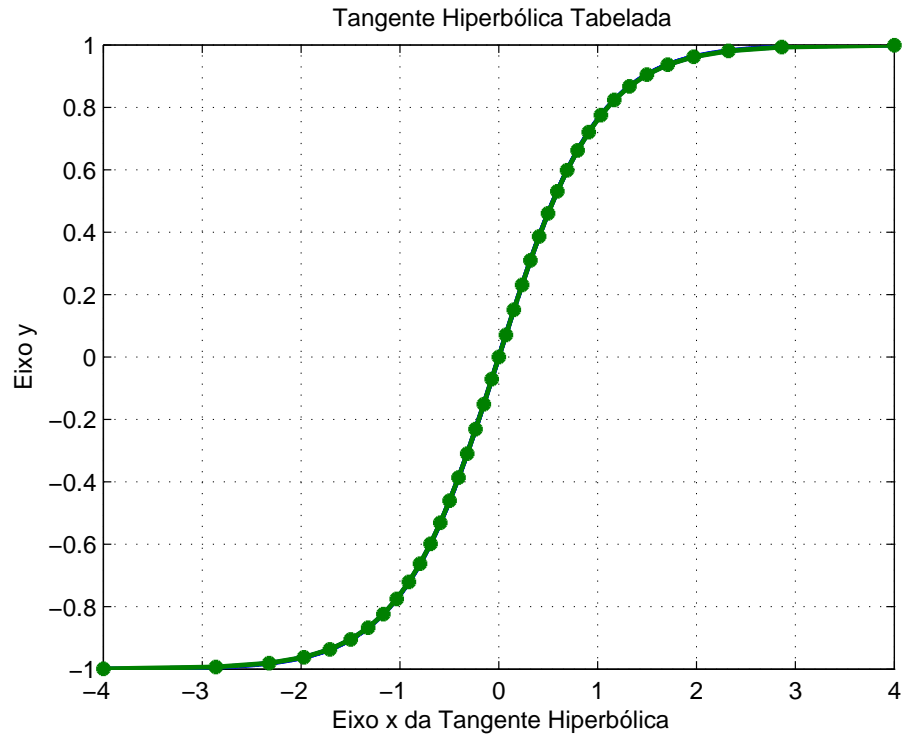

(b) Tangente com 39 pontos.

Figura 5.24: Tangente tabulada com 21 e 39 pontos. 


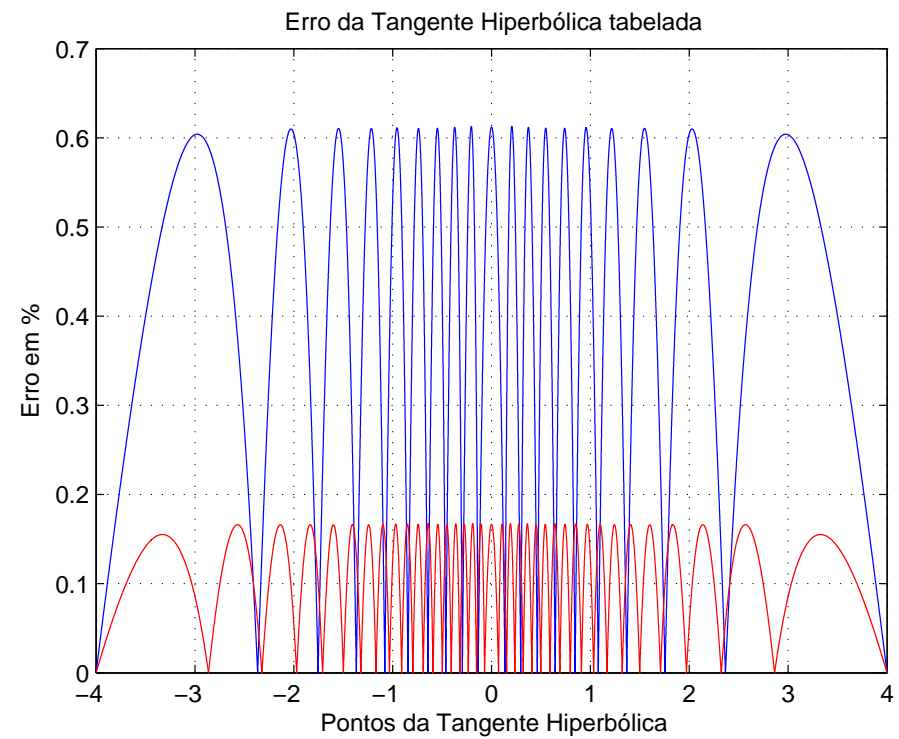

Figura 5.25: Erro comparativo das curvas tabeladas com 21 e 39 pontos.

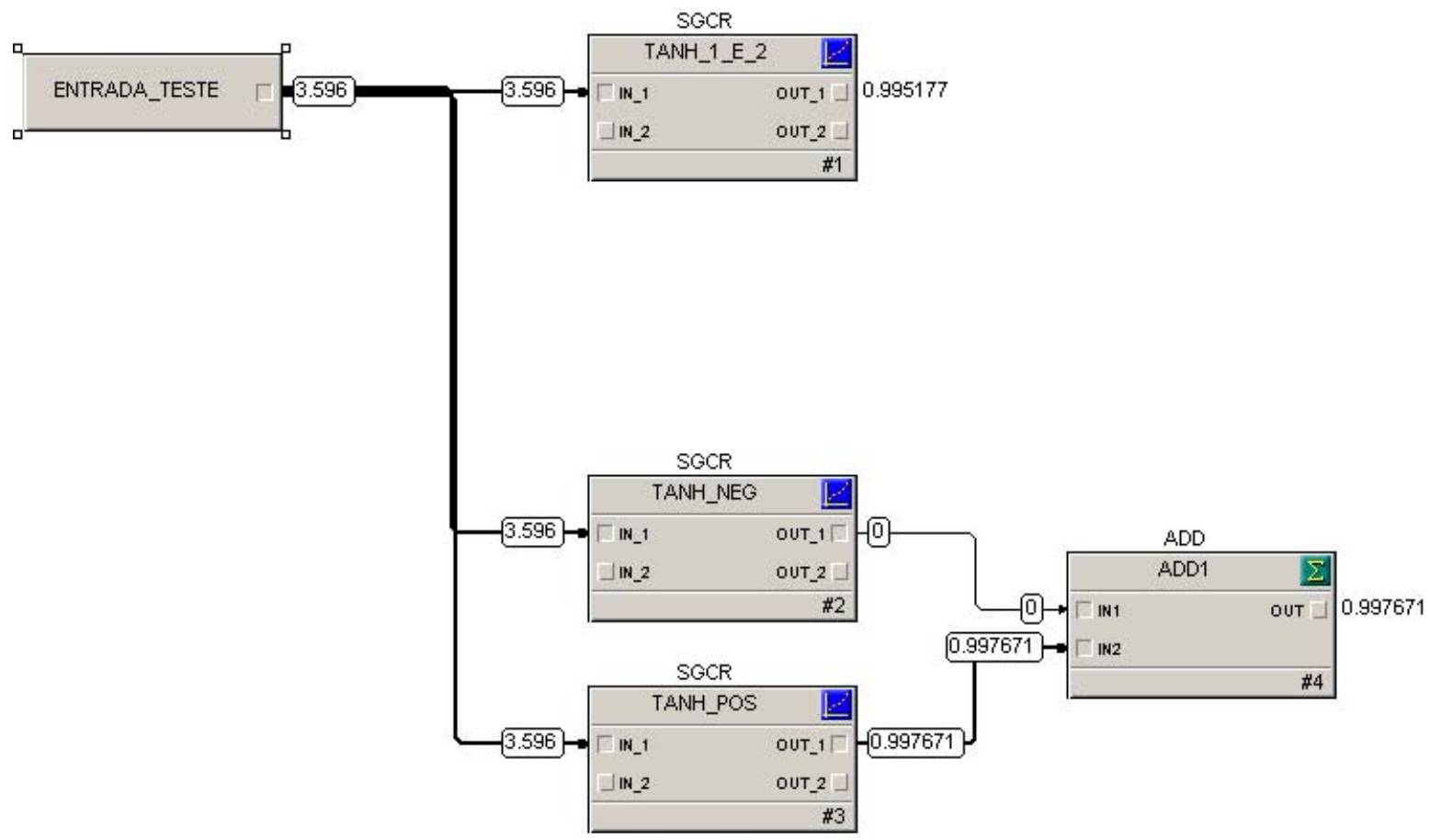

Figura 5.26: Estratégia montada para comparação entre as tangentes elaboradas com 21 e 39 pontos. 
com 21 e 39 pontos.

A Figura 5.29 ilustra o resultado de uma rede de 5 neurônios. Os valores de erro relativo médio foram de 0,5116 e $0,7604 \%$. O primeiro valor percentual se refere ao gráfico superior e ilustra o valor de erro relativo médio para o cálculo da vazão com relação ao valor gerado pelo transmissor multivariável sendo a curva da tangente calculada no Matlab ${ }^{T M}$. O segundo valor percentual se refere ao gráfico inferior e também ilustra o valor de erro relativo médio para o cálculo da vazão com relação ao valor gerado pelo transmissor multivariável com a diferença da curva da tangente ser tabelada em 39 pontos como é realizado no ambiente foundation fieldbus. As amostras para o segundo cenário começam com os valores mínimos das faixas de pressão diferencial, pressão estática e temperatura para o primeiro padrão. Para o segundo padrão os valores de pressão diferencial e pressão estática são conservados iguais ao do primeiro padrão e a temperatura é maior que a do primeiro padrão. Os próximos padrões seguem essa mesma regra até se atingir um valor alto da faixa de temperatura, então os valores de pressão diferencial e temperatura são fixados e um valor maior de pressão estática é utilizado. Somente depois dessas alterações na pressão estática e na temperatura atingindo os valores máximos em suas faixas é que o valor da pressão diferencial é incrementado. Dessa forma, embora haja essa oscilação (valores do início da faixa e valores do final da faixa) para as variáveis de pressão estática e de temperatura, o valor de pressão diferencial é sempre crescente ao longo das amostras. Isso explica a tendência do gráfico de apresentar altos valores de erro no início da faixa e valores menores para valores maiores de pressão diferencial. Os gráficos de precisão do valor de vazão por pressão diferencial tem essa característica bem definida de erros maiores próximos a valores baixos de pressão diferencial. Essa característica está ligada à imprecisão do sensor de pressão diferencial que é maior para baixos valores de pressão. O valor do erro cai segundo uma curva até atingir um patamar constante, a partir do qual, mesmo com o aumento do valor da pressão diferencial, não há queda no valor do erro da vazão medida. Os gráficos tipo histograma mostrados abaixo nas figuras 5.27 e 5.28 onde os padrões foram agrupados respectivamente em 25 e 100 divisões, comprovam essa caracterítica do erro maior no início da faixa.

Para o primeiro cenário, esse padrão não pode ser observado devido à ordem utilizada para os padrões ter sido pressão estática, temperatura e pressão diferencial. Pode-se acrescentar também que o número relativamente pequeno de padrões de testes utilizados não evidencia esse comportamento da curva ilustrada nos gráficos do primeiro cenário.

A Figura 5.29 mostra o erro de uma rede de 5 neurônios. Os valores de erro relativo médio 


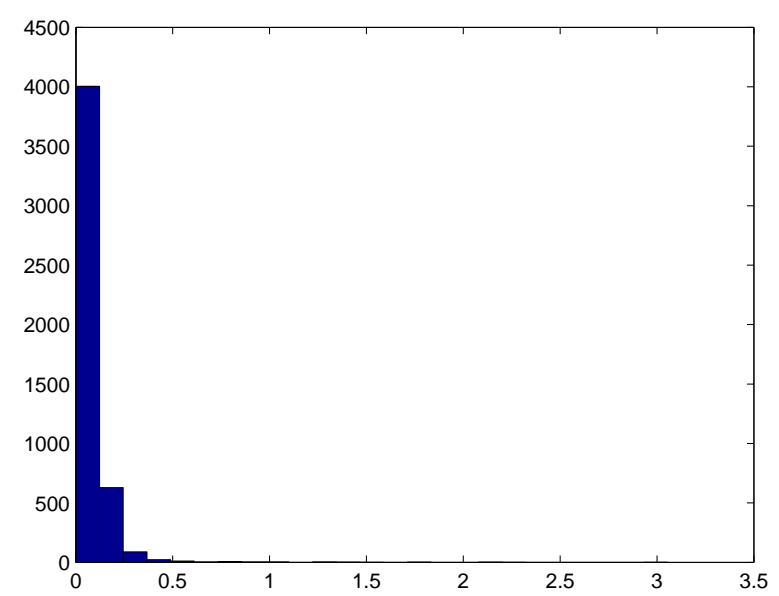

Figura 5.27: Histograma do erro agrupando-se os padrões em 25 divisões

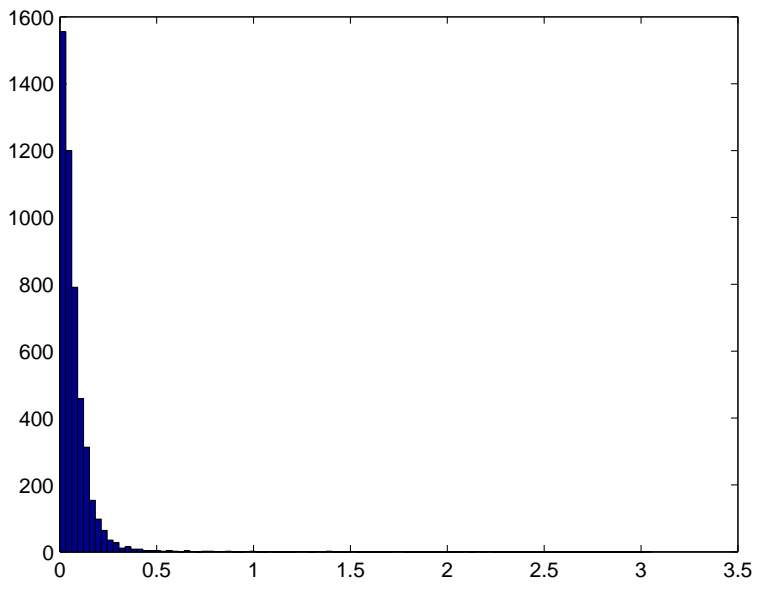

Figura 5.28: Histograma do erro agrupando-se os padrões em 100 divisões 
foram de 0,5116 e de $0,7604 \%$.
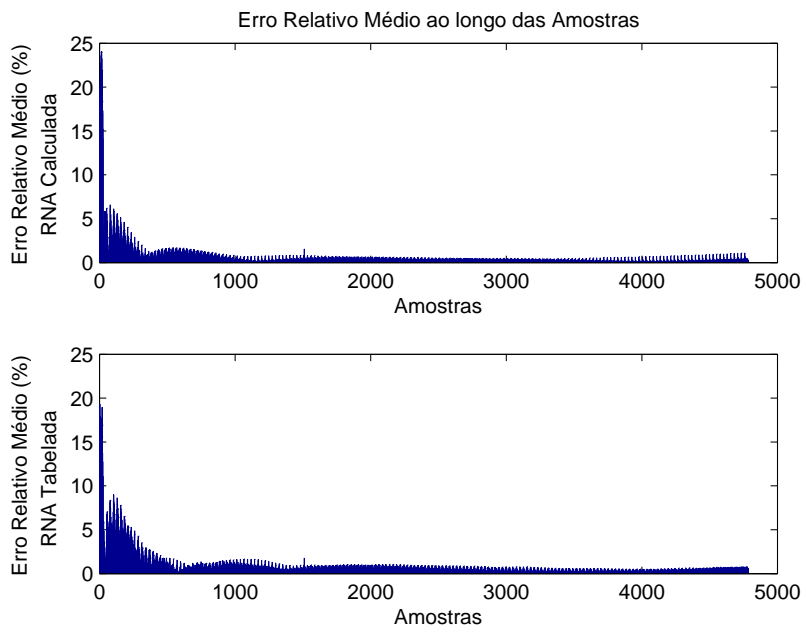

Figura 5.29: Gráfico comparativo - rede de 5 neurônios.

A Figura 5.30 mostra o erro de uma rede de 8 neurônios. Os valores de erro relativo médio foram de 0,1608 e de $0,1695 \%$.
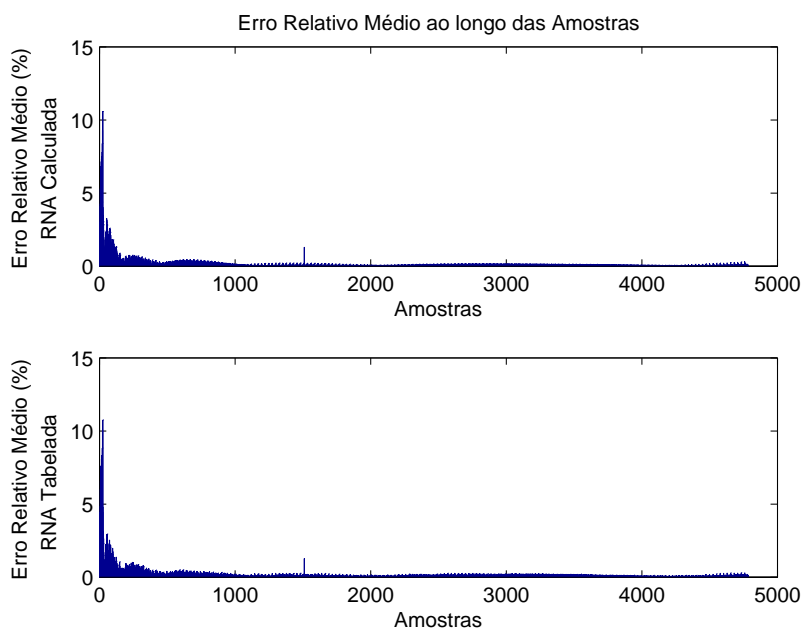

Figura 5.30: Gráfico comparativo - rede de 8 neurônios.

Na Figura 5.31 é ilustrado o erro de uma rede de 10 neurônios. Os valores de erro relativo médio foram de 0,0508 e de $0,1456 \%$.

Os valores de erro relativo médio foram de 0,0276 e de 0,0902 \% para a rede de 15 neurônios ilustrada na Figura 5.32 .

Os valores de erro relativo médio foram de 0,0319 e de 0,0698 \% para a rede de 20 neurônios ilustrada na Figura 5.33 . 

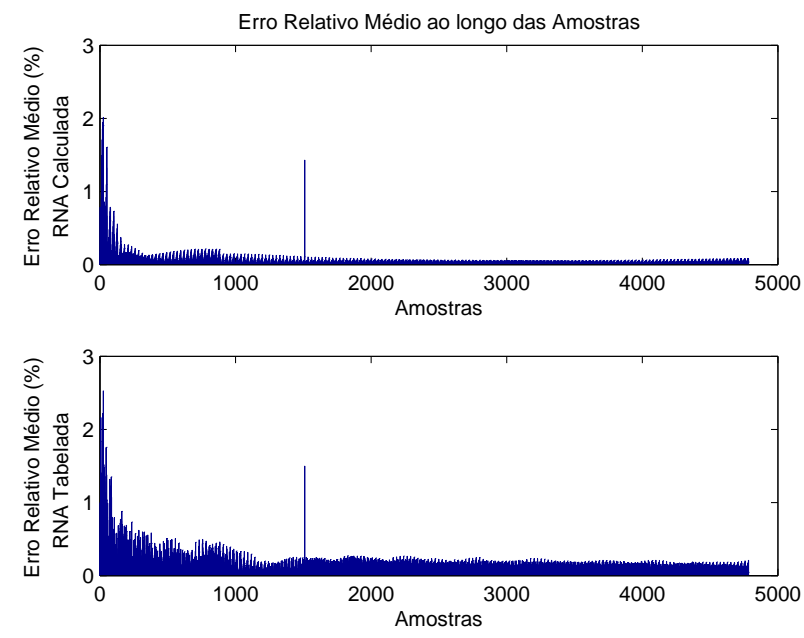

Figura 5.31: Gráfico comparativo - rede de 10 neurônios.
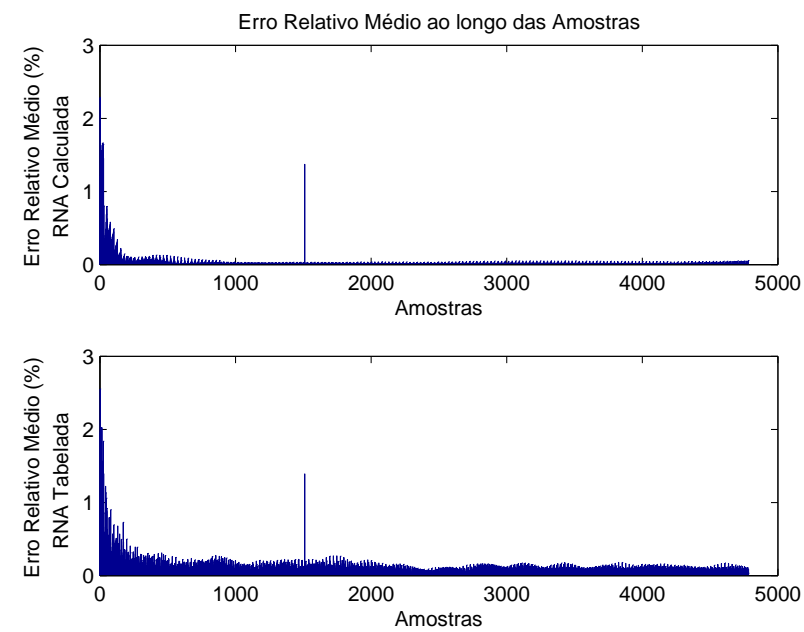

Figura 5.32: Gráfico comparativo - rede de 15 neurônios.
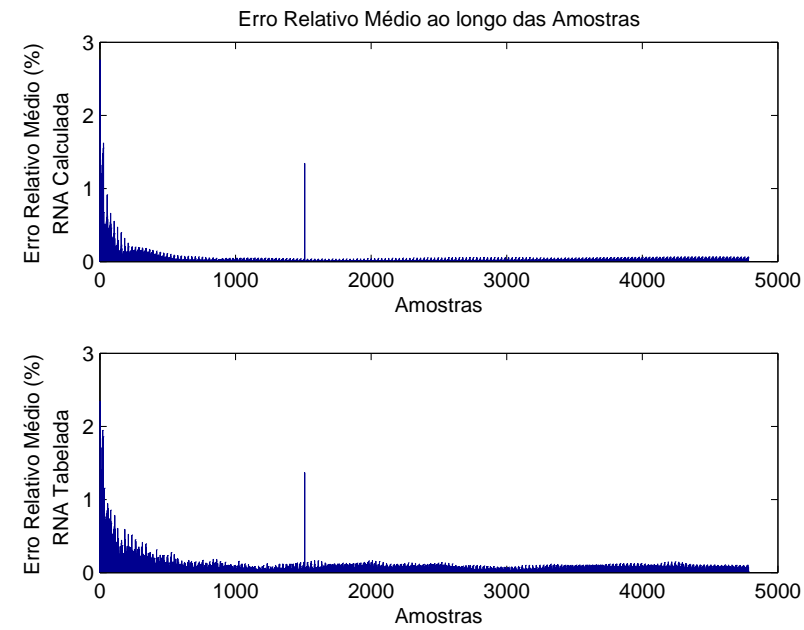

Figura 5.33: Gráfico comparativo - rede de 20 neurônios. 
Observou-se que ao treinar redes de 12 neurônios, foram encontrados valores de erro relativo médio da ordem de $0,3 \%, 0,2 \%$ e até menores. O valor de 12 neurônios parece um compromisso bom entre o número de neurônios e um erro relativo médio da ordem de 0,2 \%. Nos manuais de medidores de vazão em geral (medidores de vazão por pressão diferencial, vortex, eletromagnéticos...) um erro na faixa de 1,5 até $2 \%$ é aceitável.

Como houve um aumento no número de blocos caracterizadores para se melhorar a precisão da tangente, a rede foundation fieldbus se tornou mais complexa que a desenvolvida para o primeiro cenário. Dessa forma, aumentar a rede para valores acima de 12 neurônios, embora seja possível, aumenta o custo computacional e o tempo de implementação da rede sem necessidade porque o erro já está num patamar aceitável.

Os próximos gráficos são todos desenvolvidos com redes de 12 neurônios e 1000 épocas. As variações do erro relativo médio se devem aos valores iniciais dos pesos e limiares serem aleatórios. A Figura 5.34 mostra a distribuição de erros de uma rede com 12 neurônios com ERM (erro relativo médio) de 0,0619 e de $0,0743 \%$.
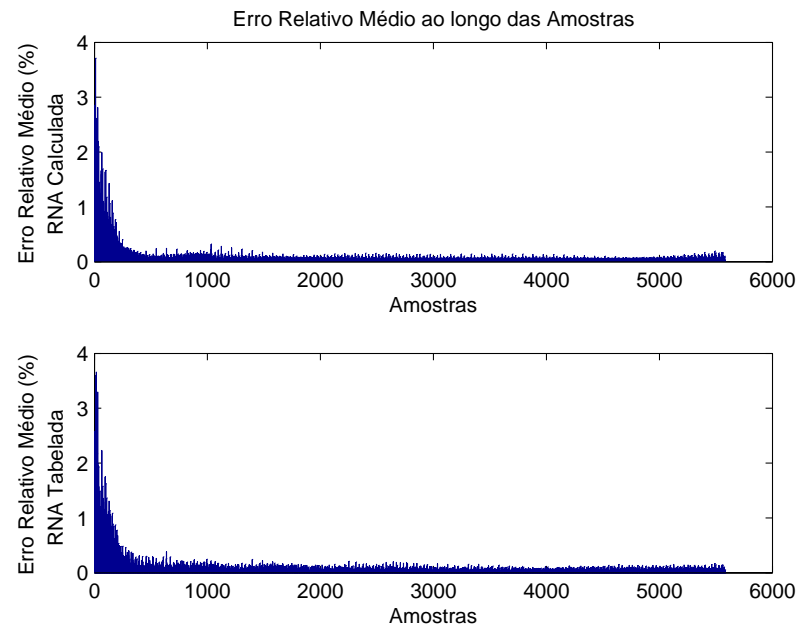

Figura 5.34: Gráfico comparativo - rede de 12 neurônios - treinamento 1.

A Figura 5.35 mostra a distribuição de erros de outra rede com 12 neurônios com erro relativo médio de 0,0533 e de $0,1637 \%$.

Na Figura 5.36 é ilustrada a comparação dos ERMs de 0,0421 e de 0,1122 \%.

Os valores de 0,0528 e de 0,1501 \% são ilustrados na Figura 5.37.

A Figura 5.38 mostra a distribuição de erros de outra rede com 12 neurônios com erro relativo médio de 0,0482 e de $0,2844 \%$. 

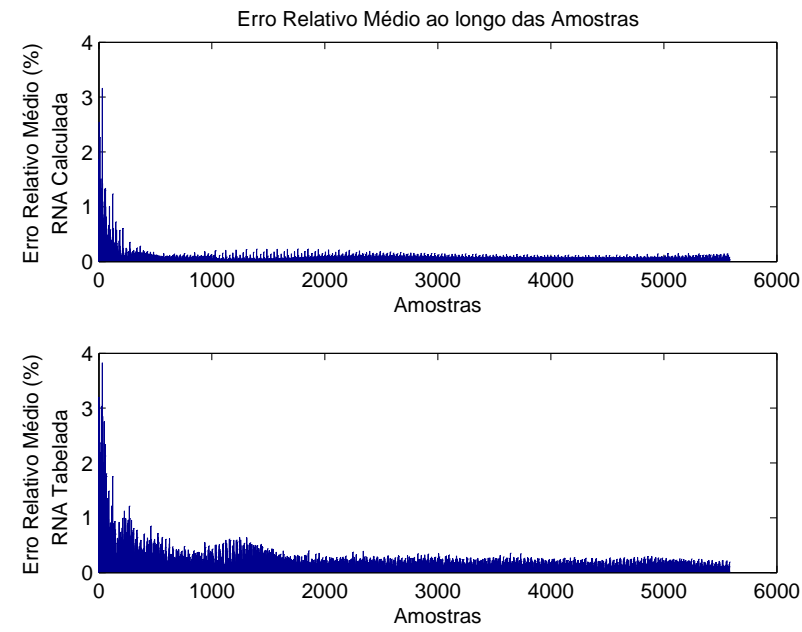

Figura 5.35: Gráfico comparativo - rede de 12 neurônios - treinamento 2.
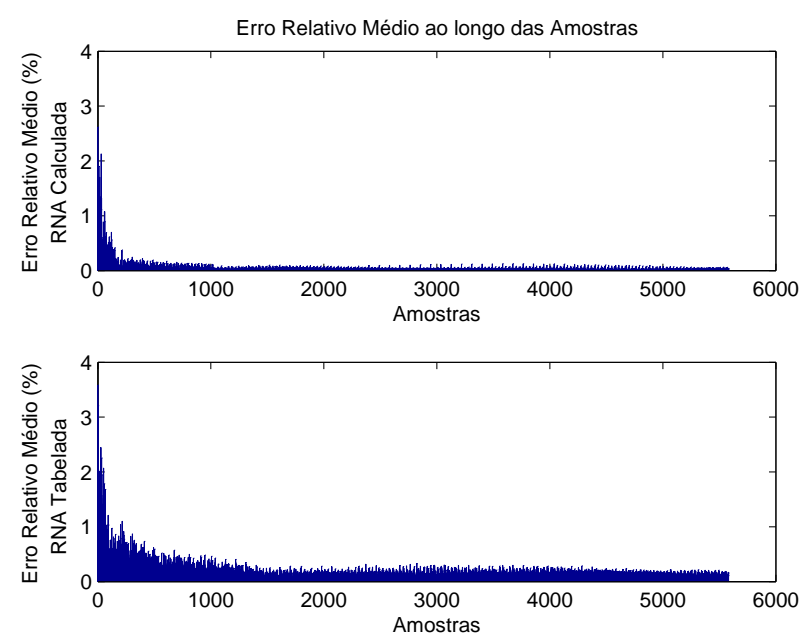

Figura 5.36: Gráfico comparativo - rede de 12 neurônios - treinamento 3.
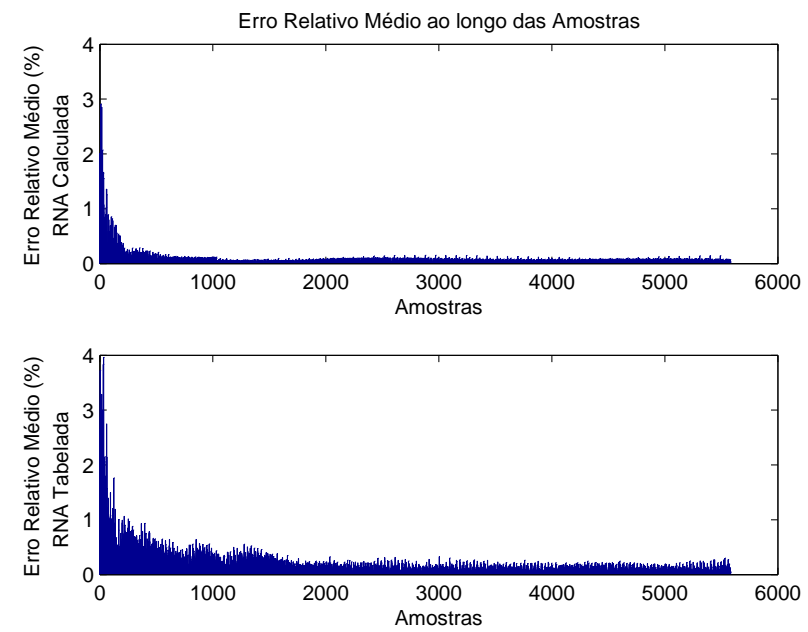

Figura 5.37: Gráfico comparativo - rede de 12 neurônios - treinamento 4. 

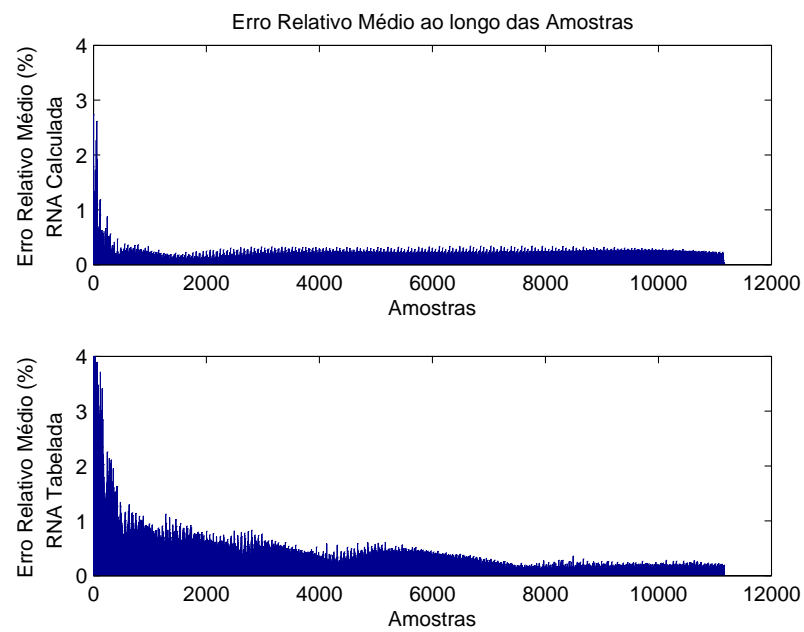

Figura 5.38: Gráfico comparativo - rede de 12 neurônios - treinamento 5.

Essa última rede de 12 neurônios mostrada na Figura 5.39 foi a escolhida por ter sido a que apresentou menor erro relativo médio para o segundo cenário. Os valores dessa rede foram transportados para o ambiente foundation fieldbus. O erro relativo médio encontrado para esse treinamento foi de 0,0590 e de $0,0732 \%$. Os valores dos pesos e limiares estão indicados no apêndice nas tabelas A.9, A.10, A.11 e A.12.
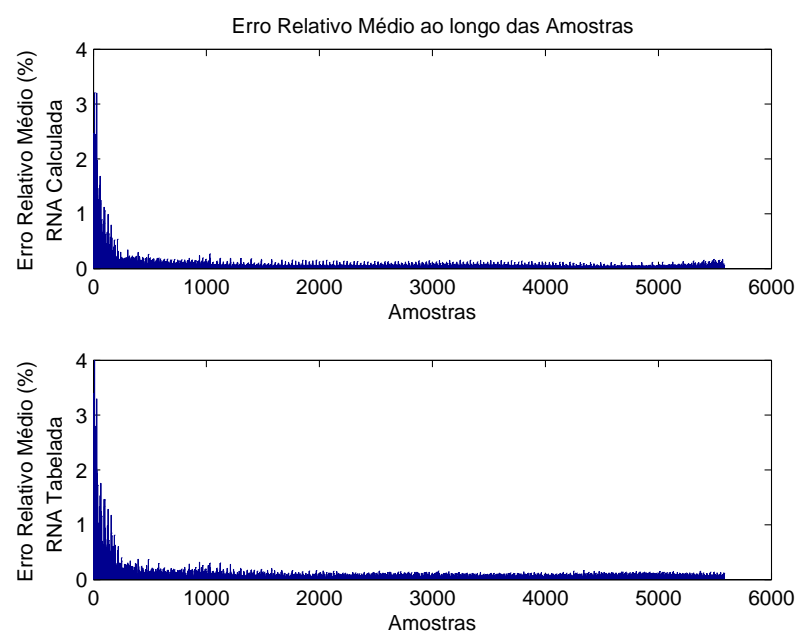

Figura 5.39: Gráfico comparativo - rede escolhida de 12 neurônios.

Na figura 5.40 é possível se observar o gráfico de desempenho do treinamento da rede neural efetuado pelo toolbox de redes neurais do Matlab ${ }^{T M}$. 


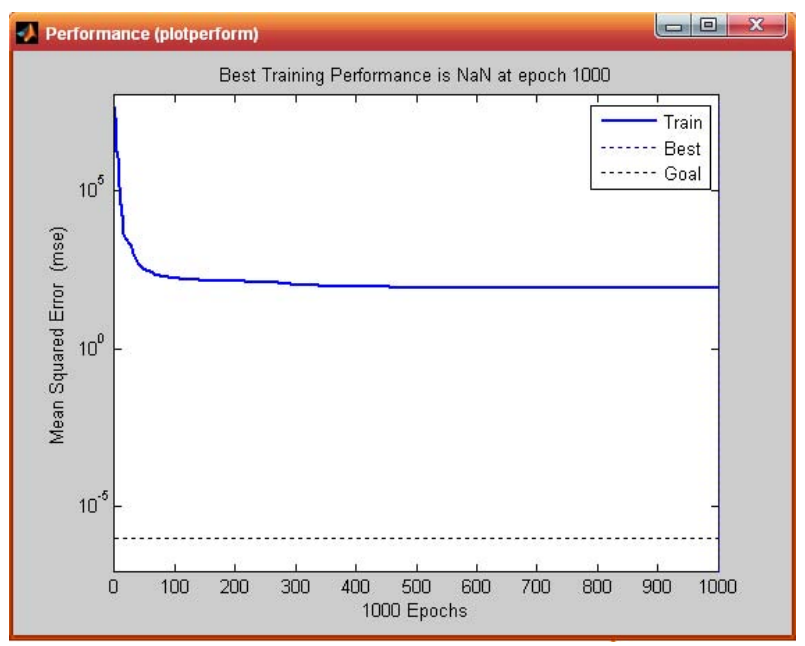

Figura 5.40: Desempenho do treinamento da rede neural 


\section{Capítulo 6}

\section{Conclusão}

Esse trabalho apresentou uma metodologia para o cálculo de vazão de fluidos compressíveis em dutos fechados a partir da valores medidos de pressão diferencial, pressão estática e temperatura utilizando se de técnicas de redes neurais cujos parâmetros de treinamento e a topologia da rede foram transportados para blocos funcionais em um ambiente foundation fieldbus.

É possível concluir-se que os valores encontrados de erro médio de 1,43\% em relação aos valores de vazão obtidos pelo transmissor multivariável no primeiro cenário com uma topologia multicamadas perceptron de 8 neurônios, que é possível e viável a utilização de uma rede neural trabalhando em ambiente foundation fieldbus.

A melhoria do projeto do cálculo da tangente hiperbólica discretizada com mais pontos no segundo cenário, trabalhando-se com dados reais de uma medição de vazão de gás natural da Braskem na Bahia, validou novamente o método aplicado sendo que foi atingido um erro relativo médio de $0.07 \%$ em relação aos valores do transmissor multivariável. Para o segundo cenário foi desenvolvido uma topologia multicamadas perceptron de 12 neurônios. Uma dificuldade que poderia ser levantada seria as aplicações que sofrem alterações frequentes do fluido do processo, o que traria a necessidade de downloads frequentes na rede foundation fieldbus para os novos pesos e limiares para a rede (talvez até de número diferente de blocos da rede). A grande maioria dos sistemas fieldbus atualmente permitem downloads parciais, sem afetar, portanto, o funcionamento de outras áreas da planta. Levando se isso em conta, haveria a possibilidade de alteração da topologia da rede neural ou dos pesos e limiares para adequação da rede às novas condições de processo como alteração do fluido do processo. Pode-se ainda ratificar que o emprego de redes neurais torna possível a utilização de blocos padrão fieldbus já que cálculos mais 
complexos como exponenciais necessitariam de blocos especiais que não garantiriam a portabilidade e interoperabilidade para outros sistemas foundation fieldbus. Essa aplicação tem ainda o benefício do baixo custo de implementação quando comparado aos custos de um instrumento multivariável.

Como sugestão de continuação do trabalho dessa dissertação pode se citar a aplicação desse método com outros elementos deprimogênios como pitots de média, venturis e também a aplicação em outros ambientes de cálculos como controladores lógico programáveis. 


\section{Referências Bibliográficas}

BERGE, J. (2004). Fieldbuses for process control: engineering, operation and maintenance. Research Triangle: ISA, $460 \mathrm{p}$.

BROWN, G. J. et al. (2009). A multipath ultrasonic meter with reducing nozzle for improved performance in the laminar / turbulent transition region. In:International North Sea Flow Measurement Workshop, 27., Tonsberg. Proceedings... Tonsberg: Tekna, 2009. p. 1-25.

CAPONETTO, R. et al. (2009). FPGA based soft sensor for the estimation of the kerosene freezing point. In:IEEE International Symposium on Industrial Embedded Systems, Lausanne. Proceedings... 2009, p. 228-236.

COSTA, I. M. et al. (2005). Embedded FASTICA algorithm applied to the sensor noise extrac- tion problem of foundation fieldbus network. In:International Joint Conference on Neural Networks, Montreal. Proceedings... 2005, p. 1-6.

COSTA, I. et al. (2010). Placa de orifício e tubo de Pitot como instrumentos de medição de vazão. Disponível em: <http://www.scribd.com/Grupo-5-Tubo-de-Pitot-e-Placade-Orificio/d/32085407>. Acesso em: 2 maio 2010

DELAJOUD, P.; GIRARD, M.; BAIR, M. (2005). The implementation of toroidal throat venturi nozzles to maximize precision in gas flow transfer standard applications. Disponível em: < http://www.dhinstruments.com/prod1/pdfs/papers/mf/tpmf0506.pdf >. Acesso em: 2 maio 2010.

DELMEÉ, GÉRARD J. (2003). Manual de medição de vazão. 3. ed. São Paulo: Edgard Blücher. 366 p.

DEVOGELAERE, D. et al. (2002). Application of Feedforward Neural Networks for Soft Sensors in the Sugar Industry. In: Brazilian Symposium on Neural Networks, 7., Recife. Proceedings... 2002. 
FERNANDES, R. G. et al. (2007). Faults Detection and Isolation Based On Neural Networks Applied to a Levels Control System. In: International Joint Conference on Neural Networks,. Proceedings... 2007, p. 1859-1864.

FLOMEKO (2010). The 15th International Flow Measurement Conference. Disponível em: <www.flomeko2010.itri.org.tw/program.html>. Acesso em: 2 mar. 2010.

GOEDTEL, A. et al. (2009). Compact artificial neural network for induction motor speed estimation. In: International Conference on Electrical Machines and Systems, Tóquio. Proceedings... 2009, p. 1-6.

GUIDE, Q. I. (2007). Guia de instalação - Rosemount 1495 Orifice Plate. Disponível em: $<$ http://www2.emersonprocess.com/siteadmincenter/PM\%20Rosemount\%20Documents/008250100-4792.pdf $>$. Acesso em: 2 mar. 2010.

GUIXUE, C. et al. (2009). A Soft-Sensor Method Based on Fuzzy Rules for Pulverized Coal Mass Flow Rate Measurement in Power Plant. In: International Conference on Artificial Intelligence and Computational Intelligence, Las Vegas. Proceedings... 2009, p. 472-476.

HAYKIN, S. (2008). Neural Networks and Learning Machines. 3. ed. Prentice Hall. 936 p.

HONEYWELL (1997). Datasheet of SMV 3000 Smart Multivariable Flow Transmit- ter. Honeywell Process Solutions. Disponível em: <http://hpsweb.honeywell.com/Cultures/en-US/Pro ducts/Instrumentation/flow/smv3000/Features/default.htm>.

Acesso em: 2 mar. 2010

INTERNATIONAL ORGANIZATION FOR STANDARDIZATION. ISO 5167-2 (2003): Measurement of fluid flow by means of pressure differential devices inserted in circular crosssection conduits running full.

LIPTAK, B. G. (Ed.) (1995). Instrument engineers handbook: process measurement and analysis. 3. ed., Research Triangle: ISA. v. 1.

LIPTAK, B. G. (Ed.) (1995). Instrument engineers handbook: process measurement and analysis. 3. ed., Research Triangle: ISA. v. 2.

MACHADO, V.; NETO, A.; MELO, J. D. (2010). A neural network multiagent archi-tecture applied to industrial networks for dynamics allocation of control strategies using stander function blocks. IEEE Transactions on Industrial Electronics, New York, v. 57, p. 1823-1834, abr. 
MELO, F. B. (2007). Avaliação Metrológica da incerteza na medição de vazão mássica de gases com tecnologias volumétrica e pressão diferencial. $74 \mathrm{f}$. Tese (Doutorado pelo Instituto de Pesquisas Energéticas e Nucleares) - Universidade de São Paulo, São Paulo, 2007.

MILLER, R. W. (1996). Flow Measurement Engineering Handbook. 3. ed. McGrawHill.

PETROVIC, I.; DOMIJAN, P.; JELAVIC, M. (2003). Estimation of lube oil viscosities on a vacuum distillation column. In: IEEE International Conference on Industrial Technology. Proceedings... 2003, v. 1, p. 265-270.

ROGERS, STEVEN B. (1998). DPFLOW Theory - Tehcnical Report.

ROSEMOUNT (2009). Datasheet of Rosemount 3095 Multi-Variable Mass Flow Transmitter. Emerson Process Management. Disponível em: <http://www2.emersonprocess.com/siteadmin center/PM\%20Rosemount\%20Documents/00813-0100-4716.pdf>. Acesso em: 2 mar. 2010.

ROSEMOUNT (2007). Quick installation guide - Rosemount 1495 Orifice Plate. Disponível em: <www2.emersonprocess.com/siteadmincenter/PM\%20Rosemount\%20Documents/00825-01004792.pdf>. Acesso em: 28 fev. 2010.

SILVA, D. R. C. et al. (2005). Implementation of neural networks in foundation fieldbus environment using standard function blocks. In: IEEE CONFERENCE ON EMERGING TECHNOLOGIES AND FACTORY AUtOMAtion, 10., Catania. Anais... New York: IEEE. p. 341-345.

SILVA, I. N.; SPATTI, D. H.; FLAUZINO, R. A. (2010). Redes neurais artificiais para engenharia e ciências aplicadas - curso prático. [S. 1.]: Artliber.

SMAR (2007). Manual de Instruções dos Blocos Funcionais. Disponível em: <www.smar.com .br>. Acesso em: 28 fev. 2010.

WANG, Y.; LI, Z (2009). Temperature Compensation of Ultrasonic Flow Measurement Based on the Neural Network . In: International Conference on Artificial Intelligence and Computational Intelligence (AICI '09). Proceedings... 2009, v. 3, p. 21-24.

WILLIS, M. J. (1992). Soft-sensing via artificial neural networks. In: IEE Colloquium on Automation and Control in Food Processing. Proceedings... 1992, p. 3/1 - 3/3.

YOKOGAWA ELETRIC CORPORATION (2010). Datasheet of EJX910A multivariable 
transmitter. Disponível em: < http://www.yokogawa.com/rd/pdf/TR/rd-tr-r00042-004.pdf>. Acesso em: 4 mar. 2010.

ZANKER, K. J. (2005). Gas flow conditioning: devices used to pre-condition the gas flow profile prior to measurement. Disponível em:

<http://www.asgmt.com/default/papers/asgmt2004/docs/B11.pdf>. Acesso em: 23 fev. 2011. 


\section{Apêndice A}

\section{Dados para treinamento da rede, dados de validação e resultado dos}

\section{testes.}

Tabela A.1: Dados de treinamento para a rede neural.

\begin{tabular}{|c|c|c|c|c|c|c|c|}
\hline Pressão & Temp & $\begin{array}{c}\text { Pres.Dif. } \\
\mathrm{mmH}_{2} \mathrm{O}\end{array}$ & Vazão & Pressão & Temp & $\begin{array}{c}\text { Pres.Dif. } \\
\mathrm{mmH}_{2} \mathrm{O}\end{array}$ & Vazão \\
bar (abs) & ${ }^{\circ} \mathrm{C}$ & $\mathrm{a} 68^{\circ} \mathrm{F}$ & $\mathrm{Nm}^{3} / \mathrm{h}$ & $\mathrm{bar}(\mathrm{abs})$ & ${ }^{\circ} \mathrm{C}$ & $\mathrm{a} 68^{\circ} \mathrm{F}$ & $\mathrm{Nm}^{3} / \mathrm{h}$ \\
\hline 1 & 20 & 0 & 0,0000 & 3 & 30 & 40 & 304,5960 \\
1 & 20 & 0,2 & 0,0000 & 3 & 30 & 60 & 372,4550 \\
1 & 20 & 0,51 & 21,0186 & 3 & 30 & 70 & 402,0590 \\
1 & 20 & 0,75 & 25,4887 & 3 & 30 & 80 & 429,5990 \\
1 & 20 & 1 & 29,3607 & 3 & 30 & 90 & 455,4530 \\
1 & 20 & 2 & 41,1176 & 3 & 30 & 150 & 596,8140 \\
1 & 20 & 3 & 50,1195 & 3 & 30 & 200 & 676,7780 \\
1 & 20 & 4 & 57,6988 & 3 & 30 & 250 & 755,8980 \\
1 & 20 & 6 & 70,3971 & 3 & 30 & 300 & 827,3070 \\
1 & 20 & 7 & 75,9362 & 3 & 30 & 400 & 953,7880 \\
1 & 20 & 8 & 81,0893 & 3 & 30 & 500 & 1064,8600 \\
1 & 20 & 10 & 90,5010 & 3 & 30 & 600 & 1164,9700 \\
\hline \multicolumn{2}{|r|}{} \\
\hline
\end{tabular}


Tabela A.1 - continua da página anterior

\begin{tabular}{|c|c|c|c|c|c|c|c|}
\hline $\begin{array}{l}\text { Pressão } \\
\text { bar (abs) }\end{array}$ & ${ }^{\circ} \mathrm{C}$ & $\begin{array}{l}\text { Pres.Dif. } \\
\mathrm{mmH}_{2} \mathrm{O} \\
\text { a } 68{ }^{\circ} \mathrm{F}\end{array}$ & $\mathrm{Nm}^{3} / \mathrm{h}$ & $\begin{array}{c}\text { Pressão } \\
\text { bar (abs) }\end{array}$ & Temp & $\begin{array}{l}\text { Pres.Dif. } \\
\mathrm{mmH}_{2} \mathrm{O} \\
\text { a } 68{ }^{\circ} \mathrm{F}\end{array}$ & $\begin{array}{l}\text { Vazão } \\
\mathrm{Nm}^{3} / \mathrm{h}\end{array}$ \\
\hline 1 & 20 & 11 & 94,8497 & 3 & 30 & 700 & 1256,7400 \\
\hline 1 & 20 & 12 & 99,0036 & 3 & 30 & 800 & 1341,8900 \\
\hline 1 & 20 & 13 & 102,9860 & 3 & 30 & 1000 & 1496,8100 \\
\hline 1 & 20 & 14 & 106,8180 & 4 & 30 & 0 & 0,0000 \\
\hline 1 & 20 & 15 & 110,5140 & 4 & 30 & 0,2 & 0,0000 \\
\hline 1 & 20 & 25 & 142,1930 & 4 & 30 & 0,51 & 40,9064 \\
\hline 1 & 20 & 30 & 155,5880 & 4 & 30 & 0,75 & 49,3780 \\
\hline 1 & 20 & 35 & 167,8970 & 4 & 30 & 2 & 79,8801 \\
\hline 1 & 20 & 40 & 179,3450 & 4 & 30 & 3 & 97,5298 \\
\hline 1 & 20 & 50 & 200,2460 & 4 & 30 & 4 & 112,3950 \\
\hline 1 & 20 & 70 & 236,4520 & 4 & 30 & 5 & 125,8830 \\
\hline 1 & 20 & 80 & 252,5680 & 4 & 30 & 7 & 148,1810 \\
\hline 1 & 20 & 90 & 267,6880 & 4 & 30 & 8 & 158,2970 \\
\hline 1 & 20 & 100 & 281,9730 & 4 & 30 & 9 & 167,7940 \\
\hline 1 & 20 & 150 & 344,3510 & 4 & 30 & 10 & 176,7750 \\
\hline 1 & 20 & 250 & 442,5590 & 4 & 30 & 11 & 185,3150 \\
\hline 1 & 20 & 300 & 483,8410 & 4 & 30 & 13 & 201,2970 \\
\hline 1 & 20 & 400 & 556,6310 & 4 & 30 & 14 & 208,8230 \\
\hline 1 & 20 & 500 & 620,1580 & 4 & 30 & 15 & 216,0840 \\
\hline 1 & 20 & 600 & 677,0490 & 4 & 30 & 20 & 249,1980 \\
\hline 1 & 20 & 700 & 728,8700 & 4 & 30 & 25 & 278,3550 \\
\hline 1 & 20 & 900 & 821,0730 & 4 & 30 & 30 & 304,7020 \\
\hline 1 & 20 & 1000 & 862,6860 & 4 & 30 & 35 & 328,9220 \\
\hline 2 & 20 & 0 & 0,0000 & 4 & 30 & 40 & 351,4570 \\
\hline 2 & 20 & 0,2 & 0,0000 & 4 & 30 & 50 & 392,6230 \\
\hline 2 & 20 & 0,51 & 29,6505 & 4 & 30 & 70 & 464,0110 \\
\hline 2 & 20 & 0,75 & 35,7528 & 4 & 30 & 80 & 495,8210 \\
\hline 2 & 20 & 2 & 57,7162 & 4 & 30 & 90 & 525,6870 \\
\hline
\end{tabular}


Tabela A.1 - continua da página anterior

\begin{tabular}{|c|c|c|c|c|c|c|c|}
\hline $\begin{array}{c}\text { Pressão } \\
\text { bar (abs) }\end{array}$ & ${ }^{\circ} \mathrm{C}$ & $\begin{array}{l}\text { Pres.Dif. } \\
\mathrm{mmH}_{2} \mathrm{O} \\
\text { a } 68^{\circ} \mathrm{F}\end{array}$ & $\mathrm{Nm}^{3} / \mathrm{h}$ & $\begin{array}{c}\text { Pressão } \\
\text { bar (abs) }\end{array}$ & Temp & $\begin{array}{l}\text { Pres.Dif. } \\
\mathrm{mmH}_{2} \mathrm{O} \\
\text { a } 68^{\circ} \mathrm{F}\end{array}$ & $\mathrm{Nm}^{3} / \mathrm{h}$ \\
\hline 2 & 20 & 3 & 70,4213 & 4 & 30 & 100 & 553,9230 \\
\hline 2 & 20 & 4 & 81,1207 & 4 & 30 & 150 & 677,4660 \\
\hline 2 & 20 & 6 & 99,0503 & 4 & 30 & 250 & 872,9530 \\
\hline 2 & 20 & 7 & 106,8730 & 4 & 30 & 300 & 955,5600 \\
\hline 2 & 20 & 8 & 114,1510 & 4 & 30 & 400 & 1101,9600 \\
\hline 2 & 20 & 9 & 120,9840 & 4 & 30 & 500 & 1230,6200 \\
\hline 2 & 20 & 10 & 127,4450 & 4 & 30 & 600 & 1346,6700 \\
\hline 2 & 20 & 12 & 139,4580 & 4 & 30 & 700 & 1453,1300 \\
\hline 2 & 20 & 13 & 145,0850 & 4 & 30 & 800 & 1551,9900 \\
\hline 2 & 20 & 14 & 150,4990 & 4 & 30 & 900 & 1644,7200 \\
\hline 2 & 20 & 15 & 155,7220 & 5 & 30 & 0 & 0,0000 \\
\hline 2 & 20 & 20 & 179,5370 & 5 & 30 & 0,2 & 0,0000 \\
\hline 2 & 20 & 30 & 219,4460 & 5 & 30 & 0,51 & 45,6179 \\
\hline 2 & 20 & 35 & 236,8570 & 5 & 30 & 0,75 & 55,0836 \\
\hline 2 & 20 & 40 & 253,0550 & 5 & 30 & 1 & 63,4238 \\
\hline 2 & 20 & 50 & 282,6390 & 5 & 30 & 2 & 89,1689 \\
\hline 2 & 20 & 60 & 309,3630 & 5 & 30 & 3 & 108,8940 \\
\hline 2 & 20 & 80 & 356,7650 & 5 & 30 & 4 & 125,5080 \\
\hline 2 & 20 & 90 & 378,2060 & 5 & 30 & 5 & 140,1360 \\
\hline 2 & 20 & 100 & 398,4740 & 5 & 30 & 6 & 153,3550 \\
\hline 2 & 20 & 150 & 487,0900 & 5 & 30 & 7 & 165,5060 \\
\hline 2 & 20 & 200 & 561,5970 & 5 & 30 & 9 & 187,4280 \\
\hline 2 & 20 & 300 & 686,1260 & 5 & 30 & 10 & 197,4670 \\
\hline 2 & 20 & 400 & 790,6030 & 5 & 30 & 11 & 207,0130 \\
\hline 2 & 20 & 500 & 882,2150 & 5 & 30 & 13 & 224,8770 \\
\hline 2 & 20 & 600 & 964,6530 & 5 & 30 & 14 & 233,2910 \\
\hline 2 & 20 & 700 & 1040,1100 & 5 & 30 & 15 & 241,4070 \\
\hline 2 & 20 & 900 & 1175,3700 & 5 & 30 & 20 & 278,4240 \\
\hline
\end{tabular}


Tabela A.1 - continua da página anterior

\begin{tabular}{|c|c|c|c|c|c|c|c|}
\hline $\begin{array}{l}\text { Pressão } \\
\text { bar (abs) }\end{array}$ & ${ }^{\circ} \mathrm{C}$ & $\begin{array}{l}\text { Pres.Dif. } \\
\mathrm{mmH}_{2} \mathrm{O} \\
\text { a } 68{ }^{\circ} \mathrm{F}\end{array}$ & $\mathrm{Nm}^{3} / \mathrm{h}$ & $\begin{array}{c}\text { Pressão } \\
\text { bar (abs) }\end{array}$ & Temp & $\begin{array}{l}\text { Pres.Dif. } \\
\mathrm{mmH}_{2} \mathrm{O} \\
\text { a } 68{ }^{\circ} \mathrm{F}\end{array}$ & $\mathrm{Nm}^{3} / \mathrm{h}$ \\
\hline 2 & 20 & 1000 & 1236,9000 & 5 & 30 & 30 & 340,4740 \\
\hline 3 & 20 & 0 & 0,0000 & 5 & 30 & 35 & 367,5510 \\
\hline 3 & 20 & 0,2 & 0,0000 & 5 & 30 & 40 & 392,7460 \\
\hline 3 & 20 & 0,51 & 36,1067 & 5 & 30 & 50 & 438,7720 \\
\hline 3 & 20 & 0,75 & 43,5699 & 5 & 30 & 70 & 518,5950 \\
\hline 3 & 20 & 1 & 50,1450 & 5 & 30 & 80 & 554,1670 \\
\hline 3 & 20 & 3 & 85,9839 & 5 & 30 & 90 & 587,5650 \\
\hline 3 & 20 & 4 & 99,0766 & 5 & 30 & 100 & 619,1440 \\
\hline 3 & 20 & 6 & 121,0190 & 5 & 30 & 150 & 757,3290 \\
\hline 3 & 20 & 7 & 130,5930 & 5 & 30 & 200 & 873,6750 \\
\hline 3 & 20 & 8 & 139,5010 & 5 & 30 & 300 & 1069,5200 \\
\hline 3 & 20 & 9 & 147,8650 & 5 & 30 & 400 & 1232,4400 \\
\hline 3 & 20 & 11 & 163,2940 & 5 & 30 & 500 & 1376,5700 \\
\hline 3 & 20 & 12 & 170,4780 & 5 & 30 & 600 & 1506,6100 \\
\hline 3 & 20 & 13 & 177,3680 & 5 & 30 & 700 & 1626,0100 \\
\hline 3 & 20 & 14 & 183,9950 & 5 & 30 & 800 & 1737,2800 \\
\hline 3 & 20 & 20 & 219,5460 & 5 & 30 & 1000 & 1940,0900 \\
\hline 3 & 20 & 25 & 245,2180 & 1 & 40 & 0 & 0,0000 \\
\hline 3 & 20 & 30 & 268,4160 & 1 & 40 & 0,2 & 0,0000 \\
\hline 3 & 20 & 35 & 289,7390 & 1 & 40 & 0,51 & 20,3493 \\
\hline 3 & 20 & 40 & 309,5780 & 1 & 40 & 0,75 & 24,6769 \\
\hline 3 & 20 & 50 & 345,8170 & 1 & 40 & 2 & 39,8930 \\
\hline 3 & 20 & 60 & 378,5590 & 1 & 40 & 3 & 48,6135 \\
\hline 3 & 20 & 70 & 408,6520 & 1 & 40 & 4 & 55,9556 \\
\hline 3 & 20 & 80 & 436,6480 & 1 & 40 & 6 & 68,2560 \\
\hline 3 & 20 & 90 & 462,9300 & 1 & 40 & 7 & 73,6214 \\
\hline 3 & 20 & 150 & 596,4640 & 1 & 40 & 8 & 78,6128 \\
\hline 3 & 20 & 200 & 687,9180 & 1 & 40 & 10 & 87,7289 \\
\hline
\end{tabular}


Tabela A.1 - continua da página anterior

\begin{tabular}{|c|c|c|c|c|c|c|c|}
\hline $\begin{array}{c}\text { Pressão } \\
\text { bar (abs) }\end{array}$ & ${ }^{\circ} \mathrm{C}$ & $\begin{array}{l}\text { Pres.Dif. } \\
\mathrm{mmH}_{2} \mathrm{O} \\
\text { a } 68^{\circ} \mathrm{F}\end{array}$ & $\mathrm{Nm}^{3} / \mathrm{h}$ & $\begin{array}{c}\text { Pressão } \\
\text { bar (abs) }\end{array}$ & ${ }^{\circ} \mathrm{C}$ & $\begin{array}{l}\text { Pres.Dif. } \\
\mathrm{mmH}_{2} \mathrm{O} \\
\text { a } 68{ }^{\circ} \mathrm{F}\end{array}$ & $\begin{array}{l}\text { Vazão } \\
\mathrm{Nm}^{3} / \mathrm{h}\end{array}$ \\
\hline 3 & 20 & 250 & 768,3480 & 1 & 40 & 11 & 91,9411 \\
\hline 3 & 20 & 300 & 840,9400 & 1 & 40 & 12 & 95,9644 \\
\hline 3 & 20 & 500 & 1082,4300 & 1 & 40 & 13 & 99,8221 \\
\hline 3 & 20 & 600 & 1184,2000 & 1 & 40 & 14 & 103,5330 \\
\hline 3 & 20 & 700 & 1277,4900 & 1 & 40 & 15 & 107,1130 \\
\hline 3 & 20 & 900 & 1445,1100 & 1 & 40 & 20 & 123,4320 \\
\hline 3 & 20 & 1000 & 1521,5400 & 1 & 40 & 30 & 150,7690 \\
\hline 4 & 20 & 0,2 & 0,0000 & 1 & 40 & 35 & 162,6890 \\
\hline 4 & 20 & 0,51 & 41,5456 & 1 & 40 & 40 & 173,7770 \\
\hline 4 & 20 & 0,75 & 50,1560 & 1 & 40 & 60 & 212,2960 \\
\hline 4 & 20 & 1 & 57,7424 & 1 & 40 & 70 & 229,0830 \\
\hline 4 & 20 & 2 & 81,1595 & 1 & 40 & 80 & 244,6910 \\
\hline 4 & 20 & 3 & 99,0999 & 1 & 40 & 90 & 259,3330 \\
\hline 4 & 20 & 5 & 127,5140 & 1 & 40 & 100 & 273,1680 \\
\hline 4 & 20 & 6 & 139,5360 & 1 & 40 & 150 & 333,5770 \\
\hline 4 & 20 & 7 & 150,5870 & 1 & 40 & 250 & 428,6810 \\
\hline 4 & 20 & 8 & 160,8700 & 1 & 40 & 300 & 468,6590 \\
\hline 4 & 20 & 9 & 170,5240 & 1 & 40 & 400 & 539,1460 \\
\hline 4 & 20 & 11 & 188,3350 & 1 & 40 & 500 & 600,6640 \\
\hline 4 & 20 & 12 & 196,6280 & 1 & 40 & 700 & 705,9360 \\
\hline 4 & 20 & 13 & 204,5810 & 1 & 40 & 800 & 752,1950 \\
\hline 4 & 20 & 15 & 219,6130 & 1 & 40 & 900 & 795,2210 \\
\hline 4 & 20 & 20 & 253,2740 & 1 & 40 & 1000 & 835,5160 \\
\hline 4 & 20 & 25 & 282,9140 & 2 & 40 & 0 & 0,0000 \\
\hline 4 & 20 & 30 & 309,6970 & 2 & 40 & 0,2 & 0,0000 \\
\hline 4 & 20 & 40 & 357,2270 & 2 & 40 & 0,75 & 34,6932 \\
\hline 4 & 20 & 50 & 399,0750 & 2 & 40 & 1 & 39,9005 \\
\hline 4 & 20 & 60 & 436,8890 & 2 & 40 & 2 & 55,9685 \\
\hline
\end{tabular}


Tabela A.1 - continua da página anterior

\begin{tabular}{|c|c|c|c|c|c|c|c|}
\hline $\begin{array}{l}\text { Pressão } \\
\text { bar (abs) }\end{array}$ & ${ }^{\circ} \mathrm{C}$ & $\begin{array}{l}\text { Pres.Dif. } \\
\mathrm{mmH}_{2} \mathrm{O} \\
\text { a } 68{ }^{\circ} \mathrm{F}\end{array}$ & $\mathrm{Nm}^{3} / \mathrm{h}$ & $\begin{array}{c}\text { Pressão } \\
\text { bar (abs) }\end{array}$ & Temp & $\begin{array}{l}\text { Pres.Dif. } \\
\mathrm{mmH}_{2} \mathrm{O} \\
\text { a } 68{ }^{\circ} \mathrm{F}\end{array}$ & $\mathrm{Nm}^{3} / \mathrm{h}$ \\
\hline 4 & 20 & 70 & 471,6470 & 2 & 40 & 4 & 78,6377 \\
\hline 4 & 20 & 80 & 503,9840 & 2 & 40 & 5 & 87,7605 \\
\hline 4 & 20 & 100 & 563,0500 & 2 & 40 & 6 & 96,0030 \\
\hline 4 & 20 & 150 & 688,6430 & 2 & 40 & 7 & 103,5790 \\
\hline 4 & 20 & 200 & 794,3630 & 2 & 40 & 8 & 110,6280 \\
\hline 4 & 20 & 250 & 887,7350 & 2 & 40 & 9 & 117,2460 \\
\hline 4 & 20 & 300 & 971,3550 & 2 & 40 & 11 & 129,4530 \\
\hline 4 & 20 & 500 & 1250,9900 & 2 & 40 & 12 & 135,1370 \\
\hline 4 & 20 & 600 & 1368,9600 & 2 & 40 & 13 & 140,5870 \\
\hline 4 & 20 & 700 & 1477,1900 & 2 & 40 & 14 & 145,8300 \\
\hline 4 & 20 & 800 & 1577,7100 & 2 & 40 & 15 & 150,8870 \\
\hline 4 & 20 & 900 & 1672,2000 & 2 & 40 & 20 & 163,9510 \\
\hline 5 & 20 & 0 & 0,0000 & 2 & 40 & 25 & 194,2550 \\
\hline 5 & 20 & 0,2 & 0,0000 & 2 & 40 & 30 & 212,5990 \\
\hline 5 & 20 & 0,51 & 46,3359 & 2 & 40 & 35 & 229,4600 \\
\hline 5 & 20 & 1 & 64,4348 & 2 & 40 & 40 & 245,1450 \\
\hline 5 & 20 & 2 & 90,6045 & 2 & 40 & 50 & 263,7930 \\
\hline 5 & 20 & 3 & 110,6550 & 2 & 40 & 70 & 323,4540 \\
\hline 5 & 20 & 4 & 127,5440 & 2 & 40 & 80 & 345,5740 \\
\hline 5 & 20 & 5 & 142,4140 & 2 & 40 & 90 & 366,3370 \\
\hline 5 & 20 & 7 & 168,204 & 2 & 40 & 100 & 385,9620 \\
\hline 5 & 20 & 8 & 179,698 & 2 & 40 & 150 & 471,7710 \\
\hline 5 & 20 & 9 & 190,49 & 2 & 40 & 250 & 607,3200 \\
\hline 5 & 20 & 10 & 200,695 & 2 & 40 & 300 & 664,4990 \\
\hline 5 & 20 & 11 & 210,399 & 2 & 40 & 400 & 765,6620 \\
\hline 5 & 20 & 12 & 219,669 & 2 & 40 & 500 & 854,3680 \\
\hline 5 & 20 & 14 & 237,1120 & 2 & 40 & 600 & 934,1900 \\
\hline 5 & 20 & 15 & 245,3630 & 2 & 40 & 700 & 1007,2500 \\
\hline
\end{tabular}


Tabela A.1 - continua da página anterior

\begin{tabular}{|c|c|c|c|c|c|c|c|}
\hline $\begin{array}{c}\text { Pressão } \\
\text { bar (abs) }\end{array}$ & ${ }^{\circ} \mathrm{C}$ & $\begin{array}{l}\text { Pres.Dif. } \\
\mathrm{mmH}_{2} \mathrm{O} \\
\text { a } 68^{\circ} \mathrm{F}\end{array}$ & $\mathrm{Nm}^{3} / \mathrm{h}$ & $\begin{array}{c}\text { Pressão } \\
\text { bar (abs) }\end{array}$ & ${ }^{\circ} \mathrm{C}$ & $\begin{array}{l}\text { Pres.Dif. } \\
\mathrm{mmH}_{2} \mathrm{O} \\
\text { a } 68{ }^{\circ} \mathrm{F}\end{array}$ & $\begin{array}{l}\text { Vazão } \\
\mathrm{Nm}^{3} / \mathrm{h}\end{array}$ \\
\hline 5 & 20 & 20 & 282,9940 & 2 & 40 & 800 & 1074,9400 \\
\hline 5 & 20 & 25 & 316,1300 & 2 & 40 & 1000 & 1197,7900 \\
\hline 5 & 20 & 35 & 373,6010 & 3 & 40 & 0 & 0,0000 \\
\hline 5 & 20 & 40 & 399,2140 & 3 & 40 & 0,2 & 0,0000 \\
\hline 5 & 20 & 50 & 446,0060 & 3 & 40 & 0,51 & 35,0337 \\
\hline 5 & 20 & 60 & 488,2880 & 3 & 40 & 0,75 & 42,2629 \\
\hline 5 & 20 & 80 & 563,3190 & 3 & 40 & 1 & 48,6315 \\
\hline 5 & 20 & 90 & 597,2720 & 3 & 40 & 2 & 68,2864 \\
\hline 5 & 20 & 100 & 629,3760 & 3 & 40 & 3 & 83,3421 \\
\hline 5 & 20 & 150 & 769,8600 & 3 & 40 & 4 & 96,0218 \\
\hline 5 & 20 & 200 & 888,1420 & 3 & 40 & 5 & 107,1850 \\
\hline 5 & 20 & 300 & 1086,2300 & 3 & 40 & 6 & 117,2710 \\
\hline 5 & 20 & 400 & 1252,8800 & 3 & 40 & 7 & 126,5430 \\
\hline 5 & 20 & 500 & 1399,4100 & 3 & 40 & 10 & 150,9280 \\
\hline 5 & 20 & 600 & 1531,6200 & 3 & 40 & 11 & 158,2100 \\
\hline 5 & 20 & 700 & 1653,2400 & 3 & 40 & 12 & 165,1670 \\
\hline 5 & 20 & 800 & 1766,3700 & 3 & 40 & 13 & 171,8380 \\
\hline 5 & 20 & 900 & 1872,4300 & 3 & 40 & 14 & 178,2560 \\
\hline 5 & 20 & 1000 & 1972,5700 & 3 & 40 & 15 & 184,4470 \\
\hline 1 & 30 & 0 & 0,0000 & 3 & 40 & 20 & 212,6810 \\
\hline 1 & 30 & 0,2 & 0,0000 & 3 & 40 & 25 & 237,5400 \\
\hline 1 & 30 & 0,75 & 25,0726 & 3 & 40 & 35 & 280,6490 \\
\hline 1 & 30 & 1 & 28,9206 & 3 & 40 & 40 & 299,8590 \\
\hline 1 & 30 & 2 & 40,4898 & 3 & 40 & 50 & 334,9490 \\
\hline 1 & 30 & 3 & 49,3475 & 3 & 40 & 60 & 366,6520 \\
\hline 1 & 30 & 4 & 56,8052 & 3 & 40 & 70 & 395,7900 \\
\hline 1 & 30 & 5 & 63,3694 & 3 & 40 & 90 & 448,3450 \\
\hline 1 & 30 & 7 & 74,7497 & 3 & 40 & 100 & 472,4030 \\
\hline
\end{tabular}


Tabela A.1 - continua da página anterior

\begin{tabular}{|c|c|c|c|c|c|c|c|}
\hline $\begin{array}{c}\text { Pressão } \\
\text { bar (abs) }\end{array}$ & ${ }^{\circ} \mathrm{C}$ & $\begin{array}{l}\text { Pres.Dif. } \\
\mathrm{mmH}_{2} \mathrm{O} \\
\text { a } 68{ }^{\circ} \mathrm{F}\end{array}$ & $\begin{array}{l}\text { Vazão } \\
\mathrm{Nm}^{3} / \mathrm{h}\end{array}$ & $\begin{array}{c}\text { Pressão } \\
\text { bar (abs) }\end{array}$ & Temp & $\begin{array}{l}\text { Pres.Dif. } \\
\mathrm{mmH}_{2} \mathrm{O} \\
\text { a } 68^{\circ} \mathrm{F}\end{array}$ & $\begin{array}{l}\text { Vazão } \\
\mathrm{Nm}^{3} / \mathrm{h}\end{array}$ \\
\hline 1 & 30 & 8 & 79,8199 & 3 & 40 & 150 & 577,6390 \\
\hline 1 & 30 & 9 & 84,5798 & 3 & 40 & 200 & 666,1870 \\
\hline 1 & 30 & 10 & 89,0800 & 3 & 40 & 250 & 744,0610 \\
\hline 1 & 30 & 11 & 93,3588 & 3 & 40 & 300 & 814,3450 \\
\hline 1 & 30 & 13 & 101,3650 & 3 & 40 & 400 & 938,8340 \\
\hline 1 & 30 & 14 & 105,1340 & 3 & 40 & 500 & 1048,1600 \\
\hline 1 & 30 & 15 & 108,7700 & 3 & 40 & 600 & 1146,6900 \\
\hline 1 & 30 & 25 & 139,9390 & 3 & 40 & 700 & 1237,0100 \\
\hline 1 & 30 & 30 & 153,1180 & 3 & 40 & 800 & 1320,8200 \\
\hline 1 & 30 & 35 & 165,2280 & 3 & 40 & 900 & 1399,3000 \\
\hline 1 & 30 & 40 & 176,4910 & 4 & 40 & 0 & 0,0000 \\
\hline 1 & 30 & 50 & 197,0540 & 4 & 40 & 0,2 & 0,0000 \\
\hline 1 & 30 & 60 & 215,6210 & 4 & 40 & 0,51 & 40,2993 \\
\hline 1 & 30 & 70 & 232,6750 & 4 & 40 & 0,75 & 48,6388 \\
\hline 1 & 30 & 90 & 263,4060 & 4 & 40 & 1 & 55,9862 \\
\hline 1 & 30 & 100 & 277,4600 & 4 & 40 & 2 & 78,6644 \\
\hline 1 & 30 & 150 & 338,8290 & 4 & 40 & 3 & 96,0377 \\
\hline 1 & 30 & 200 & 390,3090 & 4 & 40 & 4 & 110,6700 \\
\hline 1 & 30 & 250 & 435,4460 & 4 & 40 & 6 & 135,1940 \\
\hline 1 & 30 & 300 & 476,0600 & 4 & 40 & 7 & 145,8950 \\
\hline 1 & 30 & 400 & 547,6700 & 4 & 40 & 8 & 155,8510 \\
\hline 1 & 30 & 600 & 666,1360 & 4 & 40 & 9 & 165,2000 \\
\hline 1 & 30 & 700 & 717,1160 & 4 & 40 & 10 & 174,0400 \\
\hline 1 & 30 & 800 & 764,1120 & 4 & 40 & 11 & 182,4450 \\
\hline 1 & 30 & 900 & 807,8230 & 4 & 40 & 13 & 198,1760 \\
\hline 1 & 30 & 1000 & 848,7610 & 4 & 40 & 14 & 205,5840 \\
\hline 2 & 30 & 0 & 0,0000 & 4 & 40 & 15 & 212,7310 \\
\hline 2 & 30 & 0,51 & 29,2048 & 4 & 40 & 20 & 245,3230 \\
\hline
\end{tabular}


Tabela A.1 - continua da página anterior

\begin{tabular}{|c|c|c|c|c|c|c|c|}
\hline $\begin{array}{c}\text { Pressão } \\
\text { bar (abs) }\end{array}$ & Temp & $\begin{array}{l}\text { Pres.Dif. } \\
\mathrm{mmH}_{2} \mathrm{O} \\
\text { a } 68^{\circ} \mathrm{F}\end{array}$ & $\mathrm{Nm}^{3} / \mathrm{h}$ & $\begin{array}{c}\text { Pressão } \\
\text { bar (abs) }\end{array}$ & Temp & $\begin{array}{l}\text { Pres.Dif. } \\
\mathrm{mmH}_{2} \mathrm{O} \\
\text { a } 68^{\circ} \mathrm{F}\end{array}$ & $\mathrm{Nm}^{3} / \mathrm{h}$ \\
\hline 2 & 30 & 0,75 & 35,2095 & 4 & 40 & 25 & 274,0210 \\
\hline 2 & 30 & 1 & 40,4987 & 4 & 40 & 35 & 323,7920 \\
\hline 2 & 30 & 2 & 56,8202 & 4 & 40 & 40 & 345,9730 \\
\hline 2 & 30 & 3 & 69,3209 & 4 & 40 & 50 & 386,4910 \\
\hline 2 & 30 & 5 & 89,1150 & 4 & 40 & 60 & 423,1020 \\
\hline 2 & 30 & 6 & 97,4882 & 4 & 40 & 70 & 456,7530 \\
\hline 2 & 30 & 7 & 105,1840 & 4 & 40 & 80 & 488,0620 \\
\hline 2 & 30 & 8 & 112,3450 & 4 & 40 & 90 & 517,4560 \\
\hline 2 & 30 & 9 & 119,0680 & 4 & 40 & 100 & 545,2480 \\
\hline 2 & 30 & 10 & 125,4240 & 4 & 40 & 150 & 666,8420 \\
\hline 2 & 30 & 11 & 131,4690 & 4 & 40 & 250 & 859,2430 \\
\hline 2 & 30 & 13 & 142,7790 & 4 & 40 & 300 & 940,5460 \\
\hline 2 & 30 & 14 & 148,1050 & 4 & 40 & 400 & 1084,6300 \\
\hline 2 & 30 & 15 & 153,2440 & 4 & 40 & 500 & 1211,2600 \\
\hline 2 & 30 & 20 & 176,6730 & 4 & 40 & 600 & 1325,4700 \\
\hline 2 & 30 & 30 & 215,9360 & 4 & 40 & 700 & 1430,2600 \\
\hline 2 & 30 & 35 & 233,0650 & 4 & 40 & 900 & 1618,7300 \\
\hline 2 & 30 & 40 & 249,0010 & 4 & 40 & 1000 & 1704,9200 \\
\hline 2 & 30 & 50 & 278,1050 & 5 & 40 & 0 & 0,0000 \\
\hline 2 & 30 & 60 & 304,3960 & 5 & 40 & 0,2 & 0,0000 \\
\hline 2 & 30 & 70 & 328,5560 & 5 & 40 & 0,51 & 44,9358 \\
\hline 2 & 30 & 80 & 351,0290 & 5 & 40 & 0,75 & 54,2536 \\
\hline 2 & 30 & 100 & 392,0610 & 5 & 40 & 1 & 62,4633 \\
\hline 2 & 30 & 150 & 479,2380 & 5 & 40 & 2 & 87,8048 \\
\hline 2 & 30 & 200 & 552,5350 & 5 & 40 & 4 & 123,5730 \\
\hline 2 & 30 & 250 & 616,9490 & 5 & 40 & 5 & 137,9710 \\
\hline 2 & 30 & 300 & 675,0400 & 5 & 40 & 6 & 150,9820 \\
\hline 2 & 30 & 400 & 777,8190 & 5 & 40 & 7 & 162,9420 \\
\hline
\end{tabular}


Tabela A.1 - continua da página anterior

\begin{tabular}{|c|c|c|c|c|c|c|c|}
\hline $\begin{array}{l}\text { Pressão } \\
\text { bar (abs) }\end{array}$ & Temp & $\begin{array}{l}\text { Pres.Dif. } \\
\mathrm{mmH}_{2} \mathrm{O} \\
\text { a } 68^{\circ} \mathrm{F}\end{array}$ & $\mathrm{Nm}^{3} / \mathrm{h}$ & $\begin{array}{c}\text { Pressão } \\
\text { bar (abs) }\end{array}$ & Temp & $\begin{array}{l}\text { Pres.Dif. } \\
\mathrm{mmH}_{2} \mathrm{O} \\
\text { a } 68{ }^{\circ} \mathrm{F}\end{array}$ & $\begin{array}{l}\text { Vazão } \\
\mathrm{Nm}^{3} / \mathrm{h}\end{array}$ \\
\hline 2 & 30 & 500 & 867,9420 & 5 & 40 & 8 & 174,0700 \\
\hline 2 & 30 & 600 & 949,0390 & 5 & 40 & 9 & 184,5190 \\
\hline 2 & 30 & 800 & 1092,0400 & 5 & 40 & 11 & 203,7950 \\
\hline 2 & 30 & 900 & 1156,3300 & 5 & 40 & 12 & 212,7710 \\
\hline 2 & 30 & 1000 & 1216,8500 & 5 & 40 & 13 & 221,3780 \\
\hline 3 & 30 & 0 & 0,0000 & 5 & 40 & 14 & 229,6590 \\
\hline 3 & 30 & 0,2 & 0,0000 & 5 & 40 & 15 & 237,6470 \\
\hline 3 & 30 & 0,51 & 35,5565 & 5 & 40 & 20 & 274,0800 \\
\hline 3 & 30 & 1 & 49,3689 & 5 & 40 & 25 & 306,1610 \\
\hline 3 & 30 & 2 & 69,3350 & 5 & 40 & 30 & 335,1510 \\
\hline 3 & 30 & 3 & 84,6295 & 5 & 40 & 40 & 386,5980 \\
\hline 3 & 30 & 4 & 97,5105 & 5 & 40 & 50 & 431,8980 \\
\hline 3 & 30 & 5 & 108,8510 & 5 & 40 & 60 & 472,8320 \\
\hline 3 & 30 & 6 & 119,0980 & 5 & 40 & 70 & 510,4600 \\
\hline 3 & 30 & 7 & 128,5170 & 5 & 40 & 80 & 545,4700 \\
\hline 3 & 30 & 9 & 145,5090 & 5 & 40 & 100 & 609,4190 \\
\hline 3 & 30 & 10 & 153,2900 & 5 & 40 & 150 & 745,4200 \\
\hline 3 & 30 & 11 & 160,6880 & 5 & 40 & 200 & 859,9250 \\
\hline 3 & 30 & 12 & 167,7560 & 5 & 40 & 300 & 1051,6900 \\
\hline 3 & 30 & 13 & 174,5330 & 5 & 40 & 400 & 1213,0100 \\
\hline 3 & 30 & 14 & 181,0530 & 5 & 40 & 500 & 1354,8600 \\
\hline 3 & 30 & 20 & 216,0270 & 5 & 40 & 700 & 1600,3200 \\
\hline 3 & 30 & 25 & 241,2820 & 5 & 40 & 800 & 1709,6300 \\
\hline 3 & 30 & 30 & 264,1030 & 5 & 40 & 900 & 1812,2900 \\
\hline 3 & 30 & 35 & 285,0790 & 5 & 40 & 1000 & 1909,2200 \\
\hline
\end{tabular}


Tabela A.2: Dados de validação da rede neural com 8 neurônios e os erros associados a cada padrão.

\begin{tabular}{|c|c|c|c|c|c|}
\hline $\begin{array}{c}\text { Pressão } \\
\text { bar (abs) }\end{array}$ & ${ }^{\circ} \mathrm{C}$ & $\begin{array}{l}\text { Pres.Dif. } \\
\mathrm{mmH}_{2} \mathrm{O} \\
\text { a } 68^{\circ} \mathrm{F}\end{array}$ & $\mathrm{Nm}^{3} / \mathrm{h}$ & $\mathrm{Nm}^{3} / \mathrm{h}$ & erro \\
\hline 1 & 20 & 5 & $-64,37$ & 63,24 & 1,76 \\
\hline 1 & 20 & 9 & 85,93 & 86,10 & 0,20 \\
\hline 1 & 20 & 20 & 127,36 & 129,39 & 1,59 \\
\hline 1 & 20 & 60 & 219,12 & 220,40 & 0,58 \\
\hline 1 & 20 & 200 & 396,68 & 394,14 & 0,64 \\
\hline 1 & 20 & 800 & 776,64 & 770,74 & 0,76 \\
\hline 2 & 20 & 1 & 41,13 & 57,71 & 40,31 \\
\hline 2 & 20 & 5 & 90,54 & 90,88 & 0,38 \\
\hline 2 & 20 & 11 & 133,59 & 132,45 & 0,85 \\
\hline 2 & 20 & 25 & 200,50 & 201,02 & 0,26 \\
\hline 2 & 20 & 70 & 333,92 & 333,22 & 0,21 \\
\hline 2 & 20 & 250 & 627,08 & 628,59 & 0,24 \\
\hline 2 & 20 & 800 & 1110,02 & 1100,40 & 0,87 \\
\hline 3 & 20 & 2 & 70,44 & 80,50 & 14,28 \\
\hline 3 & 20 & 5 & 110,60 & 111,36 & 0,69 \\
\hline 3 & 20 & 10 & 155,77 & 155,06 & 0,46 \\
\hline 3 & 20 & 15 & 190,39 & 190,15 & 0,12 \\
\hline 3 & 20 & 60 & 378,56 & 377,87 & 0,18 \\
\hline 3 & 20 & 100 & 487,78 & 491,37 & 0,74 \\
\hline 3 & 20 & 400 & 969,52 & 967,15 & 0,24 \\
\hline 3 & 20 & 800 & 1364,06 & 1355,98 & 0,59 \\
\hline 4 & 20 & 0 & 0,00 & 68,77 & $\# \mathrm{DIV} / 0$ ! \\
\hline 4 & 20 & 4 & 114,21 & 116,91 & 2,36 \\
\hline 4 & 20 & 10 & 179,65 & 178,03 & 0,90 \\
\hline 4 & 20 & 35 & 334,32 & 335,00 & 0,21 \\
\hline 4 & 20 & 90 & 534,35 & 535,36 & 0,19 \\
\hline
\end{tabular}


Tabela A.2 - continua da página anterior

\begin{tabular}{|c|c|c|c|c|c|}
\hline $\begin{array}{c}\text { Pressão } \\
\text { bar (abs) }\end{array}$ & Temp & $\begin{array}{l}\text { Pres.Dif. } \\
\mathrm{mmH}_{2} \mathrm{O} \\
\text { a } 68{ }^{\circ} \mathrm{F}\end{array}$ & $\mathrm{Nm}^{3} / \mathrm{h}$ & $\mathrm{Nm}^{3} / \mathrm{h}$ & erro \\
\hline 4 & 20 & 400 & 1120,19 & 1118,16 & 0,18 \\
\hline 4 & 20 & 1000 & 1761,38 & 1762,01 & 0,04 \\
\hline 5 & 20 & 1 & 55,96 & 90,40 & 61,55 \\
\hline 5 & 20 & 6 & 155,85 & 155,92 & 0,04 \\
\hline 5 & 20 & 13 & 228,56 & 230,09 & 0,67 \\
\hline 5 & 20 & 30 & 346,07 & 348,93 & 0,82 \\
\hline 5 & 20 & 70 & 527,16 & 520,64 & 1,24 \\
\hline 5 & 20 & 250 & 992,23 & 991,69 & 0,05 \\
\hline 1 & 30 & 1 & 20,68 & 35,06 & 69,55 \\
\hline 1 & 30 & 6 & 69,30 & 69,91 & 0,89 \\
\hline 1 & 30 & 12 & 97,45 & 98,53 & 1,11 \\
\hline 1 & 30 & 20 & 125,35 & 127,86 & 2,01 \\
\hline 1 & 30 & 80 & 248,53 & 248,47 & 0,02 \\
\hline 1 & 30 & 500 & 610,17 & 609,97 & 0,03 \\
\hline 2 & 30 & 0 & 0,00 & 49,88 & \#DIV $/ 0$ ! \\
\hline 2 & 30 & 4 & 79,85 & 82,19 & 2,93 \\
\hline 2 & 30 & 12 & 137,24 & 137,72 & 0,35 \\
\hline 2 & 30 & 25 & 197,30 & 197,44 & 0,07 \\
\hline 2 & 30 & 90 & 372,12 & 370,04 & 0,56 \\
\hline 2 & 30 & 700 & 1023,27 & 1018,14 & 0,50 \\
\hline 3 & 30 & 1 & 42,90 & 67,48 & 57,29 \\
\hline 3 & 30 & 8 & 137,28 & 136,46 & 0,60 \\
\hline 3 & 30 & 15 & 187,34 & 187,93 & 0,31 \\
\hline 3 & 30 & 50 & 340,25 & 339,78 & 0,14 \\
\hline 3 & 30 & 100 & 479,90 & 480,90 & 0,21 \\
\hline 3 & 30 & 900 & 1421,63 & 1416,83 & 0,34 \\
\hline 4 & 30 & 1 & 56,84 & 79,43 & 39,73 \\
\hline 4 & 30 & 6 & 137,31 & 135,78 & 1,11 \\
\hline
\end{tabular}


Tabela A.2 - continua da página anterior

\begin{tabular}{|c|c|c|c|c|c|}
\hline $\begin{array}{l}\text { Pressão } \\
\text { bar (abs) }\end{array}$ & ${ }^{\circ} \mathrm{C}$ & $\begin{array}{l}\text { Pres.Dif. } \\
\mathrm{mmH}_{2} \mathrm{O} \\
\text { a } 68^{\circ} \mathrm{F}\end{array}$ & $\mathrm{Nm}^{3} / \mathrm{h}$ & $\mathrm{Nm}^{3} / \mathrm{h}$ & erro \\
\hline 4 & 30 & 12 & 193,47 & 192,02 & 0,75 \\
\hline 4 & 30 & 60 & 429,82 & 426,22 & 0,84 \\
\hline 4 & 30 & 200 & 781,46 & 780,92 & 0,07 \\
\hline 4 & 30 & 1000 & 1732,43 & 1730,95 & 0,09 \\
\hline 5 & 30 & 8 & 176,81 & 176,13 & 0,39 \\
\hline 5 & 30 & 12 & 216,13 & 216,82 & 0,32 \\
\hline 5 & 30 & 25 & 311,02 & 315,81 & 1,54 \\
\hline 5 & 30 & 60 & 480,36 & 475,98 & 0,91 \\
\hline 5 & 30 & 250 & 976,06 & 974,70 & 0,14 \\
\hline 5 & 30 & 900 & 1841,60 & 1838,95 & 0,14 \\
\hline 1 & 40 & 1 & 28,49 & 40,14 & 40,86 \\
\hline 1 & 40 & 5 & 62,42 & 64,38 & 3,15 \\
\hline 1 & 40 & 9 & 83,30 & 85,41 & 2,54 \\
\hline 1 & 40 & 25 & 137,80 & 141,08 & 2,39 \\
\hline 1 & 40 & 50 & 194,02 & 195,85 & 0,94 \\
\hline 1 & 40 & 200 & 384,25 & 383,08 & 0,31 \\
\hline 1 & 40 & 600 & 655,76 & 655,78 & 0,00 \\
\hline 2 & 40 & 1 & 28,78 & 52,80 & 83,46 \\
\hline 2 & 40 & 3 & 68,27 & 73,49 & 7,64 \\
\hline 2 & 40 & 10 & 123,50 & 123,45 & 0,04 \\
\hline 2 & 40 & 60 & 299,67 & 295,83 & 1,28 \\
\hline 2 & 40 & 200 & 543,92 & 544,28 & 0,07 \\
\hline 2 & 40 & 900 & 1138,22 & 1135,73 & 0,22 \\
\hline 3 & 40 & 8 & 135,17 & 134,78 & 0,28 \\
\hline 3 & 40 & 9 & 143,27 & 143,24 & 0,02 \\
\hline 3 & 40 & 30 & 260,00 & 261,01 & 0,39 \\
\hline 3 & 40 & 80 & 422,90 & 422,16 & 0,17 \\
\hline 3 & 40 & 1000 & 1473,29 & 1472,29 & 0,07 \\
\hline
\end{tabular}


Tabela A.2 - continua da página anterior

\begin{tabular}{|c|c|c|c|c|c|}
\hline $\begin{array}{l}\text { Pressão } \\
\text { bar (abs) }\end{array}$ & Temp & $\begin{array}{l}\text { Pres.Dif. } \\
\mathrm{mmH}_{2} \mathrm{O} \\
\text { a } 68^{\circ} \mathrm{F}\end{array}$ & $\mathrm{Nm}^{3} / \mathrm{h}$ & $\mathrm{Nm}^{3} / \mathrm{h}$ & erro \\
\hline 4 & 40 & 5 & 123,55 & 123,78 & 0,19 \\
\hline 4 & 40 & 12 & 190,48 & 189,72 & 0,40 \\
\hline 4 & 40 & 30 & 299,95 & 301,60 & 0,55 \\
\hline 4 & 40 & 200 & 769,19 & 765,24 & 0,51 \\
\hline 4 & 40 & 800 & 1527,55 & 1527,88 & 0,02 \\
\hline 5 & 40 & 3 & 107,22 & 113,93 & 6,25 \\
\hline 5 & 40 & 10 & 194,40 & 192,88 & 0,78 \\
\hline 5 & 40 & 35 & 361,80 & 364,69 & 0,80 \\
\hline 5 & 40 & 90 & 578,34 & 578,31 & 0,01 \\
\hline 5 & 40 & 250 & 960,69 & 957,71 & 0,31 \\
\hline 5 & 40 & 600 & 1482,84 & 1483,13 & 0,02 \\
\hline
\end{tabular}

A estratégia mostrando os blocos para o primeiro cenário é mostrada a seguir na figura A.1 


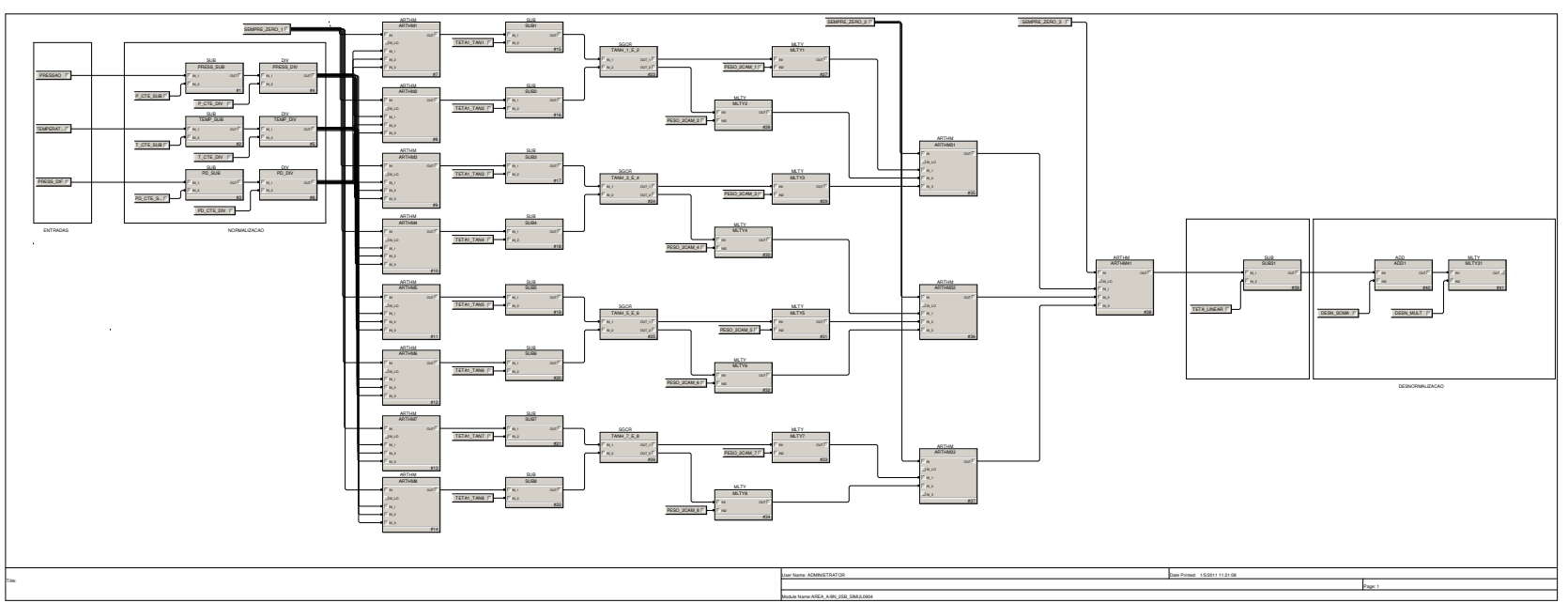

Figura A.1: Primeiro cenário implementado em ambiente foundation fieldbus. 


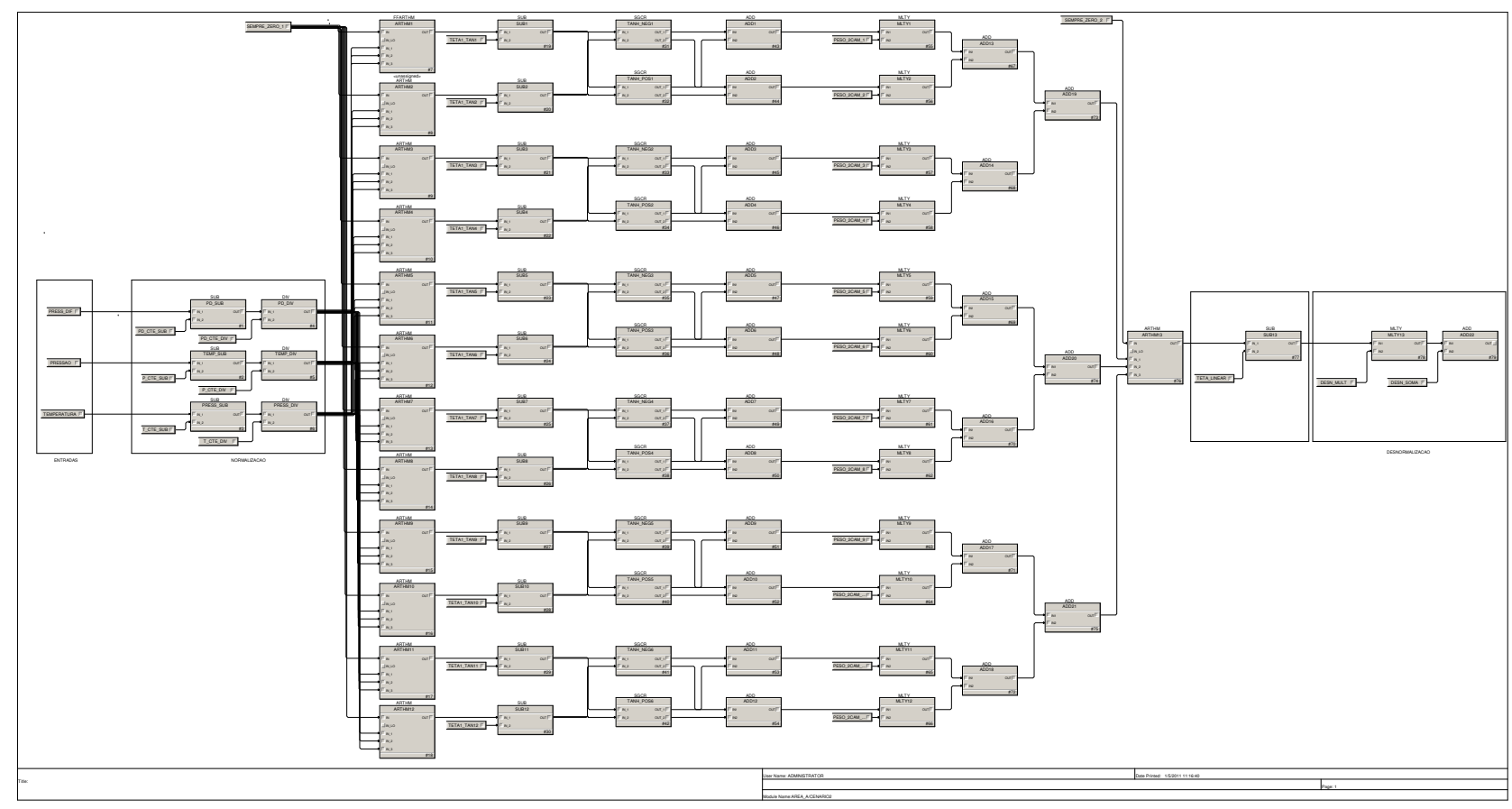

Figura A.2: Segundo cenário implementado em ambiente foundation fieldbus.

A estratégia mostrando os blocos para o segundo cenário é mostrada a seguir na figura A.2

Por terem ficado pequeno em folha A4, essas 2 estratégias serão entregues em formato A3 para facilitar a leitura dos desenhos. 
Tabela A.3: Pesos 1 - Primeiro cenário.

\begin{tabular}{|c|c|c|}
\hline 0,2071 & $-0,0106$ & $-294,4462$ \\
$-0,5279$ & 0,0430 & 4,6256 \\
26,2440 & $-0,0223$ & 4,8575 \\
0,7365 & $-0,0200$ & 0,3944 \\
$-0,8078$ & 0,0965 & $-0,9433$ \\
0,3226 & 0,0047 & $-0,9037$ \\
$-0,3361$ & 0,0157 & 22,7301 \\
18,4617 & $-0,0248$ & 1,7758 \\
\hline
\end{tabular}

Tabela A.4: Pesos 2 - Primeiro cenário.

\begin{tabular}{|c|}
\hline$-48,1514$ \\
25,0795 \\
2,0591 \\
58,2853 \\
$-29,5303$ \\
$-70,4245$ \\
23,4720 \\
7,9860 \\
\hline
\end{tabular}

Tabela A.5: Pesos 3 - Primeiro cenário.

\begin{tabular}{|c|}
$-295,8201$ \\
4,8740 \\
4,5293 \\
$-0,1415$ \\
1,8788 \\
$-0,9575$ \\
23,3502 \\
11,3271 \\
\hline
\end{tabular}

Tabela A.6: Peso 4 - Primeiro cenário. $-114,6820$ 
Os principais dados configurados para o primeiro cenário são ilustrados na tabela A.7

Tabela A.7: Valores configurados dos principais parâmetros dos blocos em foundation fieldbus configurados no ambiente Delta $V^{T M}$ para o primeiro cenário.

\begin{tabular}{|c|c|c|c|}
\hline Bloco & Parâmetro & Valor & Função \\
\hline ARTHM1 & ARITH_TYPE & Traditional Summer & Config. de fórmulas \\
\hline ARTHM1 & GAIN_IN_1 & 0,20715 & Peso \\
\hline ARTHM1 & GAIN_IN_2 & $-0,01057$ & Peso \\
\hline ARTHM1 & GAIN_IN_3 & $-294,44600$ & Peso \\
\hline ARTHM1 & OUT_HI_LIM & 10000 & limite \\
\hline ARTHM1 & OUT_LO_LIM & -10000 & limite \\
\hline ARTHM2 & ARITH_TYPE & Traditional Summer & Config. de fórmulas \\
\hline ARTHM2 & GAIN_IN_1 & $-0,52787$ & Peso \\
\hline ARTHM2 & GAIN_IN_2 & 0,04298 & Peso \\
\hline ARTHM2 & GAIN_IN_3 & 4,62561 & Peso \\
\hline ARTHM2 & OUT_HI_LIM & 10000 & limite \\
\hline ARTHM2 & OUT_LO_LIM & -10000 & limite \\
\hline ARTHM3 & ARITH_TYPE & Traditional Summer & Config. de fórmulas \\
\hline ARTHM3 & GAIN_IN_1 & 26,24400 & Peso \\
\hline ARTHM3 & GAIN_IN_2 & $-0,02231$ & Peso \\
\hline ARTHM3 & GAIN_IN_3 & 4,85751 & Peso \\
\hline ARTHM3 & OUT_HI_LIM & 10000 & limite \\
\hline ARTHM3 & OUT_LO_LIM & -10000 & limite \\
\hline ARTHM4 & ARITH_TYPE & Traditional Summer & Config. de fórmulas \\
\hline ARTHM4 & GAIN_IN_1 & 0,73646 & Peso \\
\hline ARTHM4 & GAIN_IN_2 & $-0,01997$ & Peso \\
\hline ARTHM4 & GAIN_IN_3 & 0,39438 & Peso \\
\hline ARTHM4 & OUT_HI_LIM & 10000 & limite \\
\hline ARTHM4 & OUT_LO_LIM & -10000 & limite \\
\hline ARTHM5 & ARITH_TYPE & Traditional Summer & Config. de fórmulas \\
\hline
\end{tabular}


Tabela A.7 - continua da página anterior.

\begin{tabular}{|c|c|c|c|}
\hline Bloco & Parâmetro & Valor & Função \\
\hline ARTHM5 & GAIN_IN_1 & $-0,80781$ & Peso \\
\hline ARTHM5 & GAIN_IN_2 & 0,09646 & Peso \\
\hline ARTHM5 & GAIN_IN_3 & $-0,94331$ & Peso \\
\hline ARTHM5 & OUT_HI_LIM & 10000 & limite \\
\hline ARTHM5 & OUT_LO_LIM & -10000 & limite \\
\hline ARTHM6 & ARITH_TYPE & Traditional Summer & Config. de fórmulas \\
\hline ARTHM6 & GAIN_IN_1 & 0,32259 & Peso \\
\hline ARTHM6 & GAIN_IN_2 & 0,00469 & Peso \\
\hline ARTHM6 & GAIN_IN_3 & $-0,90373$ & Peso \\
\hline ARTHM6 & OUT_HI_LIM & 10000 & limite \\
\hline ARTHM6 & OUT_LO_LIM & -10000 & limite \\
\hline ARTHM7 & ARITH_TYPE & Traditional Summer & Config. de fórmulas \\
\hline ARTHM7 & GAIN_IN_1 & $-0,33614$ & Peso \\
\hline ARTHM7 & GAIN_IN_2 & 0,01573 & Peso \\
\hline ARTHM7 & GAIN_IN_3 & 22,73010 & Peso \\
\hline ARTHM7 & OUT_HI_LIM & 10000 & limite \\
\hline ARTHM7 & OUT_LO_LIM & -10000 & limite \\
\hline ARTHM8 & ARITH_TYPE & Traditional Summer & Config. de fórmulas \\
\hline ARTHM8 & GAIN_IN_1 & 18,46170 & Peso \\
\hline ARTHM8 & GAIN_IN_2 & $-0,02483$ & Peso \\
\hline ARTHM8 & GAIN_IN_3 & 1,77578 & Peso \\
\hline ARTHM8 & OUT_HI_LIM & 10000 & limite \\
\hline ARTHM8 & OUT_LO_LIM & -10000 & limite \\
\hline TANH 1 E 2 & Parameter Array [1] & $-4,00000$ & Curva da tang. \\
\hline CURVE X & Parameter Array [2] & $-2,36584$ & Curva da tang. \\
\hline & Parameter Array [3] & $-1,75418$ & Curva da tang. \\
\hline & Parameter Array [4] & $-1,36774$ & Curva da tang. \\
\hline & Parameter Array [5] & $-1,07971$ & Curva da tang. \\
\hline & Parameter Array [6] & $-0,84528$ & Curva da tang. \\
\hline & Parameter Array [7] & $-0,64366$ & Curva da tang. \\
\hline
\end{tabular}


Tabela A.7 - continua da página anterior.

\begin{tabular}{|c|c|c|c|}
\hline Bloco & Parâmetro & Valor & Função \\
\hline & Parameter Array [8] & -0.46285 & Curva da tang, \\
\hline & Parameter Array [9] & -0.29523 & Curva da tang. \\
\hline & Parameter Array [10] & $-0,13601$ & Curva da tang. \\
\hline & Parameter Array [11] & 0,00000 & Curva da tang. \\
\hline & Parameter Array [12] & 0,13601 & Curva da tang. \\
\hline & Parameter Array [13] & 0,29523 & Curva da tang. \\
\hline & Parameter Array [14] & 0,46285 & Curva da tang. \\
\hline & Parameter Array [15] & 0.64366 & Curva da tang. \\
\hline & Parameter Array [16] & 0,84528 & Curva da tang. \\
\hline & Parameter Array [17] & 1,07971 & Curva da tang. \\
\hline & Parameter Array [18] & 1,36774 & Curva da tang. \\
\hline & Parameter Array [19] & 1,75418 & Curva da tang. \\
\hline & Parameter Array [20] & 2,36584 & Curva da tang. \\
\hline & Parameter Array [21] & 4,00000 & Curva da tang. \\
\hline TANH 1 E 2 & Parameter Array [1] & $-0,99933$ & Curva da tang. \\
\hline \multirow[t]{15}{*}{ CURVE Y } & Parameter Array [2] & $-0,98253$ & Curva da tang. \\
\hline & Parameter Array [3] & $-0,94185$ & Curva da tang. \\
\hline & Parameter Array [4] & $-0,87818$ & Curva da tang. \\
\hline & Parameter Array [5] & $-0,79309$ & Curva da tang. \\
\hline & Parameter Array [6] & $-0,68860$ & Curva da tang. \\
\hline & Parameter Array [7] & $-0,56739$ & Curva da tang. \\
\hline & Parameter Array [8] & $-0,43240$ & Curva da tang. \\
\hline & Parameter Array [9] & $-0,28694$ & Curva da tang. \\
\hline & Parameter Array [10] & $-0,13518$ & Curva da tang. \\
\hline & Parameter Array [11] & 0,00000 & Curva da tang. \\
\hline & Parameter Array [12] & 0,13518 & Curva da tang. \\
\hline & Parameter Array [13] & 0,28694 & Curva da tang. \\
\hline & Parameter Array [14] & 0,43240 & Curva da tang. \\
\hline & Parameter Array [15] & 0,56739 & Curva da tang. \\
\hline & Parameter Array [16] & 0,68860 & Curva da tang. \\
\hline
\end{tabular}


Tabela A.7 - continua da página anterior.

\begin{tabular}{|c|c|c|c|}
\hline Bloco & Parâmetro & Valor & Função \\
\hline & Parameter Array [17] & 0,79309 & Curva da tang. \\
\hline & Parameter Array [18] & 0,87818 & Curva da tang. \\
\hline & Parameter Array [19] & 0,94185 & Curva da tang. \\
\hline & Parameter Array [20] & 0,98253 & Curva da tang. \\
\hline & Parameter Array [21] & 0,99933 & Curva da tang. \\
\hline DESN_MULT & & 9,86300 & Desnormalização \\
\hline DESN_SOMA & & 100,00000 & Desnormalização \\
\hline P_CTE_DIV & & 2,00000 & Normalização \\
\hline P_CTE_SUB & & 3,00000 & Normalização \\
\hline PD_CTE_DIV & & 500,00000 & Normalização \\
\hline PD_CTE_SUB & & 500,00000 & Normalização \\
\hline PESO_2CAM_1 & & $-48,15140$ & Peso \\
\hline PESO_2CAM_2 & & 25,07950 & Peso \\
\hline PESO_2CAM_3 & & 2,05915 & Peso \\
\hline PESO_2CAM_4 & & 58,28530 & Peso \\
\hline PESO_2CAM_5 & & $-29,53030$ & Peso \\
\hline PESO_2CAM_6 & & $-70,42450$ & Peso \\
\hline PESO_2CAM_7 & & 23,47200 & Peso \\
\hline PESO_2CAM_8 & & 7,98604 & Peso \\
\hline SEMPRE_ZERO_1 & & 0 & Escrita de 0 \\
\hline SEMPRE_ZERO_2 & & 0 & Escrita de 0 \\
\hline SEMPRE_ZERO_3 & & 0 & Escrita de 0 \\
\hline T_CTE_DIV & & 10,00000 & Normalização \\
\hline T_CTE_SUB & & 30,00000 & Normalização \\
\hline TETA1_TAN1 & & 295,82000 & ajuste tangente \\
\hline TETA1_TAN2 & & $-4,87396$ & ajuste tangente \\
\hline TETA1_TAN3 & & $-4,52927$ & ajuste tangente \\
\hline TETA1_TAN4 & & 0,14149 & ajuste tangente \\
\hline TETA1_TAN5 & & $-1,87882$ & ajuste tangente \\
\hline TETA1_TAN6 & & 0,95751 & ajuste tangente \\
\hline
\end{tabular}


Tabela A.7 - continua da página anterior.

\begin{tabular}{|c|c|c|c|}
\hline Bloco & Parâmetro & Valor & Função \\
\hline TETA1_TAN7 & & $-23,35020$ & ajuste tangente \\
TETA1_TAN8 & & $-11,32710$ & Ajuste da tang, \\
TETA_LINEAR & & 114,68200 & ajuste linear \\
\hline
\end{tabular}

A Tabela A.8 ilustra a diferença entre os valores das duas tangentes tabeladas com 21 e 39 pontos.

Tabela A.8: Comparação da tangente hiperbólica tabulada com 21 e 39 pontos em ambiente foundation fieldbus.

\begin{tabular}{|c|c|c|c|c|c|}
\hline Eixo x da tangente & 21 pts & 39 pts & Tangente & Erro 21 $(\%)$ & Erro 39 $(\%)$ \\
\hline$-4,000000$ & $-0,999330$ & $-0,999329$ & $-0,999329$ & 0,000070 & 0,000030 \\
$-3,919200$ & $-0,998499$ & $-0,998997$ & $-0,999212$ & 0,071327 & 0,021488 \\
$-3,838400$ & $-0,997669$ & $-0,998666$ & $-0,999074$ & 0,140582 & 0,040790 \\
$-3,757600$ & $-0,996838$ & $-0,998334$ & $-0,998911$ & 0,207537 & 0,057774 \\
$-3,676800$ & $-0,996007$ & $-0,998002$ & $-0,998720$ & 0,271673 & 0,071917 \\
$-3,596000$ & $-0,995177$ & $-0,997671$ & $-0,998496$ & 0,332397 & 0,082621 \\
$-3,515200$ & $-0,994346$ & $-0,997339$ & $-0,998232$ & 0,389329 & 0,089499 \\
$-3,434300$ & $-0,993514$ & $-0,997007$ & $-0,997922$ & 0,441747 & 0,091720 \\
$-3,353500$ & $-0,992684$ & $-0,996675$ & $-0,997558$ & 0,488626 & 0,088550 \\
$-3,272700$ & $-0,991853$ & $-0,996344$ & $-0,997131$ & 0,529289 & 0,078897 \\
$-3,191900$ & $-0,991022$ & $-0,996012$ & $-0,996628$ & 0,562527 & 0,061839 \\
$-3,111100$ & $-0,990192$ & $-0,995680$ & $-0,996038$ & 0,586937 & 0,035954 \\
$-3,030300$ & $-0,989361$ & $-0,995338$ & $-0,995345$ & 0,601185 & 0,000689 \\
$-2,949500$ & $-0,988530$ & $-0,993866$ & $-0,994531$ & 0,603363 & 0,066828 \\
$-2,868700$ & $-0,987700$ & $-0,992395$ & $-0,993574$ & 0,591243 & 0,118706 \\
$-2,787900$ & $-0,986869$ & $-0,990923$ & $-0,992452$ & 0,562517 & 0,154034 \\
$-2,707100$ & $-0,986038$ & $-0,989452$ & $-0,991134$ & 0,514127 & 0,169673 \\
\hline & Continua na próxima página & & \\
\hline
\end{tabular}


Tabela A.8 - continua da página anterior

\begin{tabular}{|c|c|c|c|c|c|}
\hline Eixo $\mathrm{x}$ da tangente & $21 \mathrm{pts}$ & $39 p t s$ & Tangente & Erro $21(\%)$ & Erro $39(\%)$ \\
\hline$-2,626300$ & $-0,985208$ & $-0,987980$ & $-0,989587$ & 0,442479 & 0,162362 \\
\hline$-2,545500$ & $-0,984377$ & $-0,986509$ & $-0,987771$ & 0,343652 & 0,127813 \\
\hline$-2,464600$ & $-0,983545$ & $-0,985036$ & $-0,985639$ & 0,212480 & 0,061208 \\
\hline$-2,383800$ & $-0,982715$ & $-0,982713$ & $-0,983142$ & 0,043411 & 0,043615 \\
\hline$-2,303000$ & $-0,978351$ & $-0,978920$ & $-0,980214$ & 0,190089 & 0,132041 \\
\hline$-2,222200$ & $-0,972977$ & $-0,975128$ & $-0,976784$ & 0,389784 & 0,169571 \\
\hline$-2,141400$ & $-0,967603$ & $-0,971336$ & $-0,972768$ & 0,530959 & 0,147208 \\
\hline$-2,060600$ & $-0,962229$ & $-0,967543$ & $-0,968068$ & 0,603163 & 0,054235 \\
\hline$-1,979800$ & $-0,956855$ & $-0,961649$ & $-0,962572$ & 0,593960 & 0,095919 \\
\hline$-1,899000$ & $-0,951482$ & $-0,954540$ & $-0,956152$ & 0,488392 & 0,168568 \\
\hline$-1,818200$ & $-0,946108$ & $-0,947432$ & $-0,948659$ & 0,268869 & 0,129303 \\
\hline$-1,737400$ & $-0,939085$ & $-0,939550$ & $-0,939924$ & 0,089302 & 0,039830 \\
\hline$-1,656600$ & $-0,925773$ & $-0,928220$ & $-0,929758$ & 0,428581 & 0,165394 \\
\hline$-1,575800$ & $-0,912460$ & $-0,916889$ & $-0,917943$ & 0,597361 & 0,114870 \\
\hline$-1,494900$ & $-0,899131$ & $-0,903284$ & $-0,904222$ & 0,563068 & 0,103778 \\
\hline$-1,454500$ & $-0,892475$ & $-0,895113$ & $-0,896579$ & 0,457751 & 0,163522 \\
\hline$-1,414100$ & $-0,885818$ & $-0,886942$ & $-0,888362$ & 0,286327 & 0,159802 \\
\hline$-1,373700$ & $-0,879162$ & $-0,878771$ & $-0,879533$ & 0,042146 & 0,086601 \\
\hline$-1,333300$ & $-0,868006$ & $-0,869587$ & $-0,870054$ & 0,235337 & 0,053624 \\
\hline$-1,292900$ & $-0,856071$ & $-0,858583$ & $-0,859884$ & 0,443451 & 0,151318 \\
\hline$-1,182000$ & $-0,823309$ & $-0,827815$ & $-0,828081$ & 0,576298 & 0,032149 \\
\hline$-1,171700$ & $-0,820266$ & $-0,824223$ & $-0,824816$ & 0,551685 & 0,071942 \\
\hline$-1,090900$ & $-0,796396$ & $-0,796044$ & $-0,797206$ & 0,101654 & 0,145809 \\
\hline$-1,010100$ & $-0,762064$ & $-0,764711$ & $-0,765803$ & 0,488295 & 0,142644 \\
\hline$-0,929300$ & $-0,726049$ & $-0,730030$ & $-0,730267$ & 0,577647 & 0,032504 \\
\hline$-0,848500$ & $-0,690035$ & $-0,689190$ & $-0,690285$ & 0,036220 & 0,158633 \\
\hline$-0,767700$ & $-0,641961$ & $-0,644575$ & $-0,645590$ & 0,562129 & 0,157228 \\
\hline$-0,686900$ & $-0,593385$ & $-0,595532$ & $-0,595987$ & 0,436556 & 0,076313 \\
\hline$-0,606100$ & $-0,539348$ & $-0,541143$ & $-0,541376$ & 0,374594 & 0,043032 \\
\hline$-0,525300$ & $-0,479024$ & $-0,481191$ & $-0,481780$ & 0,572086 & 0,122296 \\
\hline
\end{tabular}


Tabela A.8 - continua da página anterior

\begin{tabular}{|c|c|c|c|c|c|}
\hline Eixo $\mathrm{x}$ da tangente & $21 \mathrm{pts}$ & $39 \mathrm{pts}$ & Tangente & Erro $21(\%)$ & Erro $39(\%)$ \\
\hline$-0,444400$ & $-0,416389$ & $-0,416623$ & $-0,417285$ & 0,214708 & 0,158631 \\
\hline$-0,363600$ & $-0,346271$ & $-0,347787$ & $-0,348381$ & 0,605677 & 0,170521 \\
\hline$-0,282800$ & $-0,275092$ & $-0,275026$ & $-0,275495$ & 0,146122 & 0,170079 \\
\hline$-0,202000$ & $-0,198078$ & $-0,198972$ & $-0,199297$ & 0,611473 & 0,162895 \\
\hline$-0,121200$ & $-0,120460$ & $-0,120426$ & $-0,120610$ & 0,124379 & 0,152569 \\
\hline$-0,040400$ & $-0,040153$ & $-0,040331$ & $-0,040378$ & 0,557319 & 0,116486 \\
\hline 0,000000 & 0,000000 & 0,000000 & 0,000000 & 0,000000 & 0,000000 \\
\hline 0,040400 & 0,040153 & 0,040331 & 0,040378 & 0,557319 & 0,116486 \\
\hline 0,121200 & 0,120460 & 0,120426 & 0,120610 & 0,124379 & 0,152569 \\
\hline 0,202000 & 0,198078 & 0,198972 & 0,199297 & 0,611473 & 0,162895 \\
\hline 0,282800 & 0,275092 & 0,275026 & 0,275495 & 0,146122 & 0,170079 \\
\hline 0,363600 & 0,346271 & 0,347787 & 0,348381 & 0,605677 & 0,170521 \\
\hline 0,444400 & 0,416389 & 0,416623 & 0,417285 & 0,214708 & 0,158631 \\
\hline 0,525300 & 0,479024 & 0,481191 & 0,481780 & 0,572086 & 0,122296 \\
\hline 0,606100 & 0,539348 & 0,541143 & 0,541376 & 0,374594 & 0,043032 \\
\hline 0,686900 & 0,593385 & 0,595532 & 0,595987 & 0,436556 & 0,076313 \\
\hline 0,767700 & 0,641961 & 0,644575 & 0,645590 & 0,562129 & 0,157228 \\
\hline 0,848500 & 0,690035 & 0,689190 & 0,690285 & 0,036220 & 0,158633 \\
\hline 0,929300 & 0,726049 & 0,730030 & 0,730267 & 0,577647 & 0,032504 \\
\hline 1,010100 & 0,762064 & 0,764711 & 0,765803 & 0,488295 & 0,142644 \\
\hline 1,090900 & 0,796396 & 0,796044 & 0,797206 & 0,101654 & 0,145809 \\
\hline 1,171700 & 0,820266 & 0,824223 & 0,824816 & 0,551685 & 0,071942 \\
\hline 1,182000 & 0,823309 & 0,827815 & 0,828081 & 0,576298 & 0,032149 \\
\hline 1,292900 & 0,856071 & 0,858583 & 0,859884 & 0,443451 & 0,151318 \\
\hline 1,333300 & 0,868006 & 0,869587 & 0,870054 & 0,235337 & 0,053624 \\
\hline 1,373700 & 0,879162 & 0,878771 & 0,879533 & 0,042146 & 0,086601 \\
\hline 1,414100 & 0,885818 & 0,886942 & 0,888362 & 0,286327 & 0,159802 \\
\hline 1,454500 & 0,892475 & 0,895113 & 0,896579 & 0,457751 & 0,163522 \\
\hline 1,494900 & 0,899131 & 0,903284 & 0,904222 & 0,563068 & 0,103778 \\
\hline 1,575700 & 0,912460 & 0,916889 & 0,917928 & 0,595657 & 0,113157 \\
\hline
\end{tabular}


Tabela A.8 - continua da página anterior

\begin{tabular}{|c|c|c|c|c|c|}
\hline Eixo $\mathrm{x}$ da tangente & $21 \mathrm{pts}$ & $39 \mathrm{pts}$ & Tangente & Erro $21(\%)$ & Erro $39(\%)$ \\
\hline 1,656500 & 0,925773 & 0,928220 & 0,929744 & 0,427129 & 0,163939 \\
\hline 1,737400 & 0,939085 & 0,939550 & 0,939924 & 0,089302 & 0,039830 \\
\hline 1,818200 & 0,946108 & 0,947432 & 0,948659 & 0,268869 & 0,129303 \\
\hline 1,899000 & 0,951482 & 0,954540 & 0,956152 & 0,488392 & 0,168568 \\
\hline 1,979800 & 0,956855 & 0,961649 & 0,962572 & 0,593960 & 0,095919 \\
\hline 2,060600 & 0,962229 & 0,967543 & 0,968068 & 0,603163 & 0,054235 \\
\hline 2,141400 & 0,967603 & 0,971336 & 0,972768 & 0,530959 & 0,147208 \\
\hline 2,222200 & 0,972977 & 0,975128 & 0,976784 & 0,389784 & 0,169571 \\
\hline 2,303000 & 0,978351 & 0,978920 & 0,980214 & 0,190089 & 0,132041 \\
\hline 2,383800 & 0,982715 & 0,982713 & 0,983142 & 0,043411 & 0,043615 \\
\hline 2,464600 & 0,983545 & 0,985036 & 0,985639 & 0,212480 & 0,061208 \\
\hline 2,545500 & 0,984377 & 0,986509 & 0,987771 & 0,343652 & 0,127813 \\
\hline 2,626300 & 0,985208 & 0,987980 & 0,989587 & 0,442479 & 0,162362 \\
\hline 2,707100 & 0,986038 & 0,989452 & 0,991134 & 0,514127 & 0,169673 \\
\hline 2,787900 & 0,986869 & 0,990923 & 0,992452 & 0,562517 & 0,154034 \\
\hline 2,868700 & 0,987700 & 0,992395 & 0,993574 & 0,591243 & 0,118706 \\
\hline 2,949500 & 0,988530 & 0,993866 & 0,994531 & 0,603363 & 0,066828 \\
\hline 3,030300 & 0,989361 & 0,995338 & 0,995345 & 0,601185 & 0,000689 \\
\hline 3,111100 & 0,990192 & 0,995680 & 0,996038 & 0,586937 & 0,035954 \\
\hline 3,191900 & 0,991022 & 0,996012 & 0,996628 & 0,562527 & 0,061839 \\
\hline 3,272700 & 0,991853 & 0,996344 & 0,997131 & 0,529289 & 0,078897 \\
\hline 3,353500 & 0,992684 & 0,996675 & 0,997558 & 0,488626 & 0,088550 \\
\hline 3,434300 & 0,993514 & 0,997007 & 0,997922 & 0,441747 & 0,091720 \\
\hline 3,515200 & 0,994346 & 0,997339 & 0,998232 & 0,389329 & 0,089499 \\
\hline 3,595900 & 0,995177 & 0,997671 & 0,998496 & 0,332367 & 0,082591 \\
\hline 3,676800 & 0,996007 & 0,998002 & 0,998720 & 0,271673 & 0,071917 \\
\hline 3,757600 & 0,996838 & 0,998334 & 0,998911 & 0,207537 & 0,057774 \\
\hline 3,838400 & 0,997669 & 0,998666 & 0,999074 & 0,140582 & 0,040790 \\
\hline 3,919200 & 0,998499 & 0,998997 & 0,999212 & 0,071327 & 0,021488 \\
\hline
\end{tabular}


Tabela A.8 - continua da página anterior

\begin{tabular}{|c|c|c|c|c|c|}
\hline Eixo x da tangente & $21 \mathrm{pts}$ & 39pts & Tangente & Erro 21 (\%) & Erro 39 (\%) \\
\hline 4,000000 & 0,999330 & 0,999329 & 0,999329 & 0,000070 & 0,000030 \\
\hline \hline
\end{tabular}

O erro médio para a tangente tabelada com 21 pontos foi de $0,3865 \%$ e para a tabelada com 39 pontos foi de $0,1023 \%$.

Tabela A.9: Pesos 1 - Segundo cenário.

\begin{tabular}{|c|c|c|}
\hline 5,4546 & $-0,2431$ & 0,0607 \\
0,8263 & 0,3176 & $-0,4768$ \\
$-0,2666$ & 0,6231 & 0,0544 \\
$-2,2764$ & 0,0746 & $-0,2614$ \\
2,7006 & 1,6473 & 3,6435 \\
$-23,3028$ & 0,1133 & $-0,0565$ \\
0,4808 & 0,5577 & 0,0222 \\
1,2533 & $-0,1350$ & $-0,1189$ \\
$-0,4328$ & $-0,4031$ & $-1,0949$ \\
0,9954 & 0,0748 & $-0,3092$ \\
$-1,9706$ & 0,2577 & 0,0355 \\
0,3007 & 0,4521 & $-0,0712$ \\
\hline
\end{tabular}


Tabela A.10: Pesos 2 - Segundo cenário.

\begin{tabular}{|c|}
\hline 35,2660 \\
36,8232 \\
26,9871 \\
$-6,0155$ \\
0,0938 \\
$-27,7372$ \\
14,4749 \\
22,3360 \\
$-25,3960$ \\
18,5099 \\
$-31,4975$ \\
31,7527 \\
\hline
\end{tabular}

Tabela A.11: Pesos 3 - Segundo cenário.

\begin{tabular}{|c|}
\hline 6,0617 \\
$-1,8530$ \\
1,3012 \\
$-2,5094$ \\
$-3,4477$ \\
$-24,3650$ \\
0,5994 \\
0,4128 \\
3,5159 \\
$-0,5403$ \\
$-1,9076$ \\
$-0,4711$ \\
\hline
\end{tabular}

Tabela A.12: Peso 4 - Segundo cenário.

$$
-49,1644
$$


Os principais dados configurados para o segundo cenário são ilustrados na tabela A.13

Tabela A.13: Valores configurados dos principais parâmetros dos blocos em Foundation Fieldbus configurados no ambiente Delta $\mathrm{V}^{T M}$ para o segundo cenário.

\begin{tabular}{|c|c|c|c|}
\hline Bloco & Parâmetro & Valor & Função \\
\hline ARTHM1 & ARITH_TYPE & Traditional Summer & Config, de fórmulas \\
\hline ARTHM1 & GAIN_IN_1 & 5,4546 & Peso \\
\hline ARTHM1 & GAIN_IN_2 & $-0,2431$ & Peso \\
\hline ARTHM1 & GAIN_IN_3 & 0,0607 & Peso \\
\hline ARTHM1 & OUT_HI_LIM & 10000 & Limite \\
\hline ARTHM1 & OUT_LO_LIM & -10000 & Limite \\
\hline ARTHM2 & ARITH_TYPE & Traditional Summer & Config, de fórmulas \\
\hline ARTHM2 & GAIN_IN_1 & 0,8263 & Peso \\
\hline ARTHM2 & GAIN_IN_2 & 0,3176 & Peso \\
\hline ARTHM2 & GAIN_IN_3 & $-0,4768$ & Peso \\
\hline ARTHM2 & OUT_HI_LIM & 10000 & Limite \\
\hline ARTHM2 & OUT_LO_LIM & -10000 & Limite \\
\hline ARTHM3 & ARITH_TYPE & Traditional Summer & Config, de fórmulas \\
\hline ARTHM3 & GAIN_IN_1 & $-0,2666$ & Peso \\
\hline ARTHM3 & GAIN_IN_2 & 0,6231 & Peso \\
\hline ARTHM3 & GAIN_IN_3 & 0,0544 & Peso \\
\hline ARTHM3 & OUT_HI_LIM & 10000 & Limite \\
\hline ARTHM3 & OUT_LO_LIM & -10000 & Limite \\
\hline ARTHM4 & ARITH_TYPE & Traditional Summer & Config, de fórmulas \\
\hline ARTHM4 & GAIN_IN_1 & $-2,2764$ & Peso \\
\hline ARTHM4 & GAIN_IN_2 & 0,0746 & Peso \\
\hline ARTHM4 & GAIN_IN_3 & $-0,2614$ & Peso \\
\hline ARTHM4 & OUT_HI_LIM & 10000 & Limite \\
\hline ARTHM4 & OUT_LO_LIM & -10000 & Limite \\
\hline ARTHM5 & ARITH_TYPE & Traditional Summer & Config, de fórmulas \\
\hline ARTHM5 & GAIN_IN_1 & 2,7006 & Peso \\
\hline
\end{tabular}


Tabela A.13 - continua da página anterior

\begin{tabular}{|c|c|c|c|}
\hline Bloco & Parâmetro & Valor & Função \\
\hline ARTHM5 & GAIN_IN_2 & 1,6473 & Peso \\
\hline ARTHM5 & GAIN_IN_3 & 3,6435 & Peso \\
\hline ARTHM5 & OUT_HI_LIM & 10000 & Limite \\
\hline ARTHM5 & OUT_LO_LIM & -10000 & Limite \\
\hline ARTHM6 & ARITH_TYPE & Traditional Summer & Config, de fórmulas \\
\hline ARTHM6 & GAIN_IN_1 & $-23,3028$ & Peso \\
\hline ARTHM6 & GAIN_IN_2 & 0,1133 & Peso \\
\hline ARTHM6 & GAIN_IN_3 & $-0,0565$ & Peso \\
\hline ARTHM6 & OUT_HILIM & 10000 & Limite \\
\hline ARTHM6 & OUT_LO_LIM & -10000 & Limite \\
\hline ARTHM7 & ARITH_TYPE & Traditional Summer & Config, de fórmulas \\
\hline ARTHM7 & GAIN_IN_1 & 0,4808 & Peso \\
\hline ARTHM7 & GAIN_IN_2 & 0,5577 & Peso \\
\hline ARTHM7 & GAIN_IN_3 & 0,0222 & Peso \\
\hline ARTHM7 & OUT_HI_LIM & 10000 & Limite \\
\hline ARTHM7 & OUT_LO_LIM & -10000 & Limite \\
\hline ARTHM8 & ARITH_TYPE & Traditional Summer & Config, de fórmulas \\
\hline ARTHM8 & GAIN_IN_1 & 1,2533 & Peso \\
\hline ARTHM8 & GAIN_IN_2 & $-0,135$ & Peso \\
\hline ARTHM8 & GAIN_IN_3 & $-0,1189$ & Peso \\
\hline ARTHM8 & OUT_HI_LIM & 10000 & Limite \\
\hline ARTHM8 & OUT_LO_LIM & -10000 & Limite \\
\hline ARTHM9 & ARITH_TYPE & Traditional Summer & Config, de fórmulas \\
\hline ARTHM9 & GAIN_IN_1 & $-0,4328$ & Peso \\
\hline ARTHM9 & GAIN_IN_2 & $-0,4031$ & Peso \\
\hline ARTHM9 & GAIN_IN_3 & $-1,0949$ & Peso \\
\hline ARTHM9 & OUT_HI_LIM & 10000 & Limite \\
\hline ARTHM9 & OUT_LO_LIM & -10000 & Limite \\
\hline ARTHM10 & ARITH_TYPE & Traditional Summer & Config, de fórmulas \\
\hline ARTHM10 & GAIN_IN_1 & 0,9954 & Peso \\
\hline
\end{tabular}


Tabela A.13 - continua da página anterior

\begin{tabular}{|c|c|c|c|}
\hline Bloco & Parâmetro & Valor & Função \\
\hline ARTHM10 & GAIN_IN_2 & 0,0748 & Peso \\
\hline ARTHM10 & GAIN_IN_3 & $-0,3092$ & Peso \\
\hline ARTHM10 & OUT_HI_LIM & 10000 & Limite \\
\hline ARTHM10 & OUT_LO_LIM & -10000 & Limite \\
\hline ARTHM11 & ARITH_TYPE & Traditional Summer & Config, de fórmulas \\
\hline ARTHM11 & GAIN_IN_1 & $-1,9706$ & Peso \\
\hline ARTHM11 & GAIN_IN_2 & 0,2577 & Peso \\
\hline ARTHM11 & GAIN_IN_3 & 0,0355 & Peso \\
\hline ARTHM11 & OUT_HI_LIM & 10000 & Limite \\
\hline ARTHM11 & OUT_LO_LIM & -10000 & Limite \\
\hline ARTHM12 & ARITH_TYPE & Traditional Summer & Config, de fórmulas \\
\hline ARTHM12 & GAIN_IN_1 & 0,3007 & Peso \\
\hline ARTHM12 & GAIN_IN_2 & 0,4521 & Peso \\
\hline ARTHM12 & GAIN_IN_3 & $-0,0712$ & Peso \\
\hline ARTHM12 & OUT_HI_LIM & 10000 & Limite \\
\hline ARTHM12 & OUT_LO_LIM & -10000 & Limite \\
\hline ARTHM13 & ARITH_TYPE & Traditional Summer & Config, de fórmulas \\
\hline ARTHM13 & GAIN_IN_1 & 1 & Peso \\
\hline ARTHM13 & GAIN_IN_2 & 1 & Peso \\
\hline ARTHM13 & GAIN_IN_3 & 1 & Peso \\
\hline ARTHM13 & OUT_HI_LIM & 10000 & Limite \\
\hline ARTHM13 & OUT_LO_LIM & -10000 & Limite \\
\hline TANH_NEG1 & Parameter Array [1] & $-4,00000$ & Curva da tang. \\
\hline \multirow[t]{7}{*}{ CURVE X } & Parameter Array [2] & $-3,0311$ & Curva da tang. \\
\hline & Parameter Array [3] & $-2,41344$ & Curva da tang. \\
\hline & Parameter Array [4] & $-2,031$ & Curva da tang. \\
\hline & Parameter Array [5] & $-1,75218$ & Curva da tang. \\
\hline & Parameter Array [6] & $-1,53135$ & Curva da tang. \\
\hline & Parameter Array [7] & $-1,34773$ & Curva da tang. \\
\hline & Parameter Array [8] & $-1,18932$ & Curva da tang. \\
\hline
\end{tabular}


Tabela A.13 - continua da página anterior

\begin{tabular}{|c|c|c|c|}
\hline Bloco & Parâmetro & Valor & Função \\
\hline & Parameter Array [9] & $-1,0493$ & Curva da tang. \\
\hline & Parameter Array [10] & $-0,923292$ & Curva da tang. \\
\hline & Parameter Array [11] & $-0,807681$ & Curva da tang. \\
\hline & Parameter Array [12] & $-0,70047$ & Curva da tang. \\
\hline & Parameter Array [13] & $-0,59966$ & Curva da tang. \\
\hline & Parameter Array [14] & $-0,50405$ & Curva da tang. \\
\hline & Parameter Array [15] & $-0,412441$ & Curva da tang. \\
\hline & Parameter Array [16] & $-0,324032$ & Curva da tang. \\
\hline & Parameter Array [17] & $-0,238024$ & Curva da tang. \\
\hline & Parameter Array [18] & $-0,154015$ & Curva da tang. \\
\hline & Parameter Array [19] & $-0,0716072$ & Curva da tang. \\
\hline & Parameter Array [20] & 0 & Curva da tang. \\
\hline & Parameter Array [21] & 4 & Curva da tang. \\
\hline TANH_NEG1 & Parameter Array [1] & $-0,99933$ & Curva da tang. \\
\hline \multirow[t]{16}{*}{ CURVE Y } & Parameter Array [2] & $-0,995352$ & Curva da tang. \\
\hline & Parameter Array [3] & $-0,984104$ & Curva da tang. \\
\hline & Parameter Array [4] & $-0,966154$ & Curva da tang. \\
\hline & Parameter Array [5] & $-0,941623$ & Curva da tang. \\
\hline & Parameter Array [6] & $-0,910656$ & Curva da tang. \\
\hline & Parameter Array [7] & $-0,873518$ & Curva da tang. \\
\hline & Parameter Array [8] & $-0,830368$ & Curva da tang. \\
\hline & Parameter Array [9] & $-0,781536$ & Curva da tang. \\
\hline & Parameter Array [10] & $-0,727451$ & Curva da tang. \\
\hline & Parameter Array [11] & $-0,668309$ & Curva da tang. \\
\hline & Parameter Array [12] & $-0,604666$ & Curva da tang. \\
\hline & Parameter Array [13] & $-0,536808$ & Curva da tang. \\
\hline & Parameter Array [14] & $-0,465297$ & Curva da tang. \\
\hline & Parameter Array [15] & $-0,390544$ & Curva da tang. \\
\hline & Parameter Array [16] & $-0,313148$ & Curva da tang. \\
\hline & Parameter Array [17] & $-0,233628$ & Curva da tang. \\
\hline
\end{tabular}


Tabela A.13 - continua da página anterior

\begin{tabular}{|c|c|c|c|}
\hline Bloco & Parâmetro & Valor & Função \\
\hline & Parameter Array [18] & $-0,152809$ & Curva da tang. \\
\hline & Parameter Array [19] & $-0,071485$ & Curva da tang. \\
\hline & Parameter Array [20] & 0 & Curva da tang. \\
\hline & Parameter Array [21] & 0 & Curva da tang. \\
\hline TANH_POS1 & Parameter Array [1] & $-4,0000$ & Curva da tang. \\
\hline \multirow[t]{20}{*}{ CURVE X } & Parameter Array [2] & 0 & Curva da tang. \\
\hline & Parameter Array [3] & 0,0716072 & Curva da tang. \\
\hline & Parameter Array [4] & 0,154015 & Curva da tang. \\
\hline & Parameter Array [5] & 0,238024 & Curva da tang. \\
\hline & Parameter Array [6] & 0,324032 & Curva da tang. \\
\hline & Parameter Array [7] & 0,412441 & Curva da tang. \\
\hline & Parameter Array [8] & 0,50405 & Curva da tang. \\
\hline & Parameter Array [9] & 0,59966 & Curva da tang. \\
\hline & Parameter Array [10] & 0,70047 & Curva da tang. \\
\hline & Parameter Array [11] & 0,807681 & Curva da tang. \\
\hline & Parameter Array [12] & 0,923292 & Curva da tang. \\
\hline & Parameter Array [13] & 1,0493 & Curva da tang. \\
\hline & Parameter Array [14] & 1,18932 & Curva da tang. \\
\hline & Parameter Array [15] & 1,34773 & Curva da tang. \\
\hline & Parameter Array [16] & 1,53135 & Curva da tang. \\
\hline & Parameter Array [17] & 1,75218 & Curva da tang. \\
\hline & Parameter Array [18] & 2,031 & Curva da tang. \\
\hline & Parameter Array [19] & 2,41344 & Curva da tang. \\
\hline & Parameter Array [20] & 3,0311 & Curva da tang. \\
\hline & Parameter Array [21] & 4,0000 & Curva da tang. \\
\hline TANH_POS1 & Parameter Array [1] & 0 & Curva da tang. \\
\hline \multirow[t]{4}{*}{ CURVE Y } & Parameter Array [2] & 0 & Curva da tang. \\
\hline & Parameter Array [3] & 0,071485 & Curva da tang. \\
\hline & Parameter Array [4] & 0,152809 & Curva da tang. \\
\hline & Parameter Array [5] & 0,233628 & Curva da tang. \\
\hline
\end{tabular}


Tabela A.13 - continua da página anterior

\begin{tabular}{|c|c|c|c|}
\hline Bloco & Parâmetro & Valor & Função \\
\hline & Parameter Array [6] & 0,313148 & Curva da tang. \\
\hline & Parameter Array [7] & 0,390544 & Curva da tang. \\
\hline & Parameter Array [8] & 0,465297 & Curva da tang. \\
\hline & Parameter Array [9] & 0,536808 & Curva da tang. \\
\hline & Parameter Array [10] & 0,604666 & Curva da tang. \\
\hline & Parameter Array [11] & 0,668309 & Curva da tang. \\
\hline & Parameter Array [12] & 0,727451 & Curva da tang. \\
\hline & Parameter Array [13] & 0,781536 & Curva da tang. \\
\hline & Parameter Array [14] & 0,830368 & Curva da tang. \\
\hline & Parameter Array [15] & 0,873518 & Curva da tang. \\
\hline & Parameter Array [16] & 0,910656 & Curva da tang. \\
\hline & Parameter Array [17] & 0,941623 & Curva da tang. \\
\hline & Parameter Array [18] & 0,966154 & Curva da tang. \\
\hline & Parameter Array [19] & 0,984104 & Curva da tang. \\
\hline & Parameter Array [20] & 0,995352 & Curva da tang. \\
\hline & Parameter Array [21] & 0,999329 & Curva da tang. \\
\hline DESN_MULT & & 44,206 & Desnormalização \\
\hline DESN_SOMA & & 4821,48 & Desnormalização \\
\hline P_CTE_DIV & & 30 & Normalização \\
\hline P_CTE_SU & & B 90 & Normalização \\
\hline PD_CTE_DIV & & 915 & Normalização \\
\hline PD_CTE_SUB & & 925 & Normalização \\
\hline PESO_2CAM_1 & & 35,266 & Peso \\
\hline PESO_2CAM_2 & & 36,8232 & Peso \\
\hline PESO_2CAM_3 & & 26,9871 & Peso \\
\hline PESO_2CAM_4 & & $-6,0155$ & Peso \\
\hline PESO_2CAM_5 & & 0,0938 & Peso \\
\hline PESO_2CAM_6 & & $-27,7372$ & Peso \\
\hline PESO_2CAM_7 & & 14,4749 & Peso \\
\hline PESO_2CAM_8 & & 22,336 & Peso \\
\hline
\end{tabular}


Tabela A.13 - continua da página anterior

\begin{tabular}{|c|c|c|c|}
\hline Bloco & Parâmetro & Valor & Função \\
\hline PESO_2CAM_9 & & $-25,396$ & Peso \\
\hline PESO_2CAM_10 & & 18,5099 & Peso \\
\hline PESO_2CAM_11 & & $-31,4975$ & Peso \\
\hline PESO_2CAM_12 & & 31,7527 & Peso \\
\hline SEMPRE_ZERO_1 & & 0 & Escrita de 0 \\
\hline SEMPRE_ZERO_2 & & 0 & Escrita de 0 \\
\hline T_CTE_DIV & & 32,5 & Normalização \\
\hline T_CTE_SUB & & 27,5 & Normalização \\
\hline TETA1_TAN1 & & $-6,0617$ & Ajuste da tang. \\
\hline TETA1_TAN2 & & 1,853 & Ajuste da tang. \\
\hline TETA1_TAN3 & & $-1,3012$ & Ajuste da tang. \\
\hline TETA1_TAN4 & & 2,5094 & Ajuste da tang. \\
\hline TETA1_TAN5 & & 3,4477 & Ajuste da tang. \\
\hline TETA1_TAN6 & & 24,365 & Ajuste da tang. \\
\hline TETA1_TAN7 & & $-0,5994$ & Ajuste da tang. \\
\hline TETA1_TAN8 & & $-0,4128$ & Ajuste da tang. \\
\hline TETA1_TAN9 & & $-3,5159$ & Ajuste da tang. \\
\hline TETA1_TAN10 & & 0,5403 & Ajuste da tang. \\
\hline TETA1_TAN11 & & 1,9076 & Ajuste da tang. \\
\hline TETA1_TAN12 & & 0,4711 & Ajuste da tang. \\
\hline TETA_LINEAR & & 49,1644 & Ajuste da tang. \\
\hline
\end{tabular}

